SERVIÇO DE PÓS-GRADUAÇÃO DO ICMC-USP

Data de Depósito: 18.04 .2008

Assinatura:

\title{
Abstração de eventos de sensores para dispositivos de interação ${ }^{1}$
}

\author{
Felipe Silva Santos
}

Orientadora: $\operatorname{Prof}^{a}$ Dr $^{a}$ Maria da Graça Campos Pimentel

Dissertação apresentada ao Instituto de Ciências Matemáticas e de Computação - ICMC-USP, como parte dos requisitos para obtenção do título de Mestre em Ciências de Computação e Matemática Computacional.

USP - São Carlos

Abril de 2008

\footnotetext{
${ }^{1}$ Trabalho realizado com auxílio financeiro da FAPESP (06/53783-9).
} 

Abstração de eventos de sensores para dispositivos de interação 

Aos meus pais Marcelino e Patricia, meus irmãos Michel, Danielle e Lucas, ̀̀ minha orientadora Graça Pimentel, à minha namorada Daniele Schneider e aos meus amigos Matheus, Cássio e Daniel Lobato, pelo apoio incondicional. 



\section{Agradecimentos}

À minha orientadora, Graça Pimentel, por expandir meus horizontes.

Ao Cesar Augusto Camillo Teixeira, pelas contribuições técnicas na definição da arquitetura.

Aos colegas do Laboratório Intermídia e a todos os amigos que contribuíram direta e indiretamente com este trabalho.

À minha família, pelo carinho e compreensão.

À FAPESP, pelo apoio financeiro (06/53783-9). 



\section{Resumo}

Vários tipos de sensores têm sido explorados na construção de mecanismos para capturar, por exemplo, movimentos dos olhos, da cabeça, ou do tórax do usuário. A construção de dispositivos de interação baseados em tais sensores demandam conhecimentos especializados. O trabalho aqui reportado teve como objetivo desenvolver uma arquitetura de componentes de hardware e software que fornece, como dados de entrada para aplicações computacionais, eventos capturados de sensores tais como os que detectam inclinação, rotação e aceleração. A pesquisa envolveu a concepção e a implementação de uma arquitetura em camadas que possui, em sua base, uma camada de hardware composta por um conjunto de sensores e circuitos apropriados que mensuram eventos físicos e, nas demais camadas, componentes de software que permitem associar uma semântica de dados de entrada para aplicações aos dados primitivos provenientes dos sensores e das camadas intermediárias. Como resultado, a arquitetura disponibiliza os dados dos sensores como eventos em alto nivel, que podem ser associados a operações de interação usuário-computador típicas de um mouse, de um teclado ou de um joystick, por exemplo. A implementação de um dispositivo de interação baseado em sensores é facilitada, por um lado, pelo fato de o tratamento de erros associado ao uso de sensores poder ter sido realizado nas camadas inferiores e, por outro, pelo fato de os dados serem apresentados em um alto nivel de abstração que não exige conhecimento específico sobre o uso do hardware associado. Como estudo de caso, criouse um dispositivo de interação que permite interações típicas de um mouse, e que pode ser usado por usuários tetraplégicos, que possuam controle fino dos movimentos da cabeça e ausência de deficiências visuais.

Palavras-chave: Interação Usuário-Computador, Tecnologia Assistiva, Sensores, Mouse Assistivo, Acelerômetro, Bússola Eletrônica. 


\begin{abstract}
Some types of sensors have been explored in the construction of mechanisms to capture, for example, movements of the eyes, the head, or the thorax of the user. The construction of devices of interaction based in such sensors demand specialized knowledge. The work reported here had as objective to develop an architecture of components of the hardware and software that it supplies, as given of entrance for computational applications, captured events of sensors such as the ones that detect inclination, rotation and acceleration. The research involved the conception and the implementation of a in layers architecture that it possesss, in its base, a composed layer of the hardware for a set of sensors and appropriate circuits that measure physical events and, in the too much layers, software components that allow to associate a semantics of data of entrance for applications to the primitive data proceeding from the sensors and the intermediate layers. As result, the architecture makes available the data of the sensors as events in high level, that can be associates the operations of typical interaction one user-computer mouse, of a keyboard or one joystick, for example. The implementation of a device of interaction based on sensors is facilitated, on the other hand, for the fact of the treatment of errors associated to the use of sensors to be able to have been carried through in inferior layers e, for another one, the fact of the data to be presented in one high level of abstraction that does not demand specific knowledge on the use of the associated hardware. As case study, an interaction device was created that allows typical interactions of one mouse, and that it can be used for tetraplegic users, who possess fine control of the movements of the head and absence of visual deficiencies.
\end{abstract}

Keywords: Human Computer Interaction, Sensors, Assistive Mouse, Accelerometer, Electronic Compass. 


\section{Publicações realizadas no contexto deste trabalho:}

1. SANTOS, Felipe Silva; PIMENTEL, Maria da Graça Campos; TEIXEIRA, Cesar Augusto Camillo. An architecture to improve the generalization of interacting device developments for accessibility. In: XII Simpósio Brasileiro de Sistemas Multimídia e Web, 2006, Natal-RN. Proceedings. Brasil - EUA: SBC - ACM Press (Digital Library), 2006. v. 1. p. 53-60.

2. SANTOS, Felipe Silva; PIMENTEL, Maria da Graça Campos; TEIXEIRA, Cesar Augusto Camillo. Customization of sensor-based input devices. In: VII Simpósio sobre Fatores Humanos em Sistemas Computacionais, 2006, Natal-RN. Proceedings. B : SBC - ACM Press (Digital Library), 2006. v. 1. p. 5-8.

3. PIMENTEL, Maria da Graça Campos; ElEUTÉRIO, Pedro Monteiro da Silva; SANTOS, Felipe Silva; TEIXEIRA, Cesar Augusto Camillo. A Synchronous Communication Service API using J2EE and JMS. In: Simpósio Brasileiro de Sistemas Multimídia e Hipermidia, 2005, Poços de Caldas. Proceedings: posters, 2005. v. 1. p. 1-3.

\section{Outras publicações:}

4. CATTELAN, Renan Gonçalves; SANTOS, Felipe Silva; GOULARTE, Rudinei ; TEIXEIRA, Cesar Augusto Camillo; PIMENTEL, Maria da Graça Campos. Watch-and-Comment as a Paradigm toward Ubiquitous Interactive Video Editing. In: ACM Transactions on Multimedia Computing, Communications and Applications, 2008. v. 2. p. 1-21 (submetido).

5. PIMENTEL, Maria da Graça Campos; CATTELAN, Renan Gonçalves; SANTOS, Felipe Silva; GOULARTE, Rudinei ; TEIXEIRA, Cesar Augusto Camillo. Ubiquitous Interactive Video Editing via Multimodal Annotations (to appear in July 2008). In: EuroITV - European Interactive TV Conference, 2008, Salzburg. Proceedings LNCS, 2008. v. 1. p. 1-10. 
6. PIMENTEL, Maria da Graça Campos; GOULARTE, Rudinei; CATTELAN, Renan Gonçalves; SANTOS, Felipe Silva; TEIXEIRA, Cesar Augusto Camillo. Enhancing multimodal annotation with penbased information. In: Workshop on New Techniques for Consuming, Managing, and Manipulation Interactive Digital Media at Home, 2007, Taichung, Taiwan, R. O. C.. Proceedings, 2007. v.2 p. 207-212. 


\section{Sumário}

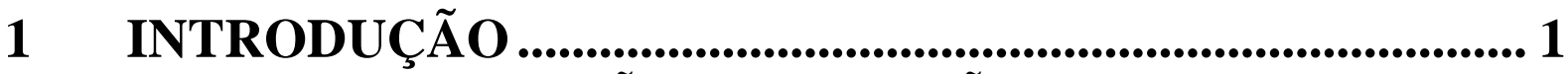

1.1 CONTEXTUALIZAÇÃO E MOTIVAÇÃO ………………………….... 1

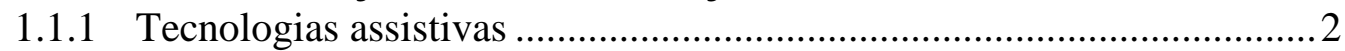

1.2 OBJETIVOS E RESULTADOS OBTIDOS _.......................................... 4

1.3 ESTRUTURA DA DISSERTAÇÃO …............................................. 5

2 INTERAÇÃO USUÁRIO-COMPUTADOR E SENSORES. 7

2.1 CONSIDERAÇÕES INICIAIS ………............................................ 7

2.2 INTERFACES FÍSICAS DE USUÁRIO_............................................. 7

2.2.1 Controles físicos e gráficos ................................................................

2.2.2 Interfaces físicas customizáveis ........................................................... 10

2.2.3 Adaptabilidade de entrada .................................................................. 13

2.2.4 Possibilidades de projeto …………………………………………..... 14

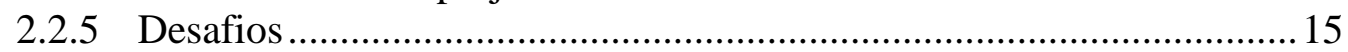

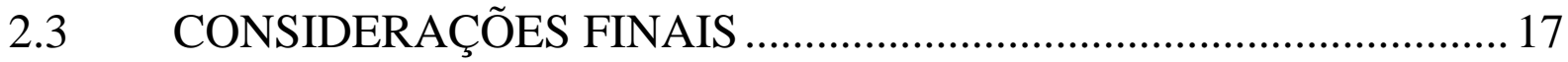

3 TRABALHOS RELACIONADOS ..................................... 19

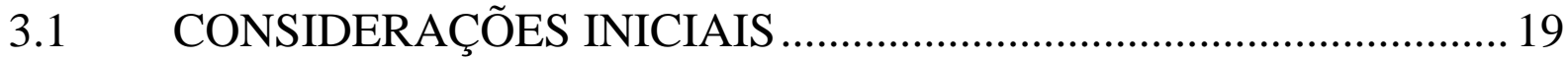

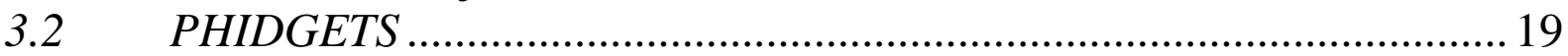

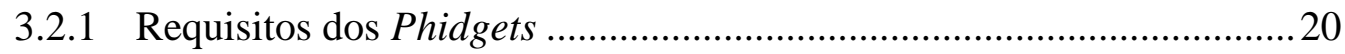

3.2.2 Exemplos de Phidgets ........................................................................21

3.2.3 Arquitetura de software e hardware ...................................................2

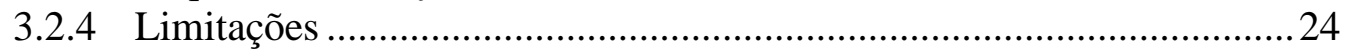

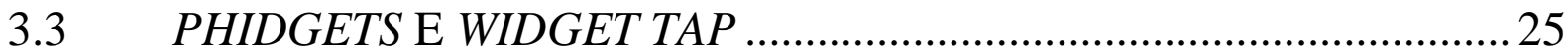

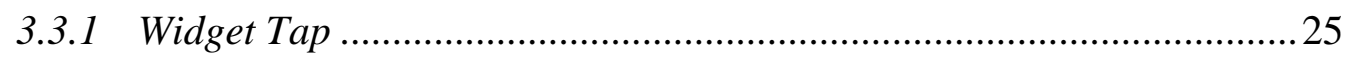

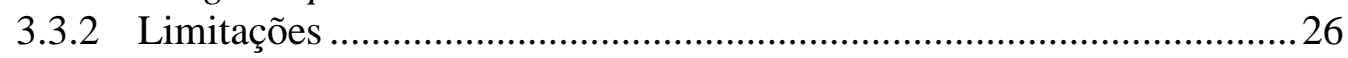

$3.4 \quad$ ICON

3.4.1 Exemplos de configurações do ICon ……………………………......28

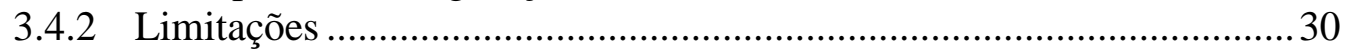

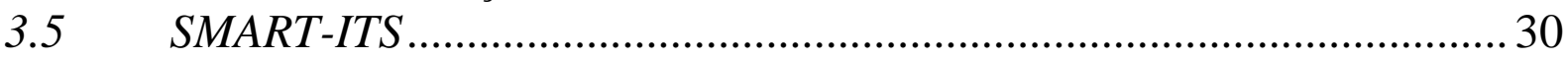

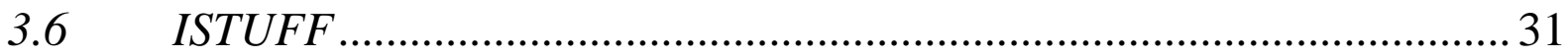

3.6.1 Requisitos do iStuff........................................................................ 31

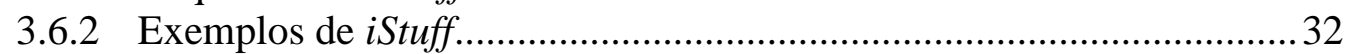

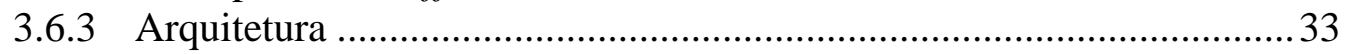

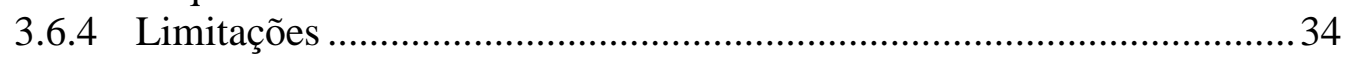

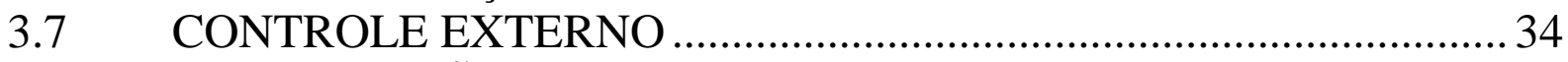

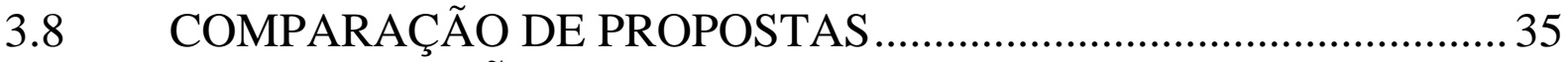

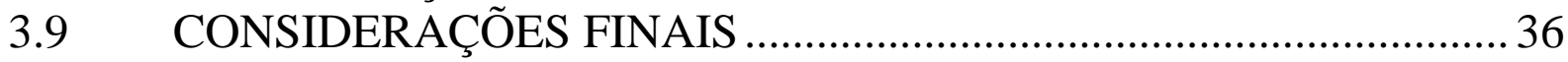

4 AMCE: ARQUITETURA DE HARDWARE E SOFWARE. 39

4.1 CONSIDERAÇÕES INICIAIS ...................................................... 39

4.2 ESPECIFICAÇÃO DAS CAMADAS DA ARQUITETURA AMCE.. 41

4.3 LEVANTAMENTO DE ALGUNS COMPONENTES DA

ARQUITETURA AMCE

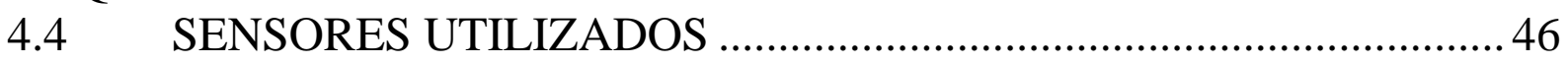


4.5 SOBRE A AVALIAÇÃO DA ARQUITETURA …............................ 48

4.6 CONSIDERAÇÕES FINAIS ......................................................... 49

5 DESENVOLVIMENTO DE UM SENSOR DE TRÊS

GRAUS DE LIBERDADE E UM MOUSE ASSISTIVO ............. 51

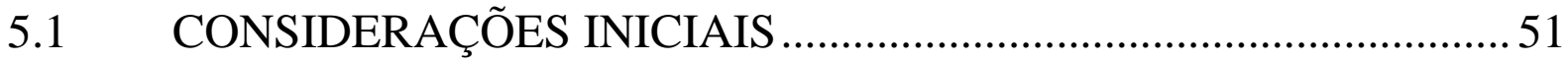

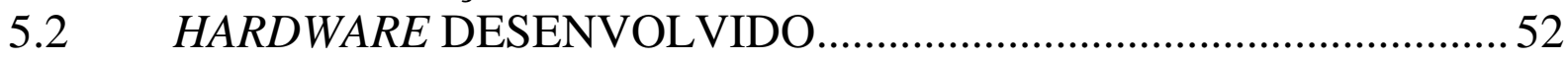

5.2.1 Diagrama da placa controladora..........................................................54

5.2.2 Diagrama da placa do sensor.................................................................56

5.2.3 Microcontrolador................................................................................56

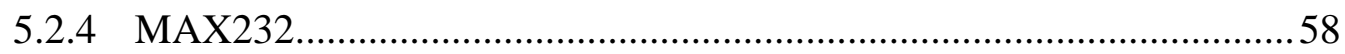

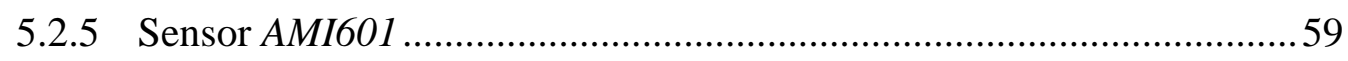

5.2.6 Aquisição de dados do sensor ami601 ………………………………....60

5.3 COMPONENTES DE HARDWARE CONSTRUÍDOS..........................61

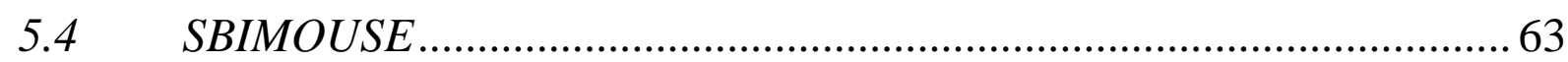

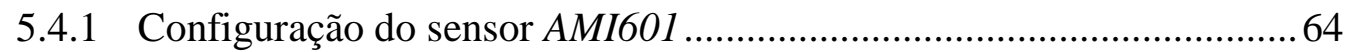

5.4.2 Calibração do sensor AMI601 ……………………………………….....64

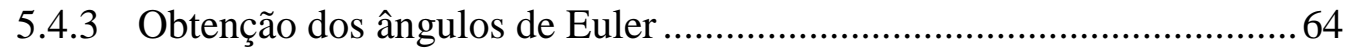

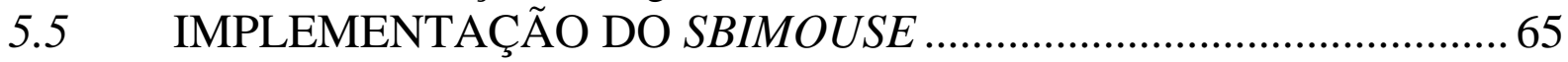

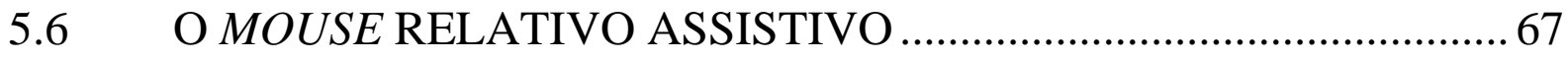

5.6.1 Mouses absolutos versus mouses relativos..............................................67

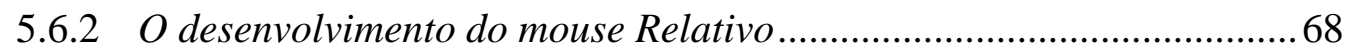

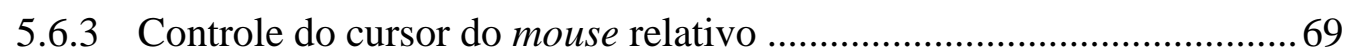

5.6.4 Controle dos cliques do mouse …………………………………….....

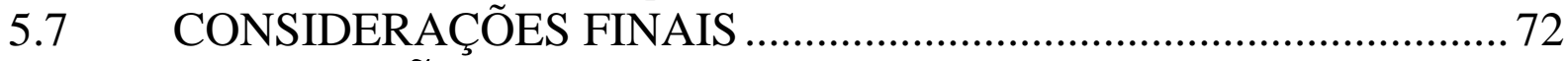

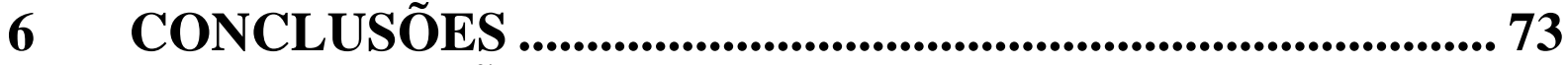

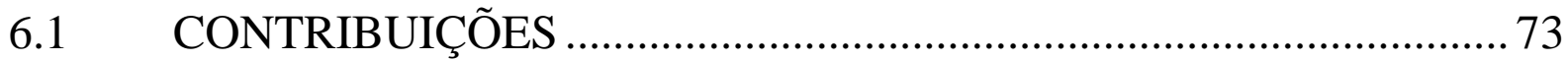

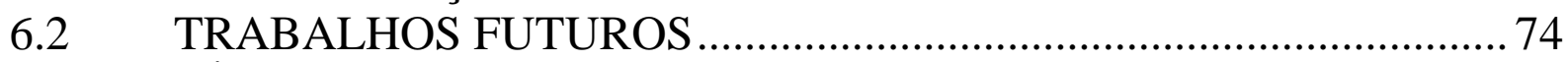

GLOSSÁRIO ......................................................................................... 75

REFERÊNCIAS BIBLIOGRÁFICAS................................................ 79

APÊNDICE A - DRIVER ASSEMBLY AMI601 ........................... 87 APÊNDICE B - CONFIGURAÇÃO DO SENSOR AMI601 ...... 91 APÊNDICE C - CALIBRAÇÃO DO SENSOR AMI601 ............ 93 APÊNDICE D - MODELO MATEMÁTICO PARA OBTENÇÃO DOS ÂNGULOS DE EULER ...........................................................97

ANEXO A - DIAGRAMA DE CLASSES PHIDGETS ............... 99 ANEXO B - DIAGRAMA DE CLASSES ICON ......................... 103 


\section{Lista de Figuras}

Figura 2.1 - Interface física com RFID (Greenberg \& Boyle, 2002) .

Figura 2.2 - Um medidor físico construído com um servomotor conectado a um medidor de energia

(Greenberg \& Boyle, 2002)

Figura 2.3 - Um console físico contendo vinte e um dispositivos (Greenberg \& Boyle, 2002)............... 12

Figura 3.1 - PhidgetServo e um servomotor (Phidgets, 2007) ............................................22

Figura 3.2 - PhidgetRFID (parte superior esquerda), 2 cartões RFID (parte superior direita), 2 chaveiros

RFID (parte inferior esquerda) e 6 discos RFID (parte inferior direita) (Phidgets, 2007) ............22

Figura 3.3 - PhidgetInterfaceKit e, chaves, LEDs, solenóides e sensores que podem ser conectados a ele

(Phidgets, 2007) .................................................................................... 22

Figura 3.4 - Arquitetura Phidgets - Adaptado de Greenberg \& Fitchett (2001) ............................23

Figura 3.5 - Componentes ICon (Dragicevic \& Fekete, 2004) ................................................ 27

Figura 3.6 - Mouse, teclado, tablet e entrada de fala (Dragicevic \& Fekete, 2004) ............................27

Figura 3.7 - Utilizando o sensor de pressão de um tablet para determinar a espessura de um traço de uma aplicação de desenho a mão livre (Dragicevic \& Fekete, 2004) ......................................28

Figura 3.8 - Controle da barra de rolagem por comandos de voz (Dragicevic \& Fekete, 2004)............29

Figura 3.9 - A arquitetura de dispositivos Smart-Its é modular e separa a interação física da comunicação

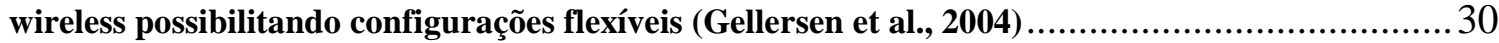

Figura 3.10 -Smart-its são baseados em módulos de hardware que são simples: (a) a placa principal com o microcontrolador e radio; exemplos de (b) um add-on sensor e (c) um atuador (Gellersen et al., 2004)

Figura 3.11 - Exemplos de componentes iStuff de entrada e saída (Ballagas et al., 2003).....................32

Figura 3.12 - Arquitetura iStuff (Ballagas et al., 2003) .................................................... 33

Figura 4.1 - Arquitetura em camadas AMCE....................................................... 41

Figura 4.2 - ADXL Breakout Board (http://www.sparkfun.com) ..................................... 47

Figura 4.3 - IMU Combo Board - ADXL203/ADXRS401 (http://www.sparkfun.com) ....................47

Figura 4.4 - OS1x00 Bússola Digital com compensação de inclinação com roll, pitch e conexão serial

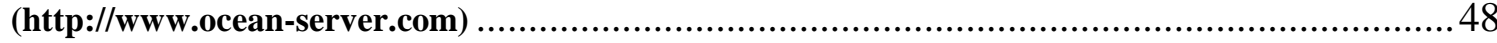

Figura 4.5 - AMI601 Acelerômetro de três eixos e sensor magnético de três eixos em uma única pastilha

(http://www.aichi-mi.com).................................................................... 48

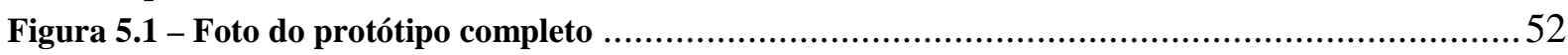

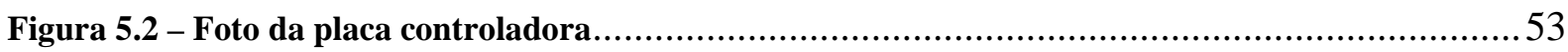

Figura 5.3 - Foto da placa do sensor ...................................................................5

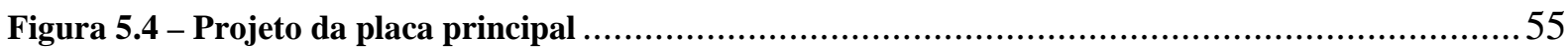

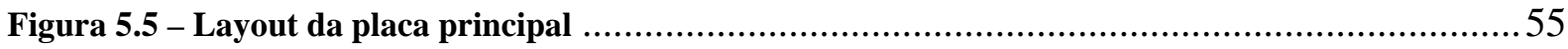

Figura 5.6 - Projeto da placa do sensor....................................................................56

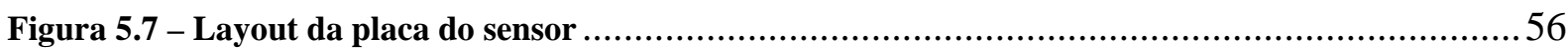

Figura 5.8 - Descrição dos pinos do PIC16F877A usados no projeto (http://www.rogercom.com) .........57

Figura 5.9 - Conversor de sinais RS232/TTL (http://www.rogercom.com) ................................58

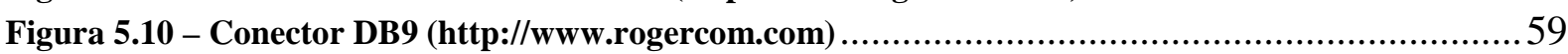

Figura 5.11 - Sensor AMI601 (http://www.aichi-mi.com) ................................................6 60

Figura 5.12 - Componente ADXL Breakout Board .....................................................6 61

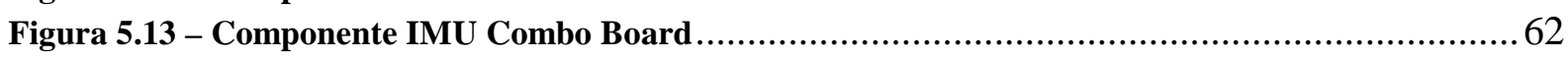

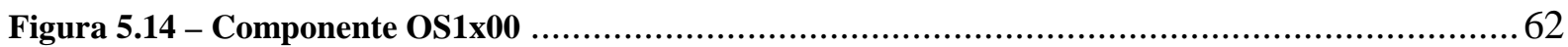

Figura 5.15 - Componente AMI601 .....................................................................6 63

Figura 5.16 - Componente para transformação de dados primitivos de aceleração e campos magnéticos

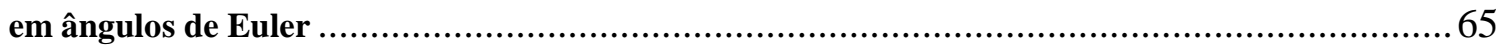

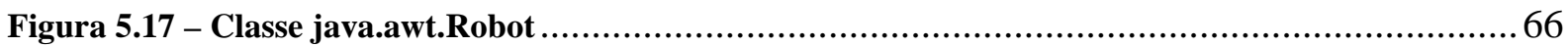

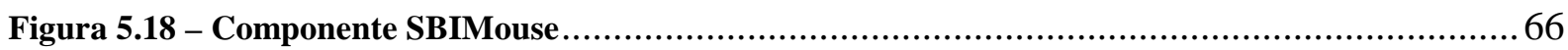

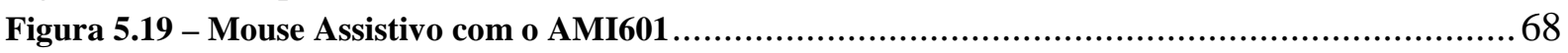

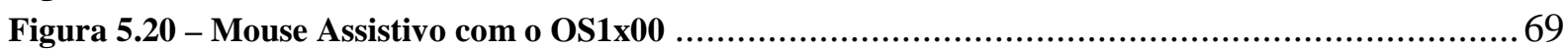




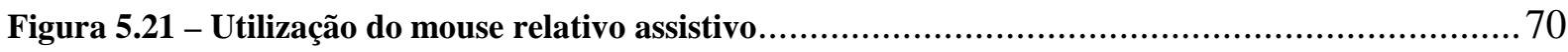

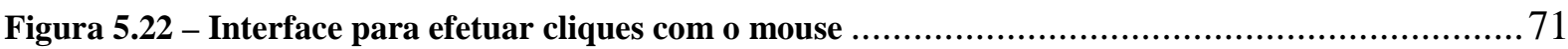

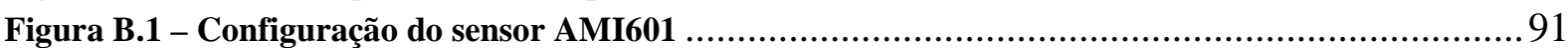

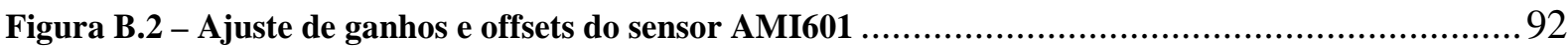

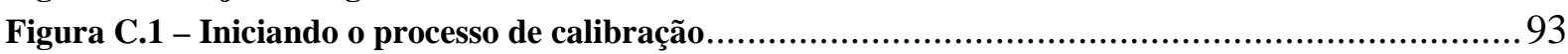

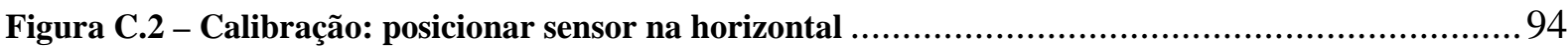

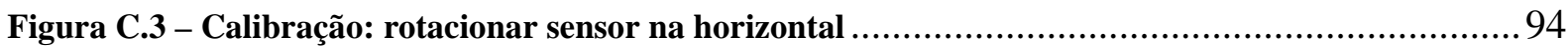

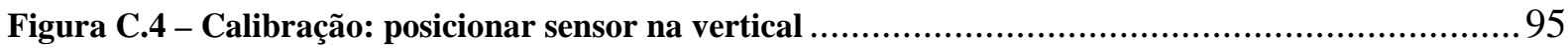

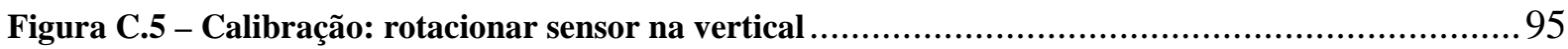

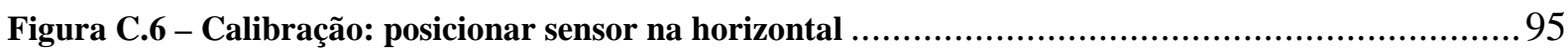

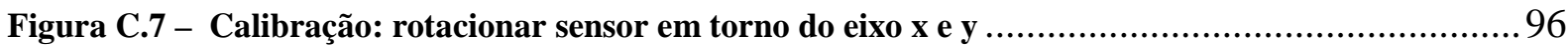

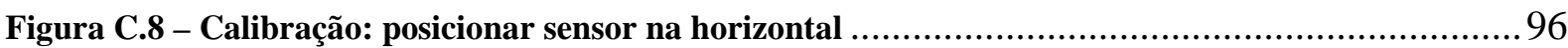

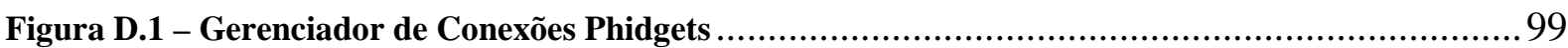

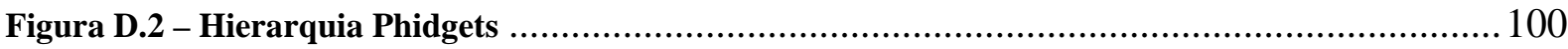

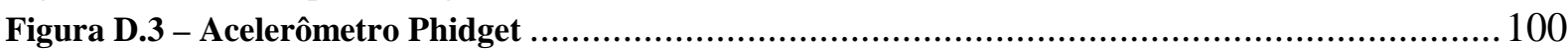

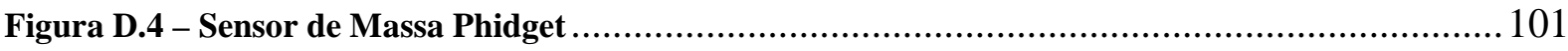

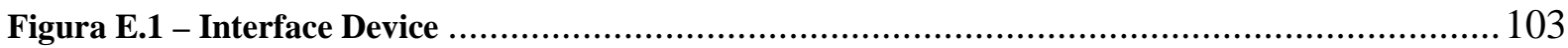

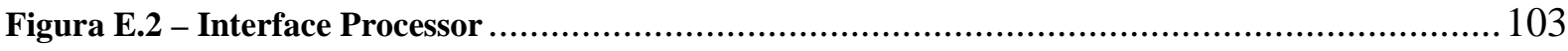

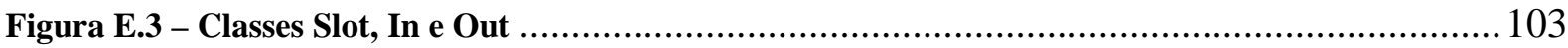

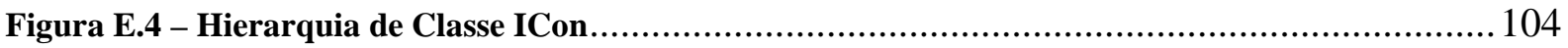




\section{Lista de Tabelas}

Tabela A.1 - Comandos aceitos pelo microcontrolador. .87

Tabela A.2 - Mensagens enviadas pelo microcontrolador 88 


\section{Lista de Abreviaturas e Siglas}

ACM - Association for Computing Machinery.

API - Application Programming Interface (Interface de Programação de Aplicativos).

EEG - Electroencephalographic.

EMG - Electromyogram.

GUI - Graphical User Interface (Interface Gráfica de Usuário).

$\mathbf{I}^{2} \mathbf{C}$ - Inter Integrated Circuit.

IBGE - Instituto Brasileiro de Geografia e Estatística.

ICon - Input Configurator (Configurador de Entrada).

IEEE - Institute of Electrical and Electronics Engineers.

IR - Infrared (Infravermelho).

ITS - Instituto de Tecnologia Social.

J2EE - Java Enterprise Edition.

JMS - Java Message Service.

LCD - Liquid Crystal Display (Tela de Cristal Líquido).

LED - Light Emitting Diode (Diodo emissor de Luz).

MCT - Ministério das Ciências e Tecnologia.

NMEA - National Marine Electronics Association.

Phidgets - Physical Widgets (Widgets Físicos).

RFID - Radio Frequency Identification (Identificação por Rádio Freqüência).

SECIS - Secretaria da Ciência e Tecnologia para a Inclusão Social.

TA - Tecnologias Assistivas.

USB - Universal Serial Bus.

WIMP - Window Icon Menu Pointer. 


\section{INTRODUÇÃO}

\subsection{CONTEXTUALIZAÇÃO E MOTIVAÇÃO}

"Entre os produtos interativos do futuro estarão dispositivos embarcados que poderão utilizar dados provenientes de vários sensores, atuar inteligentemente sobre essa informação, e fazer alguma coisa sobre ela" (Holmquist, 2006).

Aplicações desktop interativas típicas gerenciam um conjunto muito limitado de dispositivos de entrada, tipicamente um mouse e um teclado. Entretanto, a população de usuários que requerem ou simplesmente possuem dispositivos de entrada alternativos está crescendo, assim como o número de novos dispositivos físicos disponíveis. Usuários de computadores estão descobrindo novas formas de interagir, e técnicas tais como interação por gestos e reconhecimento de voz estão se tornando cada vez mais comuns (Dragicevic \& Fekete, 2004, 2001).

Segundo Dragicevic e Fekete (2001), dada a diversidade de dispositivos de entrada e a importância das tarefas realizadas pelos usuários com o apoio de um computador, ser capaz de adaptar uma aplicação existente a um ou vários dispositivos de entrada é uma característica importante para usuários com necessidades especiais, músicos, jogadores de videogame e artistas gráficos, entre outros. Esses usuários consideram seus ambientes mais usáveis ou simplesmente enriquecidos quando eles usam seus dispositivos de entrada favoritos com as aplicações existentes. Dragicevic e Fekete defendem que, para ampliar possibilidades de acessibilidade e portabilidade, é crítico que aplicações interativas sejam capazes de explorar conjuntos de dispositivos de entrada alternativos e, além disso, para otimizar a usabilidade, tais aplicações devem utilizar técnicas de interação apropriadas de acordo com os dispositivos existentes, as tarefas específicas da aplicação e as preferências do usuário final. 
Greenberg e Boyle (2002), similarmente a outros pesquisadores da área de computação tangivel, defendem a suplementação da interação com elementos de interface físicos. Eles promovem o uso de dispositivos de entrada físicos como: "push/toggle buttons" físicos, resistores (dials e sliders), cartões RFID (radio frequency identification - identificação por rádio freqüência), e sensores de luz ou pressão, e de dispositivos de saída física como LEDs (light emitting diode - diodo emissor de luz), servomotores, ou mesmo dispositivos off-the-shelf, tais como lâmpadas ou ventiladores.

Além desse contexto mais amplo, a motivação inicial deste trabalho se deu por intermédio das Tecnologias Assistivas (TA), pois em tal área, é comum a exploração de sensores e atuadores físicos. A seguir, tal conceito será explicitado.

\subsubsection{Tecnologias assistivas}

Recursos tecnológicos podem contribuir para diminuir inúmeras barreiras que pessoas com necessidades especiais encontram no seu cotidiano. Algumas dessas barreiras referem-se à dificuldade encontrada por tais usuários na interação com computadores (Steriadis et al., 2003). Na busca de soluções para esses problemas, são investigadas ferramentas de hardware e software, que se enquadram na categoria das Tecnologias Adaptativas ou Assistivas.

A lei "Technology-Related Assistance for Individuals with Disabilities Act Public 100-407", promulgada nos Estados Unidos em 1988, define Tecnologia Assistiva (TA) como: "qualquer item, peça de equipamento ou conjunto de produtos que é usado para aumentar, manter ou melhorar habilidades de pessoas com limitações funcionais, sejam fisicas ou sensoriais" (Assistive Technology Act, 1988).

O Ministério de Ciências e Tecnologia do Brasil (MCT) empregou o termo Tecnologia Assistiva no ano de 2005 ao lançar um edital para o apoio financeiro de projetos de pesquisa e desenvolvimento de "Tecnologias Assistivas", caracterizando-as como "tecnologias que reduzam ou eliminem as limitações decorrentes das deficiências física, mental, visual e/ou 
auditiva, a fim de colaborar para a inclusão social das pessoas portadoras de deficiência e dos idosos" (MCT, 2005).

Outro fato importante no contexto de Tecnologia Assistiva foi o desenvolvimento do Portal Nacional de Tecnologia Assistiva, criado como um instrumento importante de convergência e troca de informações e conhecimentos sobre as iniciativas que existem no Brasil para a pesquisa, o desenvolvimento, a aplicação e a disseminação de Tecnologia Assistiva, visando promover a inclusão social de uma população que, hoje, representa 24,6 milhões (segundo o Censo/IBGE do ano de 2000). Esse é um projeto viabilizado pela Secretaria de Ciência e Tecnologia para a Inclusão Social (SECIS), do Ministério de Ciência e Tecnologia (MCT), em parceria com o Instituto de Tecnologia Social (ITS) (Portal Nacional de Tecnologia Assistiva, 2007).

No contexto da Ciência da Computação, em termos de pesquisa acadêmica, pode-se dizer que a Tecnologia Assistiva é uma sub-área de Interação Usuário-Computador. Existem diversas conferências importantes na área de TA sendo uma das principais a conferência anual promovida pelo ACM SIGACCESS ${ }^{2}$, um grupo da Association for Computing Machinery (ACM) interessado em pesquisas em acessibilidade computacional. O SIGACCESS promove a integração de profissionais que trabalham em pesquisa e desenvolvimento de tecnologias da informação para ajudar pessoas com necessidades especiais. As ações desse grupo contemplam a aplicação de tecnologias que ajudam pessoas com necessidades especiais de visão, motoras, audição, deficiências de fala, limitações cognitivas, incluindo deficiências de aprendizagem.

Dada a diversidade de necessidades especiais, uma ampla gama de sensores $^{3}$ têm sido aplicados no desenvolvimento de Tecnologias Assistivas. Por exemplo, existem dispositivos que capturam os movimentos dos olhos do usuário (Hornof et al., 2004), movimentos da cabeça (Kim \& Cho, 2002; Santos et al., 2004), movimentos do tórax e comandos de voz (Dai et al., 2004; Beckhaus e Kruijff, 2004). A construção de dispositivos de interação

\footnotetext{
${ }^{2}$ http://www.acm.org/sigaccess.

${ }^{3}$ http://lib.f0.am/cgi-bin/view/Libarynth/ProjectLytaMaterialsResearch\#Sensors.
} 
baseados em tais sensores demandam conhecimentos especializados de hardware, o que pode dificultar a construção de dispositivos físicos adaptados às necessidades específicas de usuários.

\subsection{OBJETIVOS E RESULTADOS OBTIDOS}

O trabalho aqui reportado objetivou desenvolver uma arquitetura em camadas de componentes de hardware e software que fornece, como dados de entrada para aplicações computacionais, eventos capturados de sensores tais como os que detectam inclinação, rotação e aceleração. Como resultado, desenvolveu-se um dispositivo personalizado de interação focando a atenção no mapeamento das ações comportamentais do usuário para a interação correspondente, abstraindo, dessa forma, as informações de baixo nível provenientes do hardware e de primitivas de baixo nivel de software que combinam eventos físicos detectados pelos sensores.

Mais especificamente, o objetivo do trabalho é a proposta de uma arquitetura de componentes de hardware e software que fornece, como dados de entrada para aplicações computacionais, eventos capturados de sensores tais como sensores de inclinação, de rotação e de aceleração.

A pesquisa envolveu a concepção e a implementação de uma arquitetura em camadas que possui, em sua base, uma camada de hardware composta por um conjunto de sensores que mensuram eventos físicos do usuário e, nas demais camadas, componentes de software que permitem associar uma semântica de dados de entrada para aplicações aos dados primitivos provenientes dos sensores e de camadas intermediárias.

Como resultado, a arquitetura disponibiliza os dados dos sensores como eventos em alto nível que podem ser associados a operações de interação usuário-computador típicas de um mouse, de um teclado ou de um joystick, por exemplo. Do ponto de vista de um desenvolvedor de software, a implementação de um dispositivo de interação baseado em sensores é facilitada, por um lado, pelo fato de o tratamento de erros associados ao uso de sensores ter sido realizado nas camadas inferiores e, por outro lado, pelo 
fato de os dados serem apresentados em um alto nível de abstração que não exige conhecimento específico sobre o uso do hardware associado.

Como estudo de caso, foi projetado e desenvolvido um dispositivo de interação que permite interações típicas de um mouse, e que pode ser usado por usuários tetraplégicos, que possuam controle fino dos movimentos da cabeça e ausência de deficiências visuais.

Uma vez que a arquitetura é proposta em camadas, os sensores da camada de hardware podem ser substituídos por outros tipos de sensores. Como resultado, considerando que os dispositivos de interação criados podem ser utilizados com uma gama variada de sensores, espera-se que um amplo número de necessidades especiais possa ser atendido.

\subsection{ESTRUTURA DA DISSERTAÇÃO}

Esta dissertação está organizada de forma a apresentar o contexto teórico no qual este trabalho está inserido, bem como a pesquisa realizada.

No Capítulo 2 são apresentados alguns conceitos fundamentais sobre a área de interação usuário-computador de modo geral, e da área de interfaces físicas de modo particular. Nesse capítulo são discutidas as contribuições de diversos pesquisadores no intuito de permitir que dispositivos alternativos de entrada e saída, sobretudo físicos, sejam amplamente utilizados. Além disso, também são identificadas vantagens e desvantagens da utilização de dispositivos físicos em tais interfaces, assim como os desafios dessa área.

No Capítulo 3 são discutidos os principais trabalhos relacionados diretamente à proposta deste projeto. Nesse capítulo são apresentados pesquisas e produtos que oferecem apoio a construção de interfaces físicas de usuário ou permitem alguma forma de configuração da forma de interação. É discutido o que são Phidgets (Greenberg \& Fitchett, 2001), qual a relação de Phidgets e Widget Tap (Greenberg \& Boyle, 2002), o que são ICon (Dragicevic \& Fekete, 2004, 2001), Smart-its (Holmquist et al, 2004), iStuff (Ballagas et al., 2003) e controle externo (Greenberg \& Boyle, 2002), trabalhos esses intimamente ligados com a proposta desta dissertação. 
No Capítulo 4 a arquitetura AMCE. No Capítulo 5 detalhes da implementação são descritos.

No Capítulo 6 é apresentada a conclusão do trabalho, sumarizando as contribuições e discutindo trabalhos futuros. Finalmente é apresentado o glossário de termos e a bibliografia utilizada. 


\section{INTERAÇÃO USUÁRIO-COMPUTADOR E SENSORES}

\subsection{CONSIDERAÇÕES INICIAIS}

Este capítulo apresenta as contribuições de Greenberg, Fitchett, Boyle, Dragicevic, Fekete dentre outros, que trabalham no sentido de permitir que dispositivos de entrada e saida alternativos ao mouse e teclado convencionais, sobretudo físicos, sejam amplamente utilizados em interfaces. Além disso, também são discutidas as vantagens e as desvantagens da utilização de dispositivos físicos em interfaces usuáriocomputador, assim como os desafios dessa área.

\subsection{INTERFACES FÍSICAS DE USUÁRIO}

De acordo com Greenberg e Fitchett (2001), na década de 90 vários pesquisadores investigaram o desenvolvimento de interfaces usuáriocomputador que incluem interfaces físicas de usuário, nas áreas de computação ubíqua, calm technology, computação pervasiva, interfaces de usuário tangíveis, information appliances e computação ciente ao contexto. Pesquisadores de tais áreas demonstraram trabalhos simples, mas muito interessantes de interfaces físicas de usuário, que podem ser encontradas em Greenberg e Fitchett (2001).

A criação de novas interfaces físicas de usuário pode ser motivada por diversos fatores, dentre eles: exploração de novas idéias de interação, desenvolvimento de interfaces inovadoras, melhoria das interfaces existentes e expansão das interfaces existentes mediante novas características.

A próxima seção discute a adoção de interfaces físicas de usuário na interação usuário-computador. 


\subsubsection{Controles físicos e gráficos}

De acordo com Greenberg e Boyle (2002), controles de interfaces gráficas de usuário possuem problemas conhecidos:

1. Em função do espaço da tela ser escasso, nem todos os controles cabem no primeiro nível de exibição; muitos deles são alocados hierarquicamente em menus e caixas de diálogo; usuários podem achar dificil ou tedioso descobrir e navegar sobre esses controles.

2. Os controles que são diretamente visíveis na janela podem não ser aqueles que o usuário necessita. Além disso, esses controles competem com a própria aplicação não somente pela área de exibição, mas também pela atenção do usuário.

3. Enquanto a maioria das interfaces gráficas de usuário apóiamse no uso de mouse e teclado para entrada de dados e tela gráfica para a saída, um dispositivo de apontamento não é necessariamente o melhor dispositivo de entrada para qualquer tarefa de controle dada. Por exemplo, devido ao fato de controles gráficos proverem somente uma imitação visual do seu comportamento, eles demandam uma atenção considerável.

Ainda segundo Greenberg e Boyle (2002), controles fisicos oferecem um conjunto de vantagens sobre suas contrapartes gráficas:

- Porções da tela que seriam ocupadas por controles gráficos são liberadas, deixando mais espaço na tela para as aplicações e diminuindo a competição pela atenção do usuário.

- Controles físicos estão geralmente visíveis, e assim são mais fáceis de localizar e interagir.

- Entradas mais eficientes são possíveis, desde que a forma de um controle físico pode ser mais próxima de se adequar às necessidades de interação. Por exemplo, ajustar o volume é mais fácil por intermédio de um reostato ${ }^{4}$ deslizante quando comparado a um GUI (Graphical User

\footnotetext{
${ }^{4} \mathrm{O}$ reostato é um dispositivo utilizado para variar a resistência elétrica de um circuito e, assim, aumenta-se ou diminui -se, conforme o desejado, a intensidade de corrente nesse circuito.
} 
Interface) deslizante, porque ele limita a ação do usuário somente em uma única dimensão e provê feedback tátil.

- Entradas com duas mãos são possíveis. Por exemplo, a mão dominante pode controlar um mouse enquanto a outra mão controla outro dispositivo físico qualquer.

- Controles físicos podem ser posicionados 'ready to hand' por trazê-los próximos ao usuário quando necessários, e empurrá-los para a periferia quando conveniente.

- A memória espacial é melhor utilizada. Controles físicos não se movem sobre a área de trabalho por "vontade própria", e assim usuários podem rapidamente lembrar onde eles estão.

- Mais habilidades são usadas. Como exemplo, considere um ventilador elétrico ao invés de uma barra de progresso GUI para ilustrar o progresso feito sobre uma operação, de tal forma que o ventilador sopra mais forte quando o progresso está próximo de estar completo. Enquanto uma barra de progresso GUI utiliza somente a visão, a saída do ventilador é percebida por muitos sentidos: ver a movimentação das lâminas do ventilador, ouvir seu zumbido, e sentir o vento produzido.

Entretanto, controles físicos apresentam alguns problemas óbvios (Greenberg e Boyle, 2002):

- Consomem espaço na superficie de trabalho.

- Os menos comum levam tempo para que o usuário aprenda a interagir com eles.

- Alguns são caros.

- Não são escaláveis: utilizar dezenas de dispositivos, um para cada função da aplicação é simplesmente impraticável.

- Não são tão maleáveis quanto controles gráficos.

Não obstante aos diversos problemas mencionados, as vantagens do uso de elementos físicos motivam o desejo de introduzi-los no projeto de interfaces. Nas próximas seções serão apresentados os conceitos de 
interfaces físicas customizáveis e de adaptabilidade de entrada que visam atender tal desejo.

\subsubsection{Interfaces físicas customizáveis ${ }^{5}$}

A principal idéia de interfaces físicas customizáveis é permitir que o usuário vincule facilmente funções de uma aplicação qualquer a dispositivos físicos, e invoque a função por intermédio desse dispositivo e/ou visualize o status da aplicação sobre o dispositivo físico (Greenberg \& Boyle, 2002). A seguir são discutidos, com base no trabalho de Greenberg e Boyle (2002), alguns exemplos de tais interfaces.

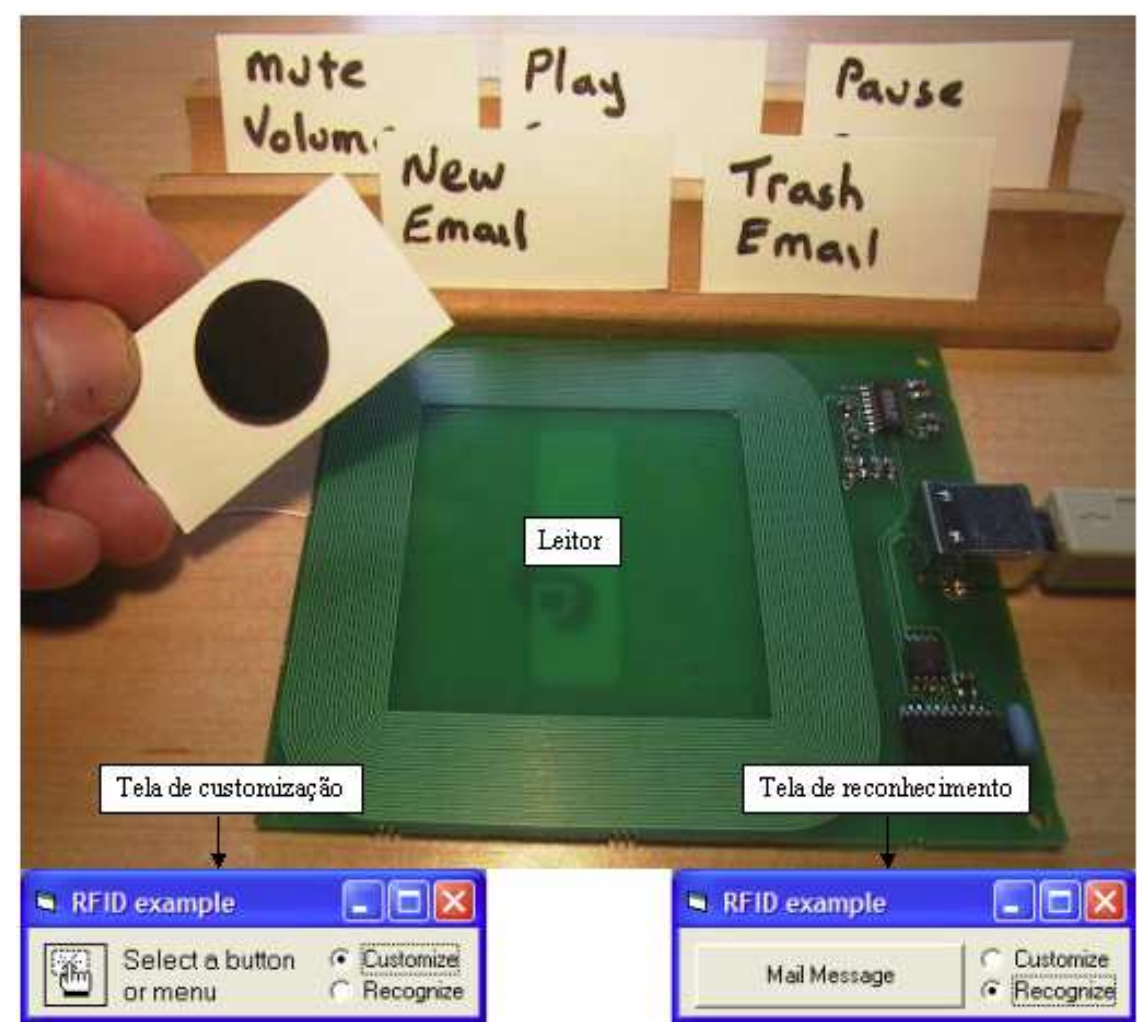

Figura 2.1 - Interface física com RFID (Greenberg \& Boyle, 2002)

O primeiro exemplo apresenta como associar cartões RFID a diferentes funções. Na Figura 2.1 (parte superior) são apresentados um leitor e vários cartões RFID rotulados com as funções que exercem (o usuário escreve a

\footnotetext{
${ }^{5}$ Vídeo que demonstra interfaces físicas customizáveis está disponível em: http://delivery.acm.org/10.1145/580000/571991/custphysinteraces.mov?key1=571991\&key2=9829435021\&coll $=\mathrm{ACM} \& \mathrm{dl}=\mathrm{ACM} \& \mathrm{CFID}=59040651 \& \mathrm{CFTOKEN}=57135646$. Visitado em março de 2008.
} 
ação sobre o rótulo do cartão para poder diferenciá-los). Quando no modo de customização (Figura 2.1, parte inferior esquerda), o usuário vincula a função a ser executada ao cartão, primeiro trazendo o cartão próximo ao leitor e, depois, selecionando um item de menu ou um botão como função a ser executada. Quando no modo de reconhecimento, o usuário invoca a função vinculada ao cartão movendo-o próximo ao leitor: o que causa a exibição do nome da função e a executa (Figura 2.1, parte inferior direita).

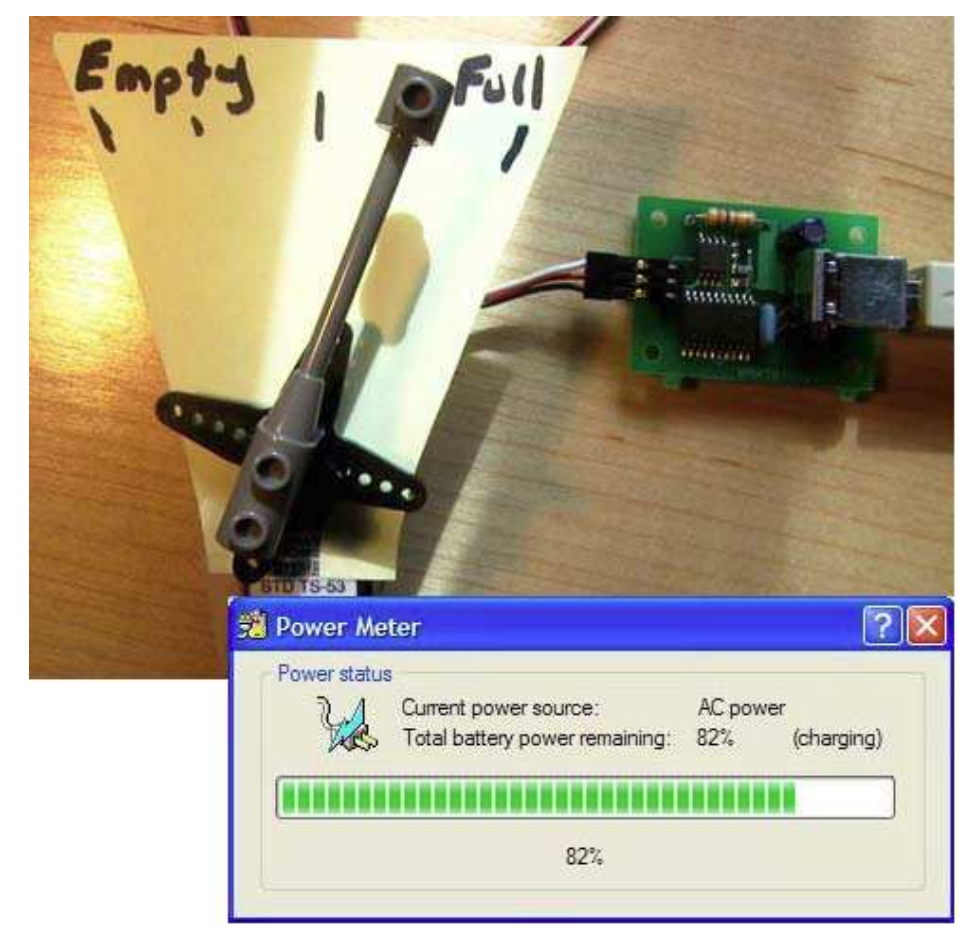

Figura 2.2 - Um medidor físico construído com um servomotor conectado a um medidor de energia (Greenberg \& Boyle, 2002)

Pode-se também exibir o status de saída em dispositivos físicos. Na Figura 2.2 é apresentado um exemplo, no qual um medidor foi construído usando um servomotor, papel e peças de Lego ${ }^{6}$. O usuário final seleciona e vincula o medidor físico a uma barra de progresso que exibe o status da carga da bateria (Figura 2.2, parte inferior). Como resultado, o motor automaticamente apresenta o valor da barra de progresso, rotacionando-se até a posição relativa a esse valor.

\footnotetext{
${ }^{6}$ http://www.lego.com.
} 


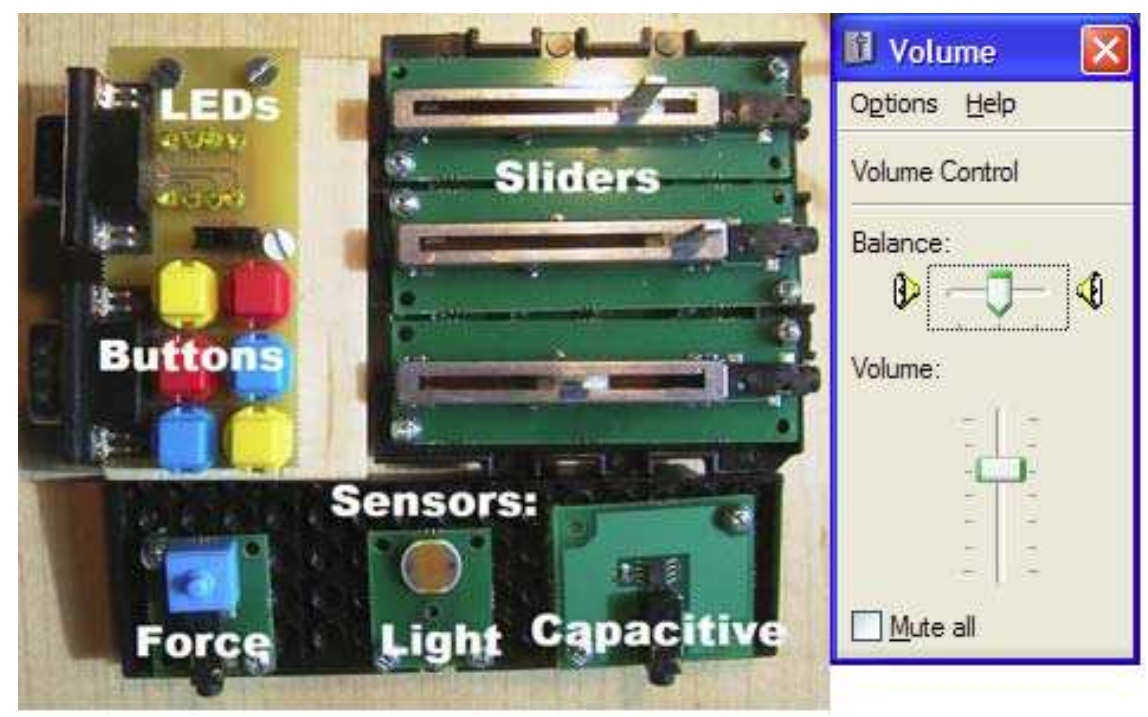

Figura 2.3 - Um console físico contendo vinte e um dispositivos (Greenberg \& Boyle, 2002)

Os exemplos anteriores ilustraram alguns tipos de customização de um único dispositivo. Vários outros dispositivos existem e podem ser combinados para criar consoles, que são kits que possuem vários sensores e/ou atuadores. Na Figura 2.3 é apresentado um console que inclui:

- Três potenciômetros deslizantes (resistores que têm o valor de sua resistência ôhmica alterado por meio do deslocamento de um atuador em um único eixo) que podem ser vinculados a qualquer controle deslizante gráfico ou barra de rolagem.

- $\quad$ Oito LEDs que podem ser vinculados a controles booleanos (por exemplo checkbox) para permitir ao usuário visualizar o estado correspondente.

- Seis push buttons e um toogle que pode ser vinculado a qualquer botão, item de menu ou checkbox.

- Sensores de força, luz e capacitivo que podem ser vinculados a qualquer widget ${ }^{7}$ que reconheça uma faixa continua de valores, por exemplo, um slider ${ }^{8}$ ou barra de rolagem.

\footnotetext{
${ }^{7}$ Os widgets são os elementos de interfaces gráficas que um usuário de computador utiliza para interagir, tais como: janelas ou caixas de texto.

${ }^{8} \mathrm{O}$ slider é um controle gráfico, tal como uma barra de rolagem, que graficamente representa uma faixa de valores (que o usuário pode configurar) ,ou que simplesmente apresenta o valor, magnitude ou posição de algo.
} 
Esse console pode ser utilizado para criar, por exemplo, uma interface física customizável vinculada a um controle de volume (Figura 2.3, direita). O primeiro slider físico foi associado ao slider volume, o segundo ao balanço e um botão ao checkbox mudo. Além disso, um LED foi vinculado ao checkbox mudo, de modo que ele fique ligado quando o volume está mudo.

Esses exemplos apresentam um conceito importante reportado pela literatura: o de interfaces físicas customizáveis. A próxima seção apresenta outro conceito importante no contexto de interfaces fisicas: adaptabilidade de entrada.

\subsubsection{Adaptabilidade de entrada ${ }^{9}$}

Adaptabilidade de entrada visa deixar a cargo do usuário de uma aplicação a seleção dos dispositivos de entrada a serem utilizados e a técnica de interação mais adequada às tarefas que pretende realizar.

Dragicevic e Fekete (2004) definem adaptabilidade de entrada como a combinação de controlabilidade, acessibilidade e configurabilidade.

Controlabilidade é a habilidade da aplicação usar entradas enriquecidas ou usar as entradas padrões (mouse e teclado) mais eficientemente. Entradas enriquecidas podem variar desde controles adicionais sobre dispositivos padrões até dispositivos multi-dimensionais, dispositivos de alta largura de banda e/ou múltiplos dispositivos e modalidades.

O uso efetivo das entradas implica o uso adequado de técnicas de interação de modo que se explore toda largura de banda e todas as compatibilidades dispositivo/tarefa. Dispositivos de entrada padrão podem também ser melhor aproveitados por novas técnicas de interação tais como reconhecimento de gestos.

Acessibilidade é a habilidade da aplicação usar entradas pobres. Isso pode variar de um dispositivo padrão até uma entrada de baixa largura de banda, tal como um simples botão. Permitir o uso de entradas pobres (em contraponto a entradas enriquecidas) eficientemente implica usar técnicas

\footnotetext{
${ }^{9}$ Vídeos que demonstram o conceito de adaptabilidade de entrada estão disponíveis em: http://www.emn.fr/xinfo/icon/examples.html. Acessado em março de 2008.
} 
de interação mais ricas para compensar a baixa largura de banda e compatibilidade dispositivo/tarefa.

Configurabilidade expressa a habilidade de o usuário escolher livremente como usar seus dispositivos de entrada para controlar a aplicação. Isso pode variar desde a seleção dos dispositivos e ações de customização básicas de mapeamento até a especificação de técnicas ricas de interação. A facilidade da especificação também é uma função crucial na adaptabilidade de entrada.

Apesar da importância da adaptabilidade de entrada, a maioria das aplicações do mundo real é desenvolvida para um conjunto de dispositivos de entradas e técnicas de interação fixas e não oferecem quase nenhuma adaptabilidade de entrada.

\subsubsection{Possibilidades de projeto}

Com os conceitos de interfaces físicas customizáveis e de adaptabilidade de entrada, muitas possibilidades de projeto são criadas. Greenberg e Boyle (2002) citam algumas como interfaces para pessoas com necessidades especiais, kits de construção e ambientes reativos customizáveis, dentre outras. Já Dragicevic e Fekete (2001) relacionam a sua proposta a áreas como tecnologias assistivas, jogos e toolkits 2D e 3D.

Todas essas áreas são de alguma forma beneficiadas com tais conceitos, mas como a motivação inicial deste trabalho recai sobre necessidades especiais, uma ênfase especial será dada a esse assunto.

\section{Interfaces para pessoas com necessidades especiais}

Enquanto muitas pessoas sugerem que computadores devam ajudar pessoas com necessidades especiais, a maioria dos computadores dá apoio somente a tipos particulares de necessidades como, por exemplo, baixa visão. Um dos problemas é o custo: a não ser que muitas pessoas tenham um tipo de necessidade particular, é muito caro inserir tais características de acessibilidade (Greenberg \& Boyle, 2002). 
Controles customizáveis podem diminuir tais custos: um painel de controle físico pode ser utilizado em várias situações, por exemplo, para dar a pessoas com problemas motores finos uma forma de acesso mais fácil a suas aplicações. Outra possibilidade é mapear o estado da aplicação em dispositivos de saída para torná-los mais perceptiveis. Por exemplo, se a barra de progresso é mapeada para um ventilador, aqueles com necessidades visuais ou auditivas podem ser beneficiados (Greenberg \& Boyle, 2002).

Como interfaces físicas customizáveis apresentam a limitação de utilizar as técnicas de interação das aplicações, seu poder será amplificado caso o conceito de adaptabilidade de entrada seja utilizado, permitindo interações mais ricas, naturais e adequadas.

É importante mencionar que produtos de tecnologias assistivas oferecem soluções similares às descritas aqui. Porém, o conceito de controles customizáveis e adaptabilidade de entrada possuem um propósito mais geral: não focam sobre um ou poucos tipos particulares de necessidades especiais e também não são restritos ao domínio de tecnologias assistivas, o que permite a redução dos custos devido à amplitude do mercado que pode ser explorada (Greenberg \& Boyle, 2002).

\subsubsection{Desafios}

Diante das inúmeras possibilidades de uso de interfaces físicas customizáveis, percebe-se claramente que a área de interfaces físicas de usuário apresenta várias possibilidades de pesquisa, mas cabe ressaltar que obstáculos ainda são encontrados ao se criar mesmo simples interfaces. Nessa seção serão ilustrados alguns deles.

Greenberg \& Fitchett (2001) sugerem que o maior problema é a dificuldade de se desenvolver e se combinar dispositivos físicos de modo que possam ser utilizados e integrados a linguagens de programação de alto nível. Além disso, os mesmos autores especificam outros problemas que são listados a seguir: 
- Mesmo dispositivos simples criados com componentes elétricos de baixo custo e confiáveis (chaves, sensores, solenóides, motores) são difíceis de serem construídos, a menos que haja disponibilidade de pessoas que tenham algum conhecimento ou experiência em eletrônica, projeto de circuitos ou engenharia elétrica, o que não é o caso da maioria dos cientistas da computação e especialistas em interação usuário-computador.

- Dispositivos comerciais podem não ter disponível uma API (application programming interface - interface de programação de aplicativos). Como resultado, um usuário não pode programar o dispositivo a menos que uma engenharia reversa seja realizada.

- Dispositivos comerciais desenvolvidos para aplicações particulares tipicamente possuem uma configuração e/ou API em um nível de abstração que nem sempre é desenvolvido com foco mais adequado para a construção dos tipos de dispositivos físicos que se deseja.

- Alguns kits de construção pertencem a mercados completamente diferentes, por exemplo, o Behaviour Construction Kit e Lego Mindstorms ${ }^{10}$ tem como usuários alvo crianças e usos educacionais.

- Desenvolvedores podem não ter esses dispositivos prontamente em estágios iniciais de seus esforços de programação, por diversas razões como custo elevado e atrasos de entrega. Apesar de um programa poder ser escrito sem um dispositivo físico, ele é difícil de ser testado.

Além dos problemas acima mencionados, Dragicevic e Fekete (2001) discutem a alta complexidade de possibilitar o uso de dispositivos alternativos de entrada. Cada aplicação tem que explicitamente implementar algum código para gerenciar cada dispositivo e todas as desejadas técnicas de interação com tais dispositivos. No melhor caso, aplicações especializadas

\footnotetext{
${ }^{10} \mathrm{http}: / /$ mindstorms.lego.com.
} 
permitem o uso de um conjunto limitado de dispositivos adequados as suas tarefas.

Em um trabalho posterior, Greenberg e Boyle (2002) vão além, discutindo não apenas o desenvolvimento de tais interfaces do ponto de vista do programador, mas buscando dar aos usuários finais das diversas aplicações um conjunto de dispositivos físicos que podem ser mapeados em poucas funções que o usuário considera importantes ou que usa freqüentemente. Segundo os autores, tal mapeamento é uma tarefa dificil de fazer, pois embora seja mostrado que usuários utilizam somente um subconjunto da totalidade de funções disponíveis na maioria das aplicações, esse subconjunto difere consideravelmente de usuário para usuário (Mcgrenere et al., 2002; Greenberg, 1993). Assim, é muito dificil determinar de antemão quais funções devem ser mapeadas em dispositivos físicos e como conseqüência essa atividade deve ser deixada a cargo do usuário.

Outro grande desafio da área é o controle externo, cujo objetivo é vincular robustamente código externo a uma aplicação de tal forma que ela possa ser controlada remotamente, isto é, ter a habilidade de invocar funcionalidades de aplicações existentes sem ter que ver ou modificar seu código-fonte (Greenberg \& Boyle, 2002).

\subsection{CONSIDERAÇÕES FINAIS}

Embora o poder de processamento e armazenamento dos computadores pessoais tenha aumentado extraordinariamente nos últimos anos, as interfaces usuário-computador continuam essencialmente as mesmas. Inovações de pesquisa em Interação Usuário-Computador são raramente incorporadas.

Segundo Beaudouin-Lafon (2004), os pesquisadores em Interação Usuário-Computador encontram duas grandes barreiras que restringem a disseminação de pesquisas de interação. A primeira é que mesmo ao criarem novas técnicas de interação e mostrarem sua efetividade em laboratórios, a ausência de modelos, métodos e ferramentas que permitam transferir tais técnicas a aplicações comerciais inviabilizam sua utilização. A segunda é que 
interfaces WIMP (Window Icon Menu Pointer) são tão estáveis e tão universalmente adotadas que o custo da mudança é muito alto.

Neste capítulo foram apresentadas pesquisas realizadas no campo de interfaces físicas de usuário, enfatizando as vantagens do uso de elementos físicos e definindo conceitos essenciais como interfaces customizáveis e adaptabilidade de entrada.

Espera-se que os desafios e barreiras da área sejam superados e que tais pesquisas possam ser incorporadas em interfaces modernas de modo que suas vantagens sejam associadas a novas aplicações.

No próximo capítulo serão apresentadas as pesquisas mais relacionadas ao contexto deste trabalho. 


\section{TRABALHOS RELACIONADOS}

\subsection{CONSIDERAÇÕES INICIAIS}

Relacionados aos desafios mencionados no capitulo anterior, diversos trabalhos têm sido propostos. A literatura reporta várias pesquisas realizadas no sentido de simplificar a conexão de dispositivos alternativos ou de especificar a configuração do modo de interação das aplicações.

Neste capítulo são apresentados algumas pesquisas e produtos, que oferecem apoio à construção de interfaces físicas de usuário ou permitem alguma forma de configuração do modo de interação. Além disso a arquitetura $A M C E$ é comparada a outras relatadas pela literatura, assim como também é sumarizado o que são os Phidgets, qual a relação de Phidgets e Widget Tap, o que é o ICon, Smart-its, iStuff e controle externo, trabalhos esses intimamente ligados com a proposta desta dissertação.

\subsection{PHIDGETS}

Construir e programar hardware são tarefas geralmente onerosas e requerem muito conhecimento especializado, devido a isso programadores encontram consideráveis obstáculos ao criar mesmo simples interfaces físicas de usuário (Greenberg \& Boyle, 2002). Segundo Greenberg e Fitchett (2001) o maior problema talvez seja a dificuldade de desenvolver e combinar dispositivos físicos com linguagens de programação convencionais.

Para resolver tal problema, Greenberg \& Fitchett (2001), criaram o conceito denominado Phidgets. Phidgets ou widgets físicos são blocos de construção que auxiliam os desenvolvedores a construir interfaces fisicas de usuário. Phidgets são dispositivos de hardware de entrada e saída - tais como botões, sensores de pressão e servomotores - encapsulados de tal forma que permitem que programadores criem dispositivos físicos de entrada e saída de uma maneira similar a construção de interfaces gráficas com widgets. Usando Phidgets, um programador médio sem conhecimento de 
hardware pode rapidamente criar protótipos sem despender esforços desenvolvendo hardware especial, firmware ou software (Greenberg \& Boyle, 2002). Dessa forma desenvolvedores podem concentrar-se no uso, na modificação e na recombinação de dispositivos físicos, ao invés da construção e implementação de baixo nível.

A abstração é feita da seguinte forma: a implementação e os detalhes de construção são escondidos pela exposição de toda a funcionalidade do dispositivo através de uma API. O dispositivo físico, a arquitetura de software para comunicação (USB) e gerenciamento de conexões são encapsulados pela API, além disso, uma interface interativa (opcional) para exibir o estado do dispositivo e/ou controlar o mesmo também pode estar disponivel.

\subsubsection{Requisitos dos Phidgets}

Assim como as convencionais GUI widgets, a idéia fundamental do Phidget é que ele apresente ao programador uma entidade que possa ser inserida facilmente em uma aplicação. Ambos conceitos, widgets e Phidgets, apresentam uma abstração e uma interface bem definida, e escondem os detalhes de como a identidade é implementada (Greenberg \& Fitchett, 2001).

Diferente dos widgets, os Phidgets possuem outros requisitos (Greenberg \& Fitchett, 2001):

1. Gerenciador de Conexões - Enquanto widgets estão sempre disponiveis para as aplicações em tempo de execução, dispositivos físicos podem estar ou não. Por exemplo, durante um tempo o dispositivo pode estar presente ou não, ou ter uma conexão intermitente (especialmente se ele é wireless). O trabalho do gerenciador de conexões é monitorar e comunicar-se com os Phidgets, para informar às aplicações a existência ou não dos mesmos, e dar aos programadores uma forma de manipulá-los quando eles forem percebidos no ambiente. Os diagramas das principais classes do gerenciador de conexões são apresentadas no Anexo A.

2. Identificação - Deve haver uma forma de vincular o software do Phidget com sua contraparte física. Apesar disso não ser um problema 
quando poucos dispositivos estão vinculados em um simples computador, a identificação de dispositivos pode tornar-se crítica quando vários dispositivos do mesmo tipo (mas talvez com diferentes usuários finais) são vinculados ao computador, ou quando os tipos e números de dispositivos não são conhecidos. Dessa forma um esquema de identificação é requerido.

3. Modo de Simulação - Para propostas de desenvolvimento de software, o mesmo código do Phidget deve trabalhar em um modo de simulação. Isto é, o programador deve ser capaz de programar, depurar e testar o sistema mesmo se o dispositivo físico estiver ausente. Isso implica na inclusão de uma API estendida para configurar as características de simulação do dispositivo e uma representação gráfica que permita uma pessoa ver e opcionalmente interagir com o estado do dispositivo.

\subsubsection{Exemplos de Phidgets}

Alguns Phidgets (2007) são listados a seguir:

- PhidgetServo - permite controlar 4 servomotores. A posição de cada motor pode ser configurada via programação (Figura 3.1).

- PhidgetRFID - lê cartões RFID que são colocadas em sua proximidade (Figura 3.2).

- PhidgetInterfaceKit - é um kit de construção de propósito geral, no qual uma combinação de dispositivos físicos podem ser utilizadas: chaves, LEDs, solenóides, sensores etc. Na Figura 3.3 é ilustrado um kit com 8 entradas analógicas, 8 entradas digitais e 8 saídas digitais, além de apresentar alguns dispositivos de entrada e saída. 


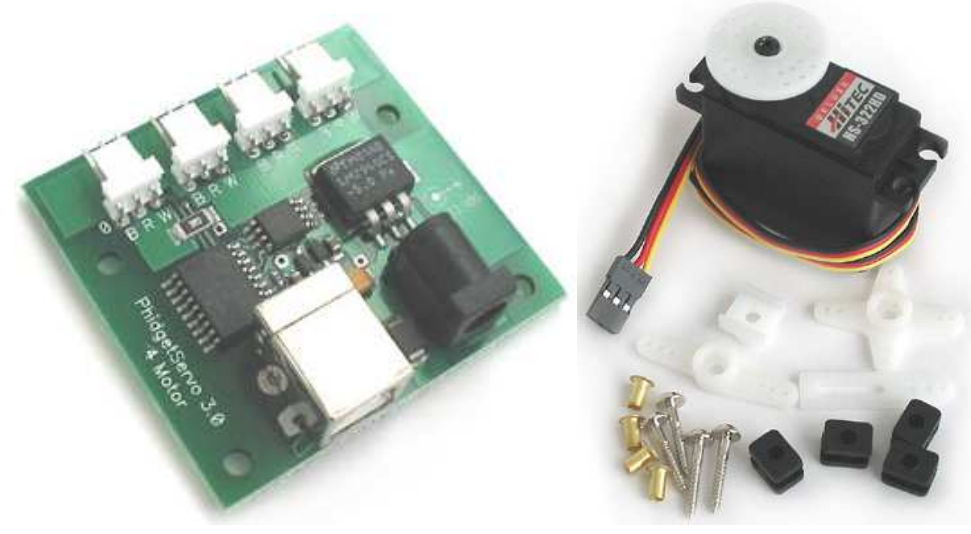

Figura 3.1 - PhidgetServo e um servomotor (Phidgets, 2007)

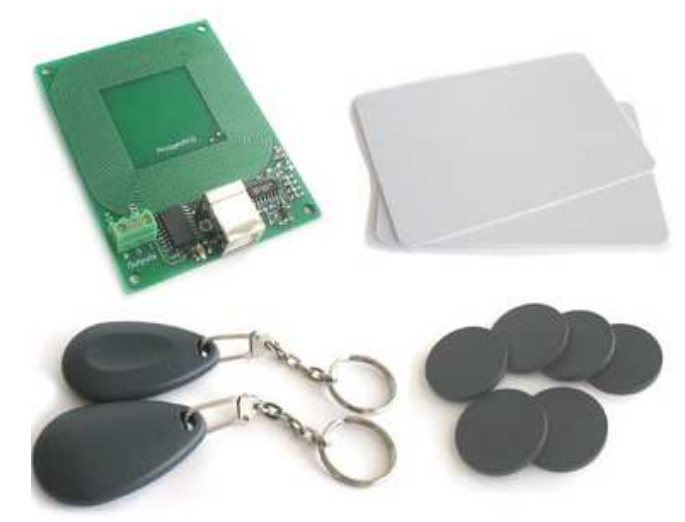

Figura 3.2 - PhidgetRFID (parte superior esquerda), 2 cartões RFID (parte superior direita), 2 chaveiros RFID (parte inferior esquerda) e 6 discos RFID (parte inferior direita) (Phidgets, 2007)

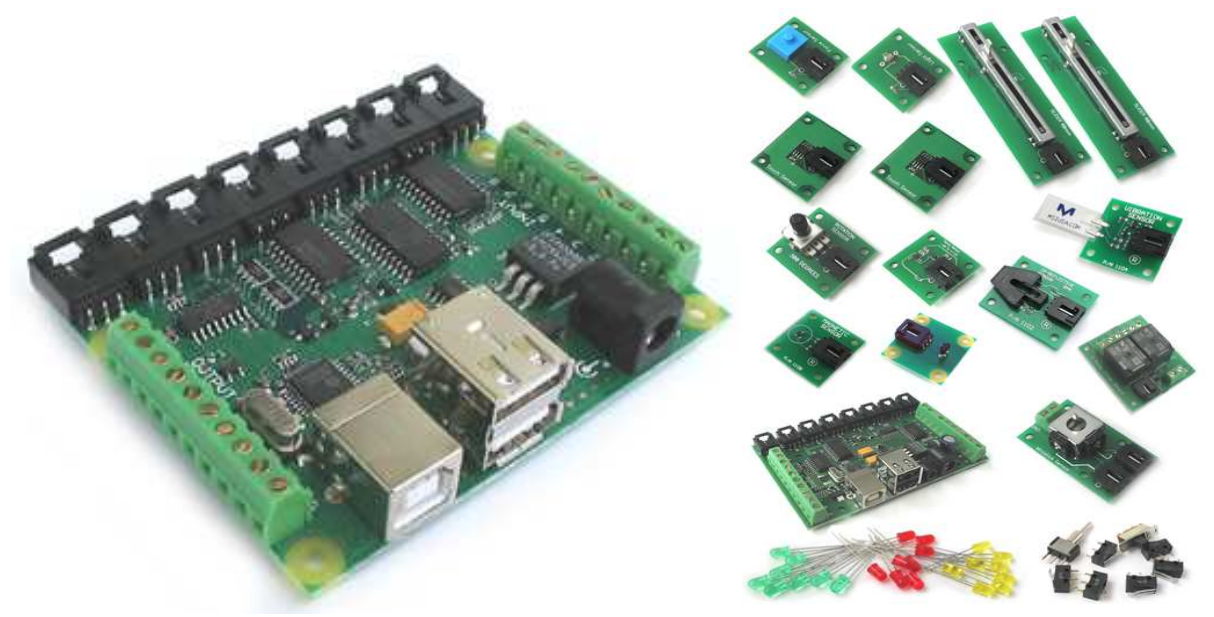

Figura 3.3 - PhidgetInterfaceKit e, chaves, LEDs, solenóides e sensores que podem ser conectados a ele (Phidgets, 2007) 
Os sensores e atuadores disponiveis são variados, entre os dispositivos de entrada destacam-se: acelerômetros; botões; circular wheels; encoders; joystick; sliders; sensores de movimento, de distância IR, de vibração, de luz, de toque, de temperatura, de força, de rotação e magnéticos. Para saída ressalta-se: LEDs, motores e tela LCD. No Anexo A são apresentados os principais Phidgets disponiveis, destacando-se o acelerômetro e o sensor de massa.

\subsubsection{Arquitetura de software e hardware}

A arquitetura Phidgets (Greenberg \& Fitchett, 2001) é composta por vários módulos como ilustrado na Figura 3.4. A seguir os detalhes de cada módulo serão apresentados.

\begin{tabular}{|c|c|c|}
\hline \multicolumn{3}{|c|}{ Usuário Final } \\
\hline Interface Física & & Interface de Software \\
\hline Projetista Físico & & Programador \\
\hline Componentes Primitivos & & Controle ActiveX \\
\hline & & Objeto COM específico ao \\
\hline Microcontrolador & & \begin{tabular}{|c|} 
phidget \\
Gerenciador Phidget \\
\end{tabular} \\
\hline Camada de Comunicação & Protocolo Wired & Camada de Comunicação \\
\hline
\end{tabular}

Figura 3.4 - Arquitetura Phidgets - Adaptado de Greenberg \& Fitchett (2001)

Dispositivo Físico (Figura 3.4, lado esquerdo) - é a unidade física dada ao projetista físico, que pode usá-la da maneira que deseja para criar uma interface física que será entregue ao usuário final. O dispositivo físico inclui: os componentes de entrada e saída primitivos (sensores, motores, chaves etc), uma placa com um microcontrolador e uma camada de comunicação. Como exemplo, os componentes físicos primitivos do PhidgetServo são os servomotores, enquanto que os componentes físicos dos PhidgetInterfaceKit são os vários sensores, chaves e atuadores que podem ser a ele vinculados. $\mathrm{Na}$ Figura 2.2 é ilustrado uma interface física que faz uso de um 
PhidgetServo, um servomotor (componente físico primitivo), peças Lego e papel.

Protocolo Wired - é o protocolo que permite a comunicação com fio entre o dispositivo físico e o computador. Ele não é visível aos programadores. A versão atual dos Phidgets utiliza o protocolo USB.

Gerenciador Phidget - é um objeto COM 11 . Inclui uma API baseada em eventos que é disponibilizada a programadores finais para gerencia de comunicação. Programadores usam essa API para descobrir todos os dispositivos acessiveis. Especificamente, os eventos OnAttach e OnDetach são automaticamente gerados quando um dispositivo físico é conectado ou desconectado ao computador.

Objeto COM especifico ao Phidget - São criados pelo Gerenciador de Phidgets quando um dispositivo é encontrado. Esse objeto corresponde diretamente ao dispositivo físico, por exemplo, um dispositivo físico PhidgetServo tem o objeto COM correspondente PhidgServo. Internamente todos os objetos COM específicos comunicam-se com o seu dispositivo físico por intermédio do gerenciador de Phidgets.

Controles ActiveX - encapsula vários objetos COM específicos para dar a cada um deles uma representação na tela e capacidades de simulação.

\subsubsection{Limitações}

A maior limitação de tal solução é que os dados provenientes dos sensores são disponibilizados em sua forma primitiva, ou seja, se o sensor é um acelerômetro, e mensura dessa forma aceleração estática e dinâmica, os dados oferecidos em alto nível, serão os valores das acelerações medidas. Isso obriga o desenvolvimento de componentes que transformem tais dados em algo mais próximo a interação, como por exemplo, inclinações. Para isso, conhecimentos da Física são necessários, fato que pode dificultar o desenvolvimento de novos dispositivos de interação.

\footnotetext{
${ }^{11}$ Objetos COM seguem o padrão da Microsoft para encapsular, distribuir e incluir módulos de software. Possuem uma interface binária bem definida (parecido com uma API) que permite que sejam acessados por uma variedade de linguagens de programação.
} 
Outra limitação é que enquanto toolkits GUI já possuem um conjunto de widgets padrão, tais como botões, listboxes, checkboxes, textboxes, ainda se faz necessário definir um conjunto padrão de Phidgets. Ainda não é claro quais Phidgets devem ser incluídos em tal conjunto.

Outra limitação encontrada é que a arquitetura Phidgets não possui comunicação wireless como outros trabalhos reportados pela literatura, e além disso, sozinhos não dão nenhum apoio a customização de aplicações GUI existentes.

\subsection{PHIDGETSE WIDGET TAP}

Como os Phidgets não possuem nenhum apoio a customização de aplicações GUI, Greenberg e Boyle (2002) propuseram uma solução parcial que alia o poder dos Phidgets a uma biblioteca denominada Widget Tap.

\subsubsection{Widget Tap}

A biblioteca Widget Tap fornece ao programador objetos que acessam a semântica dos widgets GUI das aplicações existentes, e dessa forma expõem a função controlada pelo widget selecionado, que a partir de então pode ser vinculado a um Phidget (Greenberg \& Boyle, 2002). Alguns exemplos foram ilustrados no Capítulo 2 ao se apresentar o conceito de interfaces físicas customizáveis.

A abstração é criada ao se dividir os widgets em meta-classes. Por exemplo, a classe CommandTap representa um tipo de widgets GUI que invoca uma função simples sem parâmetros, isso inclui botões, botões da barra de ferramentas, e itens de menu. Essa classe tem vários métodos e propriedades importantes. O método da classe PickCommandTap começa com um ciclo no qual o usuário é orientado a selecionar um botão, botão da barra de ferramentas ou item de menu com o mouse, retornando uma instância da classe CommandTap vinculada ao controle GUI selecionado. O programador pode, então, usar a propriedade Text dessa instância de CommandTap para recuperar qualquer texto associado com o botão ou item 
de menu selecionado, e o método Click para executar a funcionalidade da aplicação disparada pela widget GUI, como se o verdadeiro widget GUI fosse selecionado.

A biblioteca Widget Tap dá aos programadores acesso à semântica de qualquer widget GUI de qualquer aplicação, sem que o programador precise acessar o código-fonte da aplicação. De fato, o programador não precisa ter qualquer conhecimento da aplicação.

\subsubsection{Limitações}

A maioria dos problemas dessa solução estão relacionados ao conceito de controle externo (Seção 3.7) e em relação a robustez da implementação. Outra limitação é que o foco está voltado a permitir o acesso a um grande número de dispositivos enquanto que os modelos de interação são minimalistas, no qual os dispositivos físicos são vinculados diretamente a uma função e/ou funções de escala.

\section{$3.4 I C O N$}

O ICon - Input Configurator (configurador de entrada) é um sistema de gerenciamento de entradas que permite, segundo seus autores, que aplicações interativas obtenham um alto grau de adaptabilidade de entrada. Basicamente, trata-se de um toolkit e um editor que permitem selecionar dispositivos de entrada alternativos e configurar a técnica de interação interativamente (Dragicevic \& Fekete, 2004, 2001). 


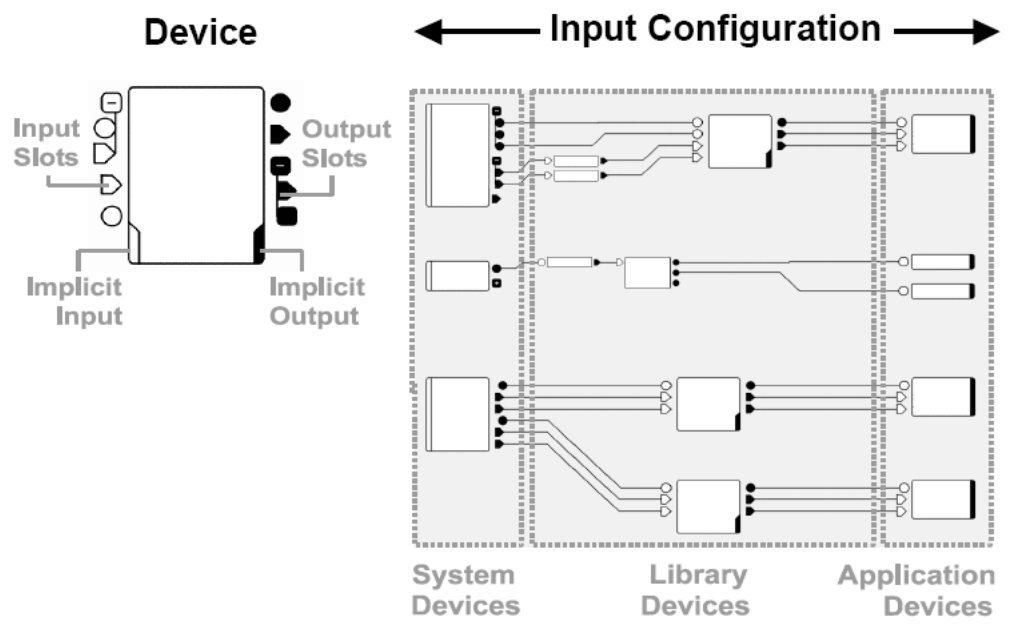

Figura 3.5 - Componentes ICon (Dragicevic \& Fekete, 2004)

A proposta de Dragicevic e Fekete $(2004,2001)$ é um modelo de entrada baseado em configurações. Tal modelo é composto por três tipos de componentes (Figura 3.5): dispositivos de sistema, de biblioteca e de aplicação. No Anexo B são apresentadas as principais classes e interfaces definidas pelo ICon, entre elas as interfaces Device e Processor e as classes Slot, In e Out.

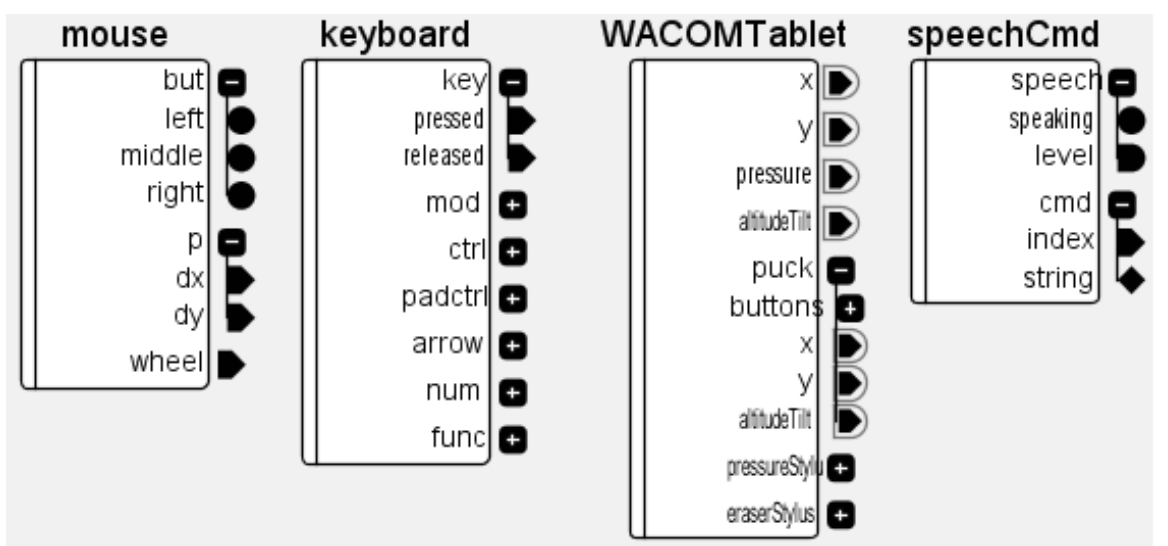

Figura 3.6 - Mouse, teclado, tablet e entrada de fala (Dragicevic \& Fekete, 2004)

Dispositivos de sistema descrevem recursos de entrada tais como periféricos de entrada. Na Figura 3.6 são ilustrados alguns dispositivos desse tipo: mouse, teclado, tablet e um dispositivo atuado por voz.

Dispositivos de biblioteca são dispositivos que vão desde simples operadores booleanos até dispositivos de interação complexos tais como 
cursores e reconhecedores de gestos. Há três categorias desse tipo: módulos de controle, primitivos e utilidades. Módulos de controle são usualmente utilizados para implementar testes e seleções. Módulos primitivos incluem operadores aritméticos, booleanos, de comparação e de memorização de valores anteriores. Módulos de utilidade incluem módulos de depuração e módulos que podem ser construídos pela composição dos primitivos, mas são mais rápidos e menores.

Dispositivos de aplicação são dispositivos que controlam uma aplicação. Eles incluem módulos específicos da aplicação e apresentam os elementos que a aplicação precisa em termos de entrada.

No ICon, uma configuração de entrada é definida por um conjunto de dispositivos de aplicação e de sistema e um conjunto de dispositivos de biblioteca e conexões por meio das quais são mapeados os dispositivos do sistema para os dispositivos de aplicação. Nas Figuras 3.7 e 3.8 são ilustrados alguns desses mapeamentos.

\subsubsection{Exemplos de configurações do ICon}

Algumas configurações possiveis são detalhadas nesta seção.

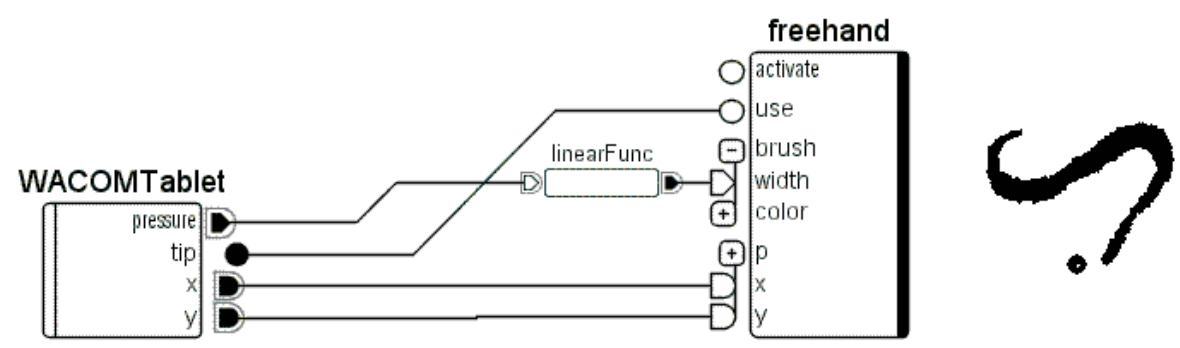

Figura 3.7 - Utilizando o sensor de pressão de um tablet para determinar a espessura de um traço de uma aplicação de desenho a mão livre (Dragicevic \& Fekete, 2004)

Na Figura 3.7 é ilustrada uma configuração possivel para o controle de uma aplicação de desenho a mão livre; nela o dispositivo de sistema existente é um tablet que apresenta as seguintes saídas: um valor de pressão (proporcional à pressão que o usuário coloca na caneta ao tocar a tela do tablet) e os pontos $x$ e $y$ que são determinados de acordo com a posição que o usuário coloca a caneta na tela do tablet. O único dispositivo de biblioteca 
utilizado é uma função linear que permite que os valores de pressão gerados pelo tablet sejam mapeados para os valores aceitos para a espessura do traço da aplicação de desenho a mão livre, isto é, supondo que o tablet gere valores de pressão de 1 a 100 e as espessuras aceitas para o traço são de 0 a 10, essa função tem como objetivo mapear os valores de pressão para os valores do comprimento do traço. Os pontos $x$ e $y$ da caneta do tablet determinarão qual ponto será criado na aplicação a mão livre. O único dispositivo de aplicação existente é o componente da aplicação de desenho a mão livre que permite determinar quais pontos serão criados (posição $x \mathrm{e} y$ ), a cor e a espessura do traço.

$\mathrm{Na}$ extremidade direita da Figura 3.7 é apresentado um traço, com espessura variada, criado a partir dessa configuração.

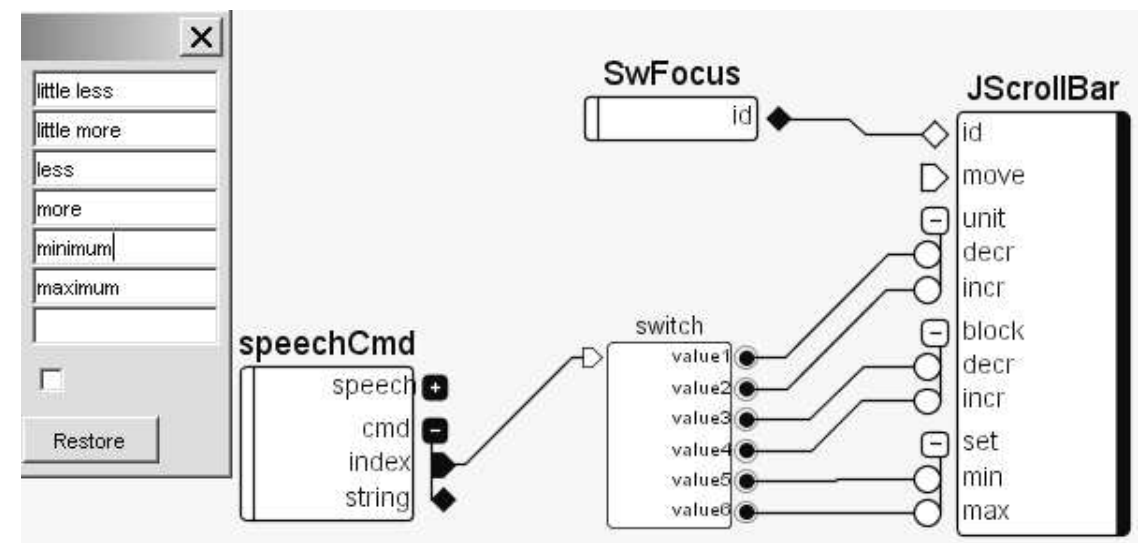

Figura 3.8 - Controle da barra de rolagem por comandos de voz (Dragicevic \& Fekete, 2004)

Na Figura 3.8 é ilustrada a configuração do controle de uma barra de rolagem por intermédio de comandos de voz. Para isso, o dispositivo de sistema atuado por voz é utilizado para reconhecer os seguintes comandos: little less, little more, less, more, minimum e maximum (Figura 3.8 extremidade esquerda). Por intermédio de um dispositivo de biblioteca de seleção, é possivel mapear cada comando a uma função específica da aplicação. Dessa forma o comando little less irá decrementar em uma unidade a posição da barra de rolagem e o comando maximum irá configurar a posição da barra de rolagem para o máximo possível. 


\subsubsection{Limitações}

ICon é implementado usando Java Swing e requer que as aplicações externalizem suas técnicas de interação para ser efetivo (Dragicevic \& Fekete, 2001), ou seja, o desenvolvedor deve implementar interfaces bem definidas (algumas delas são apresentadas no Anexo B) para que os elementos de interação de sua aplicação possam ser controlados por aplicações externas.

Outra limitação é a ausência de suporte a abstração de hardware. Se um desenvolvedor desejar adicionar novos componentes de hardware ao ICon, não terá nada no framework que o auxilie.

\subsection{SMART-ITS}

O projeto Smart-its é fruto de uma colaboração européia com o intuito de criar um kit de construção físico para aplicações distribuídas. Ele é caracterizado por um conjunto de sensores (por exemplo, sensores de luz, temperatura, movimento e som), um microprocessador, memória e um rádio (Holmquist et al., 2004). Cada dispositivo pode coletar dados do ambiente, rodar seu próprio código e comunicar-se com outros Smart-its, assim como também com servidores externos (Figura 3.9). Na Figura 3.10 são apresentados alguns módulos de hardware.

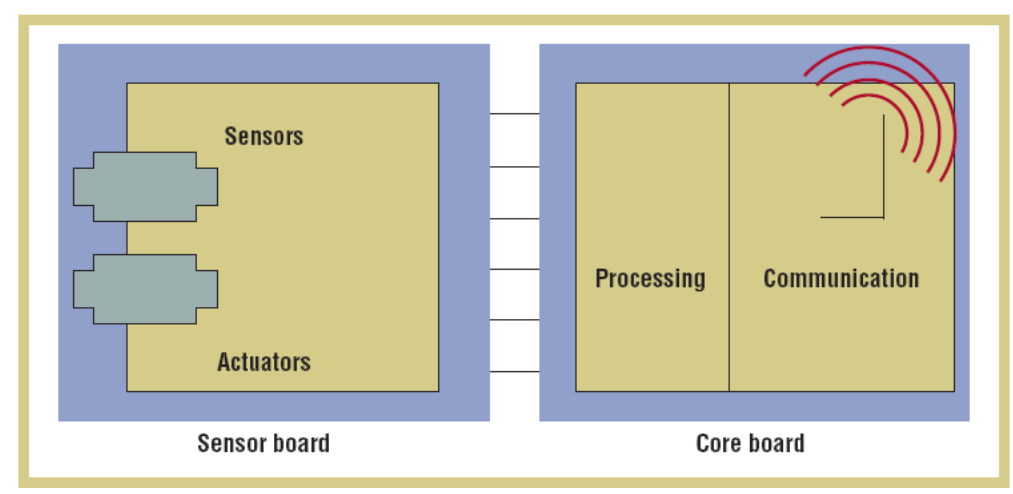

Figura 3.9 - A arquitetura de dispositivos Smart-Its é modular e separa a interação física da comunicação wireless possibilitando configurações flexíveis (Gellersen et al., 2004) 


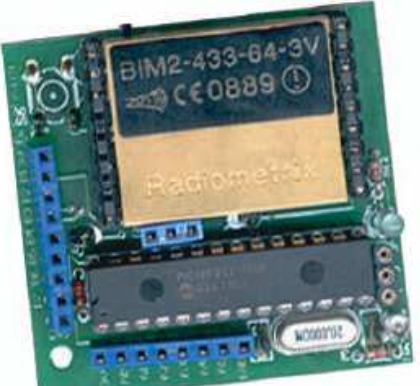

(a)

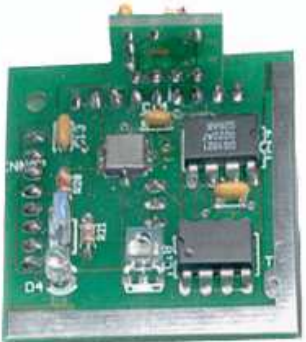

(b)

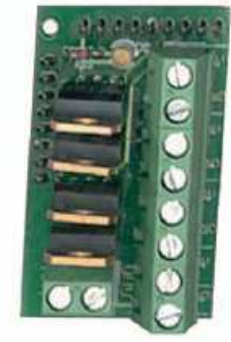

(c)

Figura 3.10 -Smart-its são baseados em módulos de hardware que são simples: (a) a placa principal com o microcontrolador e radio; exemplos de (b) um add-on sensor e (c) um atuador (Gellersen et al., 2004)

\subsection{ISTUFF}

iStuff é um toolkit para dispositivos físicos, composto por uma infraestrutura de software de apoio, que permite que projetistas simplifiquem e explorem novas técnicas de interação na era pós-desktop de múltiplos usuários, dispositivos, sistemas e colaboração de aplicações em um ambiente interativo (Ballagas et al., 2003).

O toolkit, de certa forma, estende o conceito dos Phidgets, primeiro pelo fato de permitir o uso de dispositivos wireless, e segundo, por possibilitar o rápido remapeamento dos dispositivos de entrada e as aplicações (fraco acoplamento entre entrada e lógica de aplicação), permitindo que interfaces padrões de usuário sejam controladas por novos dispositivos de entrada. Isso é feito por intermédio de uma API de software baseada em eventos.

\subsubsection{Requisitos do iStuff}

Para criar um toolkit conveniente para prototipação de interfaces físicas de usuário, os seguintes requisitos foram levantados por Ballagas et al. (2003):

- Flexibilidade, dispositivos lightweight.

- Independência de plataforma e capacidades cross-plataform.

- Independência de protocolos wireless.

- Fácil integração com aplicações existentes. 
- Suporte para múltiplos usuários simultaneamente.

\subsubsection{Exemplos de iStuff}

Vários dispositivos foram implementados. Alguns são apresentados na Figura 3.11 e discutidos a seguir:

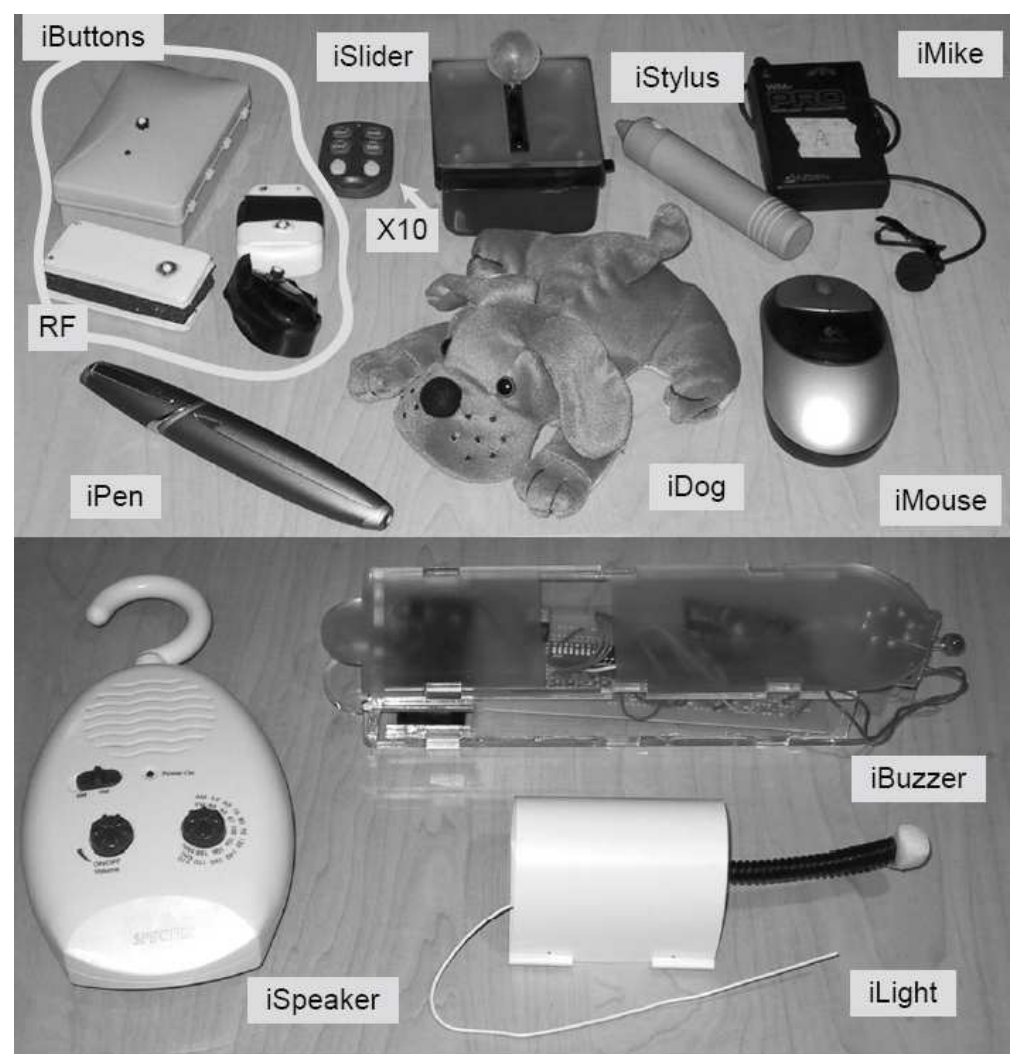

Figura 3.11 - Exemplos de componentes iStuff de entrada e saída (Ballagas et al., 2003)

- iButton: é a entrada binária mais básica e o bloco de construção essencial para muitas interfaces fisicas de usuário.

- iSlider e iKnob: são componentes de entrada unidimensionais que reportam a posição absoluta (iSlider) e relativa (iKnob) sobre seu eixo fixo.

- iMouse: é um mouse padrão Logitech wireless.

- iWand: é um componente de entrada que reporta a posição absoluta sobre um espaço de duas dimensões.

- iPen: é um componente que permite entrada a mão livre. 
- iMike: é um componente para entrada de voz, implementado usando um microfone wireless acoplado a um proxy que contêm o IBM WebSphere Voice Server.

- iLight, iBuzzer e iVibe: são componentes de saídas binárias.

- iSpeaker. é um componente de saída de áudio. O proxy aceita duas formas de entrada: textuais para tradução texto-voz e links para arquivos de áudio.

\subsubsection{Arquitetura}

O toolkit iStuff foi desenvolvido acima do iROS, um middleware baseado em TCP e Java que permite que múltiplas máquinas e aplicações troquem informações. O middleware iROS permite o estabelecimento de comunicação por intermédio de um Event Heap, na forma de um servidor central que processa os eventos recebidos e os redistribui para os recipientes adequados (Ballagas et al., 2003). Um sistema de comunicação semelhante implementado em $\mathrm{J}_{2} \mathrm{EE}^{12}$ utilizando a tecnologia $\mathrm{JMS}^{13}$ é apresentado em Pimentel et al. (2005).

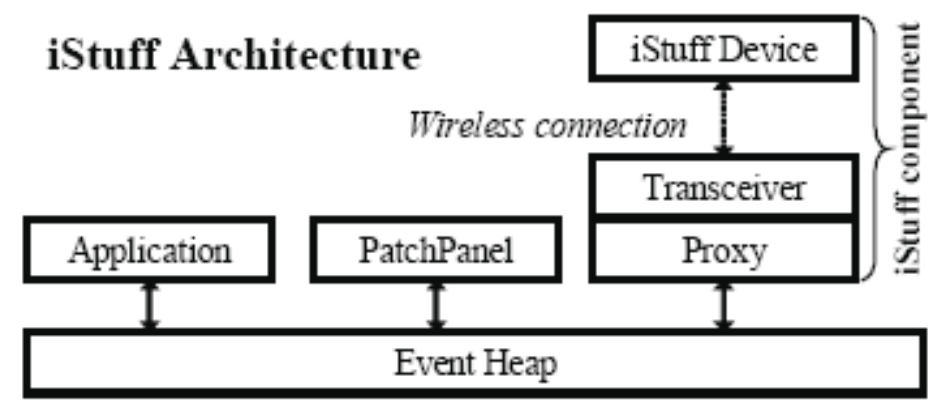

Figura 3.12 - Arquitetura iStuff (Ballagas et al., 2003)

A arquitetura iStuff é composta por vários módulos como ilustrado na Figura 3.12. A seguir alguns detalhes dos módulos serão apresentados.

Componente iStuff - Dispositivos físicos wireless de entrada e saída. O componente iStuff é constituído por dispositivos wireless e uma máquina

\footnotetext{
${ }^{12}$ http://java.sun.com/javaee.

${ }^{13} \mathrm{http}: / /$ java.sun.com/products/jms.
} 
conectada ao Event Heap que tem um Transceiver e serve como um Proxy. A função do Proxy é encapsular os dados provenientes dos dispositivos físicos em um evento.

Event Heap - Comunicação assíncrona baseada em eventos iROS.

PatchPanel - Módulo intermediário para remapear dinamicamente eventos dos componentes iStuff às aplicações. Um componente iStuff é associado a um evento iStuff, porém, em vez de trabalhar diretamente com eventos iStuff dos componentes físicos, os programadores de aplicações são encorajados a criar sua própria abstração de eventos que faça sentido em suas aplicações, e utilizar o PatchPanel para traduzir os eventos iStuff para eventos específicos da aplicação. Por exemplo, ao invés de esperar a entrada "GetMousePositionEvent", uma aplicação iStuff deve esperar um "NewPositionEvent", e tal evento pode ser gerado por um mouse, um painel de toque, um slider dependendo da configuração corrente do PatchPanel. Similarmente uma aplicação pode prover feedback com um "FeedBackEvent", o que pode ser traduzido em um evento para criar um som, luz ou mesmo um feedback gráfico em alguma tela.

\subsubsection{Limitações}

O tamanho dos componentes de hardware do iStuff torna impraticável a sua integração com dispositivos portáteis e outras áreas, nas quais o tamanho dos componentes é crítico. Outra limitação é forçar que os desenvolvedores das aplicações implementem código adicional para poder utilizar os dispositivos físicos do projeto.

Além disso, atualmente o número de dispositivos físicos disponibilizados é muito menor que o conjunto de dispositivos Phidgets.

\subsection{CONTROLE EXTERNO}

Um grande desafio da área de construção de interfaces físicas de usuário é o oferecimento de controle externo, com o qual alguém possa robustamente vincular código externo a uma aplicação de tal forma que esta possa ser 
controlada remotamente (Seção 2.3). Em outras palavras, o controle externo é a habilidade de invocar funcionalidades de aplicações existentes sem ter que modificar seu código-fonte. Algumas soluções parciais (Greenberg \& Boyle, 2002) são apresentadas a seguir.

Uma possivel solução é invocar as funcionalidades da aplicação por intermédio de API, hooks, scriptable object models e automation features predefinidos pela própria aplicação. Essa solução é problemática, primeiro porque pode-se acessar apenas aquelas funções que o programador da aplicação decidir suprir a priori. Segundo essas funções são escondidas do usuário final: elas podem não ter uma representação gráfica. Mesmo se os nomes das funções fossem expostas, elas não estariam na linguagem do usuário final, isso dificulta a identificação de qual função o usuário final deseja invocar.

Uma segunda solução usa apelidos para as funções, associando por exemplo, paper sticker que possuíam um código de barra a apelidos de ícones. Escaneando o código de barra invocava-se o apelido, que iniciava a aplicação. Essa solução é limitada, e não provê acesso a funções internas de uma aplicação.

Uma terceira solução captura a entrada sintática do usuário e a reproduz sobre a interface. Uma vantagem desse acesso sintático é que ele espelha exatamente como o usuário expressa a função. O problema do acesso sintático é a dificuldade de implementa-lo robustamente. Ele falha em GUIs quando coisas não aparecem em locais constantes ou quando a interface é rearranjada.

\subsection{COMPARAÇÃO DE PROPOSTAS}

A proposta desta dissertação é similar a outras relatadas pela literatura (Klemmer et al., 2004; Olwal \& Feiner, 2004; Greenberg \& Fitchett, 2001), no sentido que a arquitetura $A M C E$ facilita a construção de aplicações que utilizam dispositivos de entrada/saída não-tradicionais.

Em relação a prover abstrações para aplicações que utilizam tais dispositivos físicos, a arquitetura $A M C E$ apresenta similaridades com os 
trabalhos Virtual Sensors (Kabadayi et al., 2006), Papier-Mâché (Klemmer et al., 2004), assim como o UniInt Proxy de Nakajima (2006).

A arquitetura AMCE é baseada na transformação de alfabetos, o que permite associar semântica a informações de entrada e saída, tornando a solução mais geral do que aquelas que utilizam operadores que são aplicados ao processamento de entrada. Por exemplo, Unit (Olwal \& Feiner, 2004) é limitado a operadores escalares e vetoriais enquanto a arquitetura $A M C E$ suporta qualquer computação (máquina de estado finito ${ }^{14}$ ).

A arquitetura $A M C E$ também tem similaridades com a proposta de Wang e Mankoff (2003) uma vez que, em ambos os casos, um esquema de transformação é utilizado. Entretanto a arquitetura $A M C E$ é mais geral, no sentido de que as transformações consideram a semântica intrinseca a cada nivel da arquitetura (valores de sensores, valores físicos puros, valores físicos combinados levando em conta questões temporais, valores de entrada compostos, geração de eventos para a aplicação alvo). É importante observar que Wang e Mankoff (2003) focam seus esforços na redução do tempo gasto pelos desenvolvedores para adaptar suas aplicações a vários dispositivos, enquanto o foco da arquitetura $A M C E$ é permitir que novas aplicações que utilizem novos dispositivos de entrada/saída sejam desenvolvidas ou customizadas.

\subsection{CONSIDERAÇÕES FINAIS}

Neste capitulo foram discutidas algumas pesquisas estritamente relacionadas à proposta desta dissertação, em termos de uma arquitetura que busque facilitar o desenvolvimento de dispositivos de interação físicos. Diante do que foi apresentado, observa-se que as pesquisas recaem sobre três pontos principais: abstração do hardware, configuração de novas técnicas de interações com os dispositivos alternativos (mapeamento) e, por fim, controle das aplicações existentes com novas formas de interação e novos dispositivos.

\footnotetext{
${ }^{14} \mathrm{Na}$ versão corrente, a implementação demanda a programação da computação em uma linguagem de alto nível.
} 
A arquitetura proposta nesta dissertação, que será discutida em detalhes no próximo capítulo, visa ser uma solução para os pontos levantados anteriormente, ressaltando principalmente a questão do mapeamento. 


\section{AMCE: ARQUITETURA DE HARDWARE E SOFWARE}

\subsection{CONSIDERAÇÕES INICIAIS}

Embora existam muitas demonstrações de dispositivos de interação físicos, construí-los e mantê-los não é uma tarefa trivial. No Capítulo 2 foram apresentados problemas comumente encontrados na construção de dispositivos de interação físicos, entre eles, a dificuldade de se desenvolver e combinar dispositivos físicos de modo que possam ser utilizados e integrados a linguagens de programação de alto nível, a dificuldade de se prover a adaptabilidade de entrada e finalmente os problemas relacionados ao controle externo das aplicações existentes.

No Capitulo 3 foram apresentadas propostas que visam resolver tais problemas, entre elas, os Phidgets que visam abstrair todo o hardware, por meio da disponibilização de sensores e atuadores com uma API em alto nível. Porém, essa proposta resolve parcialmente os problemas encontrados, visto que simplesmente abstrai o hardware, não dando nenhum suporte a adaptabilidade de entrada e ao controle externo das aplicações existentes. Outro problema dos Phidgets é que, mesmo os dados dos sensores sendo apresentados através de uma API de alto nivel, os valores apresentados são primitivos (valores mensurados pelos sensores sem nenhuma transformação) e para que tais dados possam ser efetivamente utilizados na construção de dispositivos de interação, conhecimentos especializados sobre as informações disponibilizadas podem ser necessárias. Por exemplo, os Phidgets abstraem o uso de acelerômetros e sensores magnéticos, disponibilizando o hardware, e apresentado os valores de aceleração e campo magnético mensurados com o suporte de um conjunto de eventos como apresentados no Anexo A. Porém, transformar valores de aceleração e campo magnético em valores de inclinação e rotação, envolve um conjunto 
de conhecimentos da Física que pode dificultar o desenvolvimento de novos dispositivos de interação físicos.

Outra proposta discutida no Capítulo 3 é o ICon, que visa através de um conjunto de abstrações e uma interface de programação gráfica, prover a adaptabilidade de entrada e possibilitar o controle externo das aplicações. Porém, tal proposta resolve parcialmente os problemas encontrados, visto que, não oferece nenhum suporte a adição de novos componentes de hardware.

Há, portanto uma demanda por um modelo de desenvolvimento que permita a prototipação rápida de um dispositivo de interação físico, bem como seu desenvolvimento, manutenção e evolução, dando apoio a todos os problemas comumente encontrados na criação de dispositivos de interação físicos.

Uma abordagem comum para se atender esse tipo de requisito consiste (i) na criação de abstrações para a classe de aplicações especificada, (ii) no desenvolvimento de uma solução arquitetural para dar apoio ao projeto e à construção dessas aplicações, (iii) na implementação de infra-estruturas e serviços que englobem essas abstrações, e (iv) na experimentação com as abstrações, arquitetura e infra-estruturas por meio do desenvolvimento de aplicações dentro do espaço delimitado (Truong \& Abowd, 2004).

Neste capítulo é apresentada a arquitetura AMCE da seguinte forma: na Seção 4.2 uma descrição da arquitetura é realizada; na Seção 4.3 é mostrado como foram determinados os componentes da arquitetura a serem projetados e implementados no contexto deste trabalho; na Seção 4.4 os sensores utilizados são especificados; na Seção 4.5 considerações sobre a avaliação da arquitetura são apresentadas, e na Seção 4.6 são feitas as considerações finais. 


\subsection{ESPECIFICAÇÃO DAS CAMADAS DA ARQUITETURA AMCE}

A proposta desta dissertação é investigar uma arquitetura em camadas de hardware e software,denominada $A M C E^{15}$, conforme ilustrado na Figura 4.1. Tal proposta foi criada a partir do levantamento dos problemas comuns ao se construir dispositivos de interação físicos, e do estudo das pesquisas relacionadas reportadas pela literatura. Em trabalhos preliminares, nos quais a arquitetura $A M C E$ foi utilizada em implementações que exploram sensores como acelerômetros e giroscópios, resultados parciais foram obtidos e publicados em dois congressos nacionais: WebMedia'06 (Santos et al., 2006a) e IHC'06 (Santos et al., 2006b).

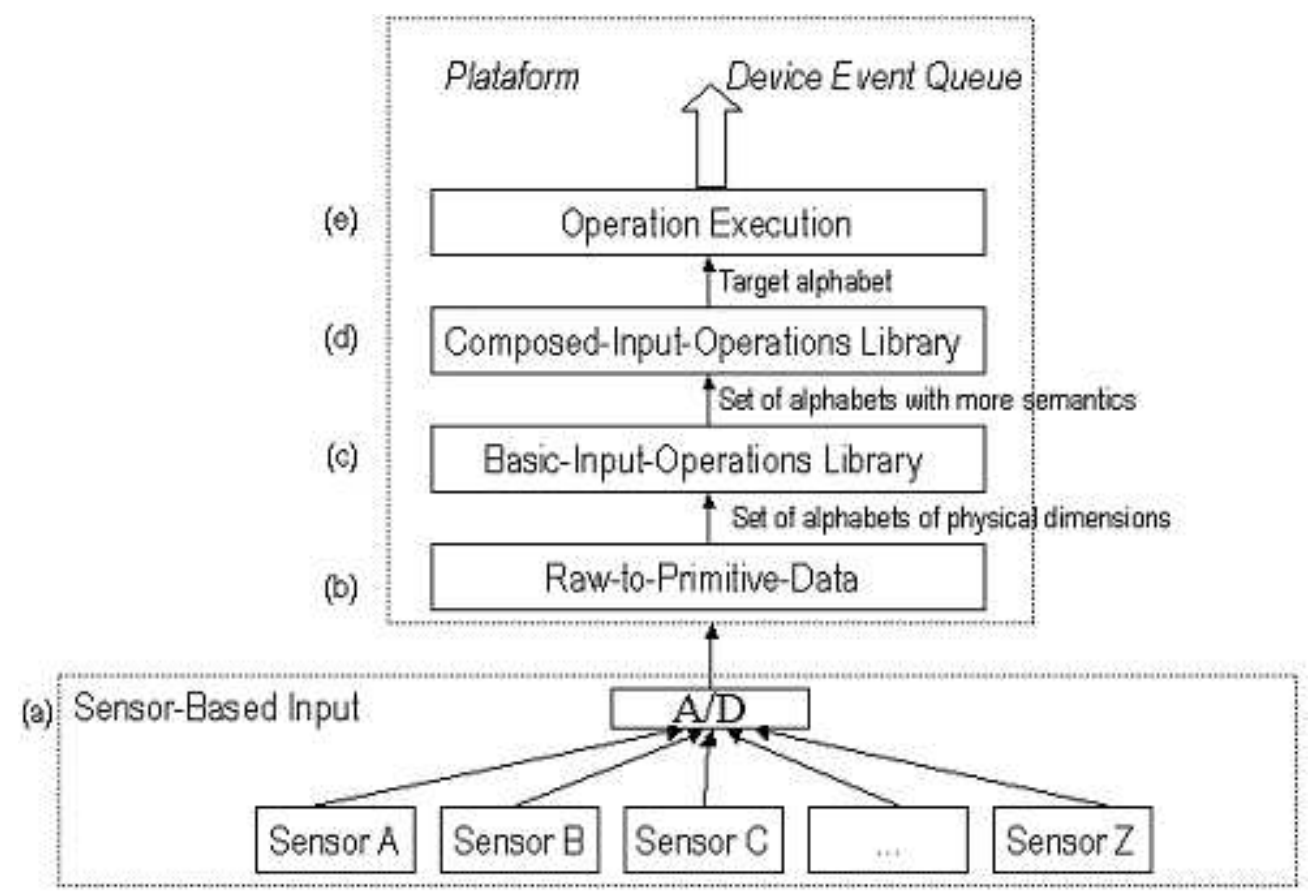

Figura 4.1 - Arquitetura em camadas AMCE

As camadas ilustradas na Figura 4.1 são propostas como segue:

- Camada de hardware, Sensor-Based Input (SBI), composta por sensores que capturam as interações físicas do usuário, que podem ser realizadas com conforto e que não sejam invasivas (ou que sejam minimamente invasivas). Essa camada deve disponibilizar um conjunto

\footnotetext{
${ }^{15}$ Um acrônimo dos objetivos da arquitetura que são: abstrair o hardware, modificar a forma de interação, combinar os diversos eventos possíveis provenientes da camada de hardware ou qualquer outra camada e permitir estender a interação.
} 
de sensores, possibilitando a conexão dos mesmos com o microcomputador (wired e/ou wireless). No Capitulo 5 é apresentado o hardware desenvolvido para captura de movimentos de rotação e inclinação.

- Camada de software Raw-to-Primitive-Data ${ }^{16}$ (RTPD), (1) recebe os dados crus provenientes da camada $S B I^{17}$; (2) implementa o tratamento básico de erros (por exemplo, filtragem de ruídos); (3) converte os valores provenientes dos sensores para dados primitivos (por exemplo, aceleração, velocidade angular, posição angular, pressão, comutação) e (4) disponibiliza o dado primitivo (por exemplo, por intermédio da geração de um evento para a próxima camada). Requisitos como gerencia da conexão, identificação e modo de simulação dos sensores devem ser atendidos por essa camada. No Anexo A são apresentados exemplos de interfaces (acelerômetro e um sensor de massa), assim como os eventos a elas relacionados. No Capítulo 5 são especificados e apresentados alguns componentes implementados nessa camada.

- Camada de software Basic-Input-Operations Library (BIOL), permite o mapeamento dos dados primitivos disponibilizados pela camada Raw-toPrimitive-Data (RTPD) em operações definidas em uma biblioteca de operações, que disponibiliza operações em maior alto nível como direção, sentido, amplitude do movimento, ou até mesmo gestos. Tal camada é necessária pois mesmo abstraindo o hardware, as informações geradas pelos sensores podem, em alguns casos, não serem diretamente mapeadas em primitivas de interação (conhecimentos especializados de Física, podem ser necessários por exemplo). No Capítulo 5 é apresentado o componente de software que transforma os eventos de aceleração e campo magnético em ângulos de Euler (heading, roll e pitch).

\footnotetext{
${ }^{16}$ Os Phidgets contemplam os requisitos das duas primeiras camadas, exceto pelo fato de permitirem apenas conexão wired (USB) com o microcomputador.

17 Como exemplo, o acelerômetro ADXL202E, da Analog Devices, codifica a aceleração em termos de dutycycle, que corresponde à razão entre o tempo que uma onda quadrada permanece em nível alto, num dado período, e o seu período. Para a obtenção da aceleração, é necessário realizar a operação: a := (DutyCycle_Atual - DutyCycle_Em_0g)/ Fator_Escala).
} 
- Camada de software Composed-Input-Operations Library (CIOL) permite a composição dos vários eventos disponibilizados pelas camadas anteriores. Dessa forma eventos de vários sensores podem ser agrupados. Componentes nessa camada seriam por exemplo máquinas de estado finito, cuja as entradas seriam provenientes dos sensores e a saída o reconhecimento de um conjunto especifico de eventos de entrada. Uma possivel implementação seria o reconhecimento da combinação de gestos simples de um acelerômetro (movimentos para cima, para baixo, para a direita e para a esquerda), com os componentes dessa camada vários movimentos possiveis poderiam ser identificados (movimentos em L para cima, para baixo, 2 movimentos para a direita, etc).

- Camada de software SBIDevice, que utiliza os eventos das camadas anteriores para prover a funcionalidade desejada a partir dos dados capturados pelo SBI (Sensor-Based Input) construído.

Um exemplo de implementação da camada de mais alto nível, SBIDevice, poderia ser a implementação de um SBIMouse que gera eventos como: mouseDragged (indicando que o mouse está sendo arrastado), mousePressed (indicando que ocorreu um click) e mouseMoved (indicando que o mouse foi movido). Uma versão preliminar de tal dispositivo foi criada para avaliação da arquitetura proposta (Santos et al., 2006a, 2006b), e uma versão final é apresentada no Capítulo 5.

A arquitetura em camadas permite que novos dispositivos de interação sejam criados a partir do desenvolvimento apenas da camada de mais alto nível, ou seja, exigindo apenas o conhecimento da biblioteca de operações definida pela arquitetura, eliminando a necessidade do programador ter conhecimentos detalhados de hardware (ou Física), permitindo, dessa forma, o reuso de implementações anteriores que capturam os eventos físicos do usuário.

Outro resultado importante é o fato de a arquitetura permitir o mapeamento de diferentes eventos físicos para uma interação. Para isso é necessário o desenvolvimento da primeira camada SBI, que captura os 
eventos físicos do usuário, e da segunda camada $R T P D$, para mapear esses dados crus em primitivos. Com isso, todo dispositivo de interação criado na camada de mais alto nível, SBIDevice, poderá ser utilizado com essa nova gama de movimentos. Por exemplo, é possível que inicialmente a camada de mais baixo nível capture os movimentos da cabeça do usuário e permita o controle do mouse e do teclado a partir desses movimentos. Entretanto, substituindo as duas primeiras camadas, é possivel controlar o mouse e o teclado a partir da movimentação dos olhos, por exemplo. Nesse caso, a mudança exige conhecimento de hardware e dos dados primitivos, mas não exige o conhecimento de como controlar o mouse e o teclado.

Como estudo de caso, criou-se um dispositivo de interação com a funcionalidade de mouse que pode ser usado por usuários tetraplégicos, que possuam controle fino dos movimentos da cabeça e ausência de deficiências visuais. Foram utilizados sensores como acelerômetros e bússolas para a captura do movimento da cabeça do usuário. Detalhes de implementação são apresentados no próximo capítulo.

\subsection{LEVANTAMENTO DE ALGUNS COMPONENTES DA ARQUITETURA AMCE}

Vários componentes podem ser instanciados nas diversas camadas propostas pela arquitetura AMCE. A partir da disponibilização e reuso de tais componentes a criação de novos dispositivos de interação é facilitada. Como um dos objetivos do trabalho é a criação de um mouse assistivo, que possa ser utilizado por usuários tetraplégicos, que possuem o movimento fino da cabeça e ausência de deficiências visuais, os seguintes requisitos e passos foram levantados e direcionaram o projeto e implementação de alguns componentes da arquitetura $A M C E$, apresentados no Capítulo 5:

1. Levantamento de requisitos:

a. Identificação dos eventos físicos de modo geral (movimentos, áudio, pressão etc) que podem ser realizados (com 
algum conforto e de forma pouco invasiva) por individuos com necessidades especiais de modo geral.

b. Identificação e especificação de eventos que podem ser utilizados por indivíduos tetraplégicos (subconjunto do item a), que possuam controle fino dos movimentos da cabeça e ausência de deficiências visuais. A partir de estudos da literatura, constatou-se várias formas de interação possiveis, entre elas: a movimentação da cabeça (Santos et al., 2004; Chen, 2001; Kim \& Cho, 2002; Evans \& Blenkhorn, 1999), a movimentação dos olhos (Hornof et al., 2004), o piscar dos olhos (Grauman et al., 2001), a estimulação nervosa como eletromiogramas (EMG - Wheeler \& Jorgensen, 2003) ou eletrocefalogramas (EEG - Guan et al., 2005), a movimentação do tórax e comandos de voz (Dai et al., 2004; Beckhaus e Kruijff, 2004) entre outras.

c. Seleção de quais eventos serão tratados no contexto do trabalho, com base em sensores disponiveis no mercado a preço acessivel, e aquisição dos sensores. Entre as várias formas de interação possiveis, optou-se por trabalhar com os movimentos de afirmação e negação da cabeça, devido a resultados positivos com tal forma de interação apresentados em Santos et al. (2004).

d. Avaliação e seleção de dispositivos físicos (sensores) que podem ser utilizados para capturar tais movimentos. A partir de estudos dos sensores comerciais capazes de mensurar os movimentos de afirmação e negação da cabeça do usuário, foram selecionados aqueles que apresentam dimensões pequenas, evitando o desconforto, visto que tal sensor ficará sobre a cabeça do usuário. Além disso, a precisão das medidas dos sensores também foi um fator limitante. Na Seção 4.4 são apresentados os sensores selecionados.

2. (a) Especificação dos requisitos de hardware que permita tratamento das operações de interação escolhidas em 1c. (b) Construção de dispositivos de acordo com os sensores selecionados em $1 \mathrm{~d}$ : 
a. Projeto do dispositivo de hardware SBI com os sensores adquiridos. No Capítulo 5 são apresentados detalhes de tal projeto.

b. Implementação do SBI.

3. Implementação da camada de software Raw-to-Primitive-Data para os sensores selecionados em $1 \mathrm{~d}$.

4. Especificação da biblioteca de operações, BIOL para os sensores selecionados. No Capítulo 5 é apresentado o componente dessa camada, responsável por transformar valores de aceleração e campo magnético em ângulos de Euler.

5. Avaliação das camadas anteriores com a especificação e implementação da camada de mais alto nivel para o dispositivo mouse: SBIMouse.

6. Experimentação e testes de usabilidade com um usuário tetraplégico fazendo uso do SBIMouse.

\subsection{SENSORES UTILIZADOS}

Para a obtenção dos objetivos propostos nesta dissertação, foi necessário a utilização de um conjunto de sensores que possibilitasse o desenvolvimento e formasse a base da arquitetura (Sensor-Based Input). Os sensores utilizados foram:

- Dois ADXL Breakout Board (Figura 4.2) - Trata-se de um acelerômetro de dois eixos, capaz de mensurar tanto aceleração estática (gravidade) quanto aceleração dinâmica (movimento). Componente adequado para se mensurar inclinações, como a rotação da cabeça (movimento semelhante ao de afirmação), devido ao seu tamanho e precisão.

- Um IMU Combo Board (Figura 4.3) - Trata-se de um acelerômetro de dois eixos e um giroscópio capaz de mensurar velocidades angulares (em qualquer posição espacial, inclusive quando paralelo à superficie terrestre). Componente adequado para se mensurar 
movimentos angulares como a rotação da cabeça (movimento de negação).

- Três OS1xOO (Figura 4.4) - Trata-se de uma bússola digital com correção de erros causados devido à inclinação. Possui um acelerômetro de dois eixos e uma bússola digital. Seu uso tem a mesma finalidade da placa IMU Combo Board.

- Dois AMI601 (Figura 4.5) - Trata-se de um acelerômetro de três eixos e um sensor magnético de três eixos em uma única pastilha, com tamanho diminuto e alta precisão ${ }^{18}$.

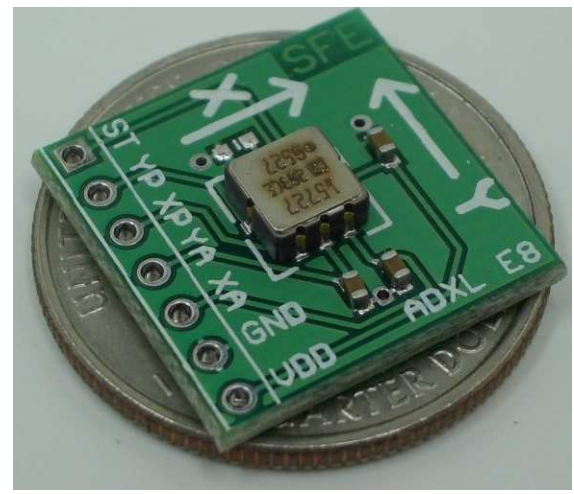

Figura 4.2 - ADXL Breakout Board (http://www.sparkfun.com)

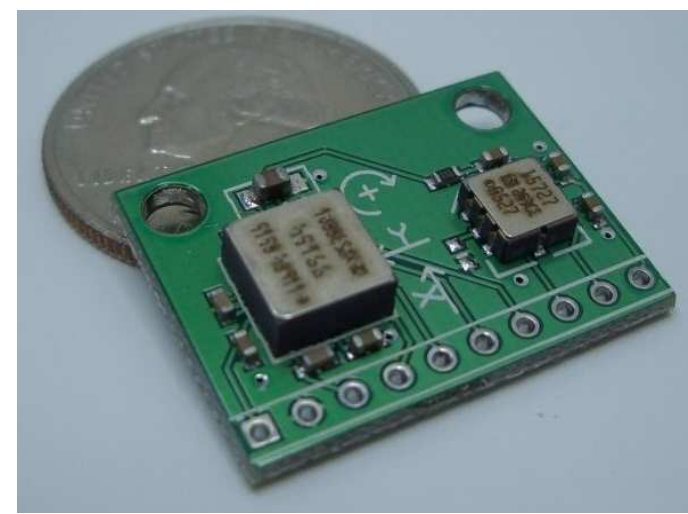

Figura 4.3 - IMU Combo Board - ADXL203/ADXRS401 ${ }^{19}$ (http://www.sparkfun.com)

\footnotetext{
${ }^{18} \mathrm{http} / / / \mathrm{www}$. sensorsexpo.com/exbdata/2732/brochures/06-02-28-Pressrelease-AMI601.pdf

${ }^{19} \mathrm{http}: / /$ www.analog.com.
} 


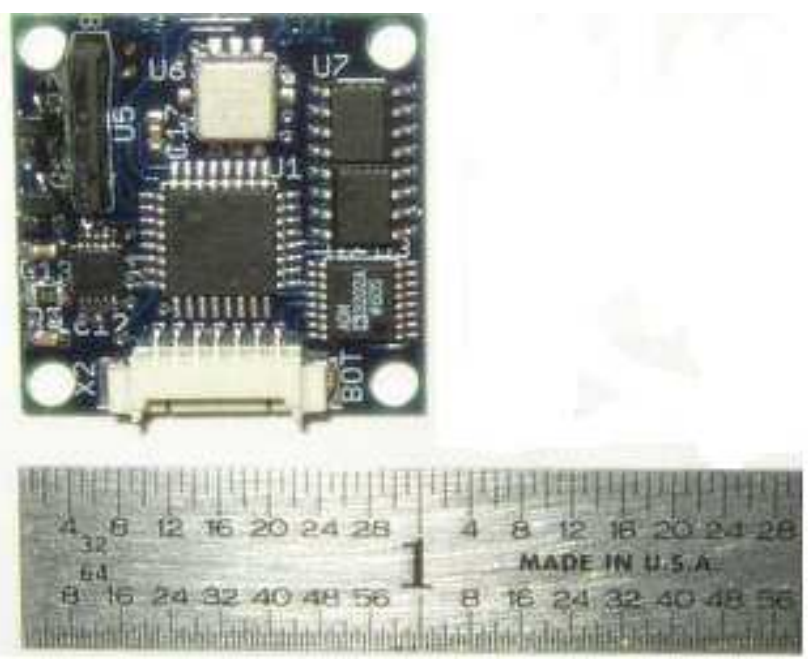

Figura 4.4 - $\operatorname{OS1x00}^{20}$ Bússola Digital com compensação de inclinação com roll, pitch e conexão serial (http://www.ocean-server.com)

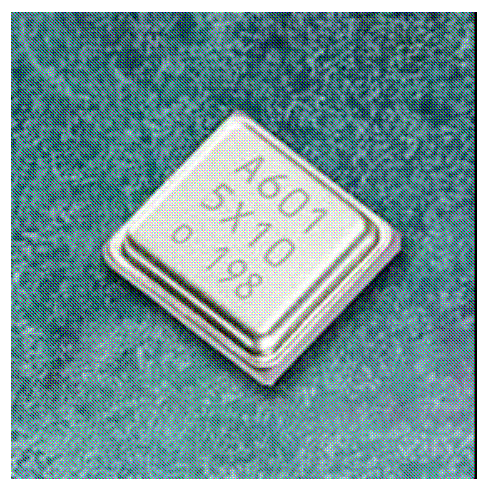

Figura 4.5 - AMI601 ${ }^{21}$ Acelerômetro de três eixos e sensor magnético de três eixos em uma única pastilha (http://www.aichi-mi.com)

\subsection{SOBRE A AVALIAÇÃO DA ARQUITETURA}

Enquanto que medidas tradicionais para avaliação de sistemas computacionais tais como desempenho, escabilidade, segurança, robustez, usabilidade, entre outras, podem ser diretamente aplicadas em dispositivos de interação, avaliar a eficiência da infra-estrutura em que as mesmas se baseiam é uma tarefa mais complicada. Edwards et al. (2003) enumeram um conjunto de questões sobre o tema, alguns dos quais experimentados e utilizados no desenvolvimento do mouse assistivo:

\footnotetext{
${ }^{20} \mathrm{http}: / / \mathrm{www}$. ocean-server.com.

${ }^{21}$ http://www.aichi-mi.com/3_products/PRODUCTS.HTM.
} 
- Os aspectos técnicos da infra-estrutura são expressos nas características e nos estilos das aplicações, e o desenvolvedor deve ser capaz de abstrair a partir deles: o mouse assistivo desenvolvido usa a abstração de hardware e software definida pela arquitetura e implementados nos componentes disponibilizados;

- O único modo de se avaliar a experiência proporcionada ao usuário pela infra-estrutura é através da construção e do uso de aplicações que se utilizem dela e da correspondente avaliação dessas aplicações: no caso do mouse assistivo desenvolvido, tal dispositivo tem sido utilizado por diversos usuários e se mostrado funcional, um desses usuários é tetraplégico, e a ele foi doado um exemplar do dispositivo. Os problemas encontrados nas primeiras avaliações são discutidos posteriormente.

- Os protótipos de aplicação construídos para avaliação devem expressar as caracteristicas básicas e os objetivos da infra-estrutura, com os usos permitidos da mesma e dentro de um escopo limitado: nesse caso a colaboração ficou restrita ao uso dos componentes de hardware construídos (sensor de orientação), e dos componentes de software que aumentam a semântica dos dados provenientes do sensores, além de componentes de software capazes de controlar o mouse.

\subsection{CONSIDERAÇÕES FINAIS}

Neste capitulo foram descritos a arquitetura proposta, os sensores utilizados no projeto e uma discussão sobre a avaliação da arquitetura.

A partir desta proposta, foram realizados o projeto e implementação de alguns componentes da arquitetura. Além disso, como resultado do estudo de caso, foi experimentado, por meio da construção de uma camada de hardware baseada em acelerômetros e bússolas eletrônicas, uma camada capaz de capturar os movimentos da cabeça de um usuário tetraplégico, que possua o controle fino dos movimentos da cabeça e não apresente 
deficiências visuais. Outra camada implementada possibilitou uma interação similar à de um dispositivo de apontamento do tipo mouse. No próximo capítulo são apresentados detalhes da implementação. 


\section{DESENVOLVIMENTO DE UM SENSOR DE TRÊS GRAUS DE LIBERDADE E UM MOUSE ASSISTIVO}

\subsection{CONSIDERAÇÕES INICIAIS}

Este capítulo apresenta o desenvolvimento de um sensor de três graus de liberdade (three degrees of freedom - 3DOF ${ }^{22}$ ), ou sensor de orientação, capaz de mensurar os três ângulos de Euler23: yaw (heading), roll e pitch. Com a implementação de tal sensor é possivel mensurar, por exemplo, dois movimentos da cabeça do usuário: o movimento de afirmação e o de negação, que são posteriormente utilizados para controlar a ponteira do mouse.

Para a construção do protótipo foi utilizado o sensor $A M I 601^{24}$, que é composto por três sensores magnéticos ortogonais e por três acelerômetros ortogonais.

A partir da construção de um sensor 3DOF, foi possível a implementação de um mouse relativo assistivo, que pode ser utilizado por usuários tetraplégicos, que possuam controle fino dos movimentos da cabeça e ausência de deficiências visuais. O funcionamento de tal dispositivo é apresentado também neste capítulo.

A estrutura do capítulo e o desenvolvimento dos componentes foi criada a partir das camadas definidas pela arquitetura $A M C E$, e portanto a Seção 5.2 apresenta os componentes de hardware criados na camada SBI, a Seção 5.3 os componentes pertencentes a camada RTPD, a Seção 5.4.3 apresenta o componente da camada BIOL e finalmente a Seção 5.5 o componente da camada SBIDevice. A Seção 5.6 mostra como a disponibilização de tais componentes facilita o desenvolvimento de um mouse assitivo.

\footnotetext{
${ }^{22}$ http://en.wikipedia.org/wiki/Degrees_of_freedom_\%28engineering $\% 29$.

${ }^{23} \mathrm{http}: / /$ en.wikipedia.org/wiki/Euler_angles.

${ }^{24} \mathrm{http}: / /$ www.aichi-mi.com.
} 


\subsection{HARDWARE DESENVOLVIDO}

Para a construção das placas que compõem o protótipo (Figura 5.1), foi primeiramente utilizada uma matriz de contatos (protoboard) para realizar os testes; em um segundo momento foi utilizado uma placa de circuito impresso com a finalidade de facilitar a calibração do sensor AMI601 e o uso do protótipo.

O circuito eletrônico foi dividido em duas placas. Na primeira (Figura 5.2) se encontram o PIC16F877A, o MAX232, o conector DB9 (comunicação serial computador) e o conector de 8 pinos (comunicação sensor AMI601), além de componentes fundamentais da eletrônica. Esta placa é responsável pela comunicação com o sensor $A M I 601$ e pela comunicação com a interface serial de um computador.

$\mathrm{Na}$ segunda placa (Figura 5.3) se encontra o sensor AMI601, um conector de 8 pinos e 3 capacitores.

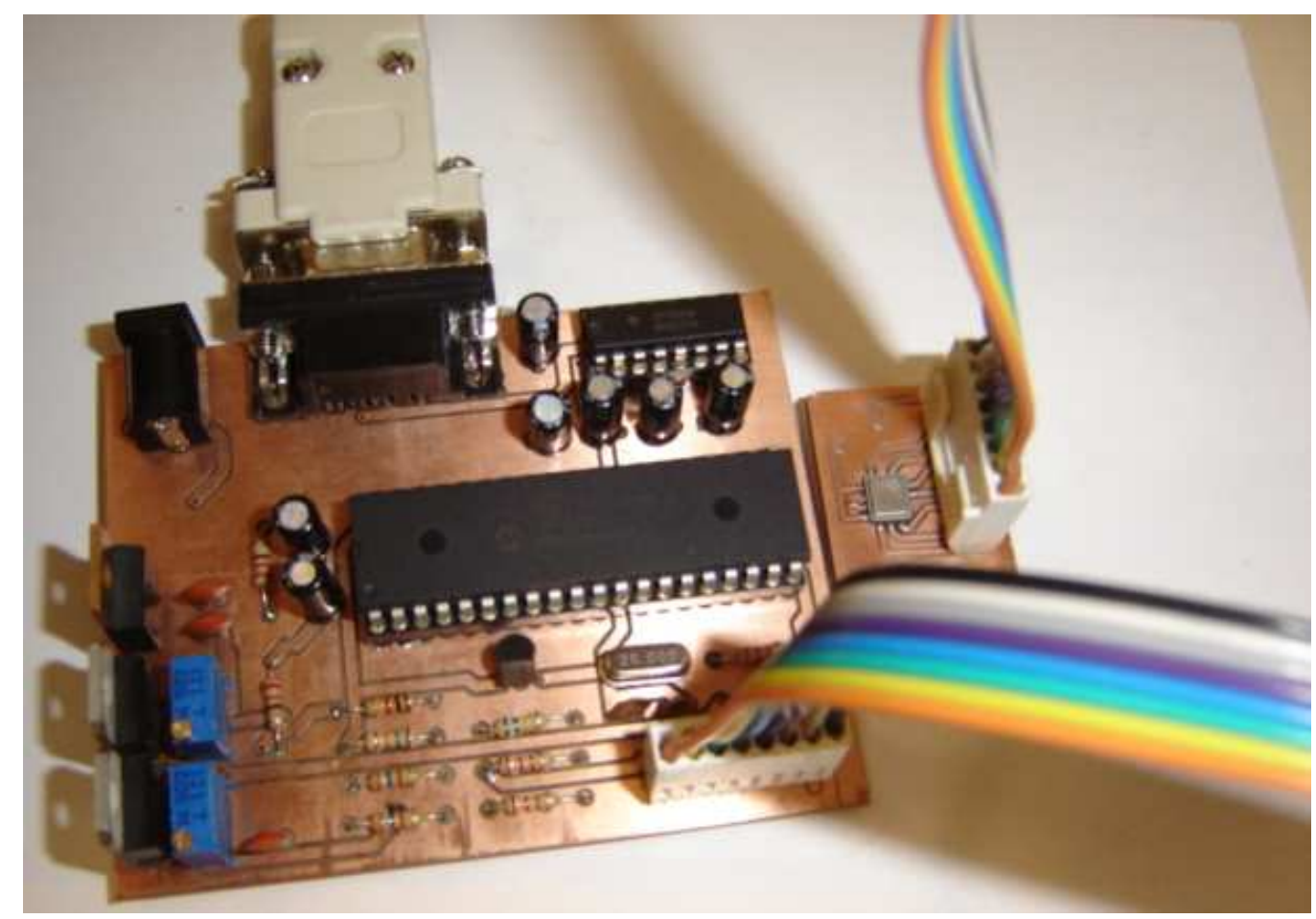

Figura 5.1 - Foto do protótipo completo 


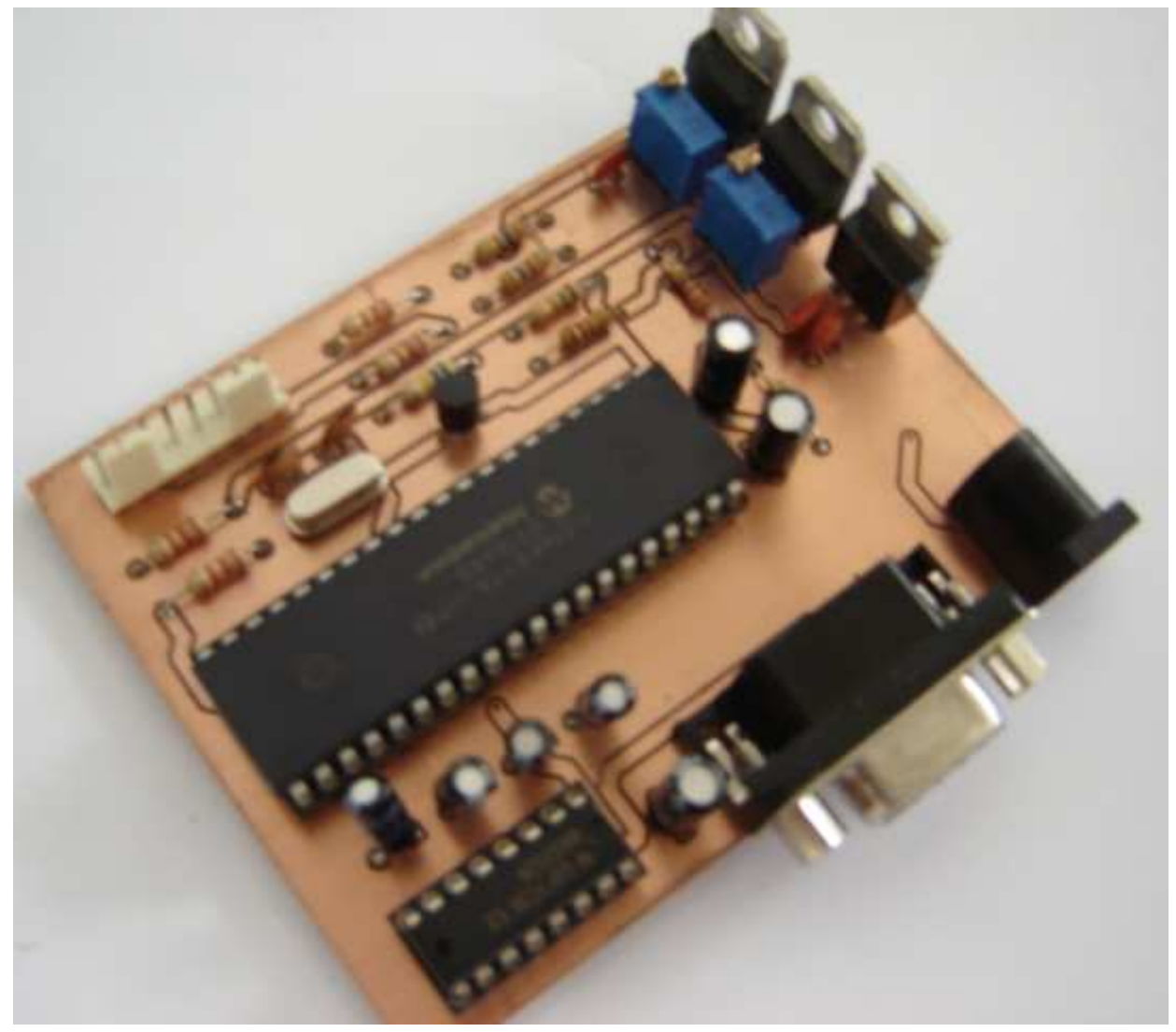

Figura 5.2 - Foto da placa controladora

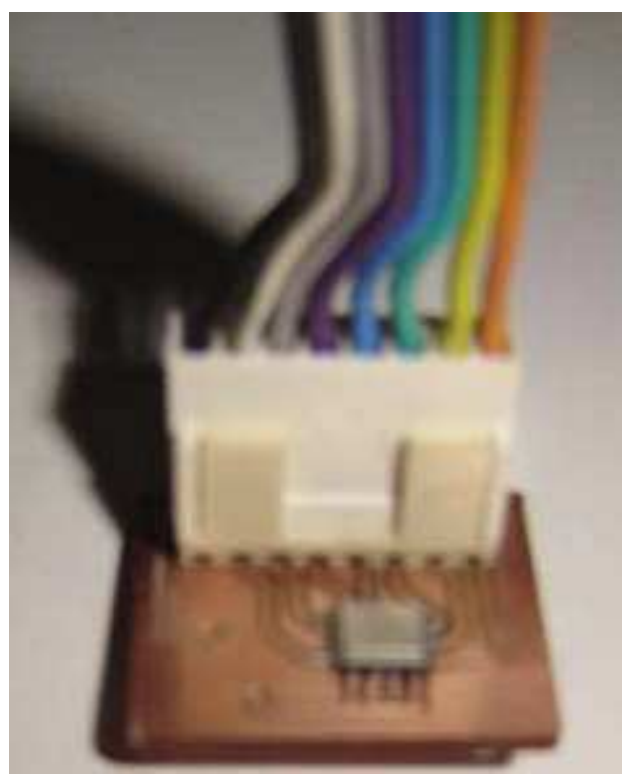

Figura 5.3 - Foto da placa do sensor 


\subsubsection{Diagrama da placa controladora}

Na Figura 5.4 o diagrama da placa ${ }^{25}$ controladora é apresentado. Na parte esquerda da figura podem ser observados três reguladores de tensão responsáveis por gerar as tensões de $5 \mathrm{~V}$ (alimentação PIC), $3.0 \mathrm{~V}$ (alimentação analógica AMI601) e $1.8 \mathrm{~V}$ (alimentação digital AMI601), necessários para outros componentes do sistema. A alimentação de tais reguladores se dá através de uma alimentação externa de $12 \mathrm{Vcc}$. Na parte direita da figura observam-se as ligações do MAX232. E na parte central as ligações do PIC16F877A. Junto ao microcontrolador pode-se visualizar um driver (transistor responsável por "transformar" OV em $5 \mathrm{~V}$ e $1.6 \mathrm{~V}$ em $0 \mathrm{~V}$ ), tal circuito foi necessário, pois o AMI601 possui uma saída digital (terminal $B U S Y)$, porém o nível de tal saída é OV para nível lógico baixo e 1,6V para nível alto, enquanto o PIC aceita OV como nível lógico baixo e $5 \mathrm{~V}$ como nível lógico alto. Tal característica também explica a necessidade do divisor de tensão nos pinos 39 e 38 do PIC. Na Figura 5.5 é apresentado o layout final da placa.

\footnotetext{
${ }^{25}$ Os diagramas de circuitos mostram em detalhes os pinos de cada componente e as conexões entre eles de forma simplificada, o que possibilita a detecção de erros e incompatibilidades.
} 

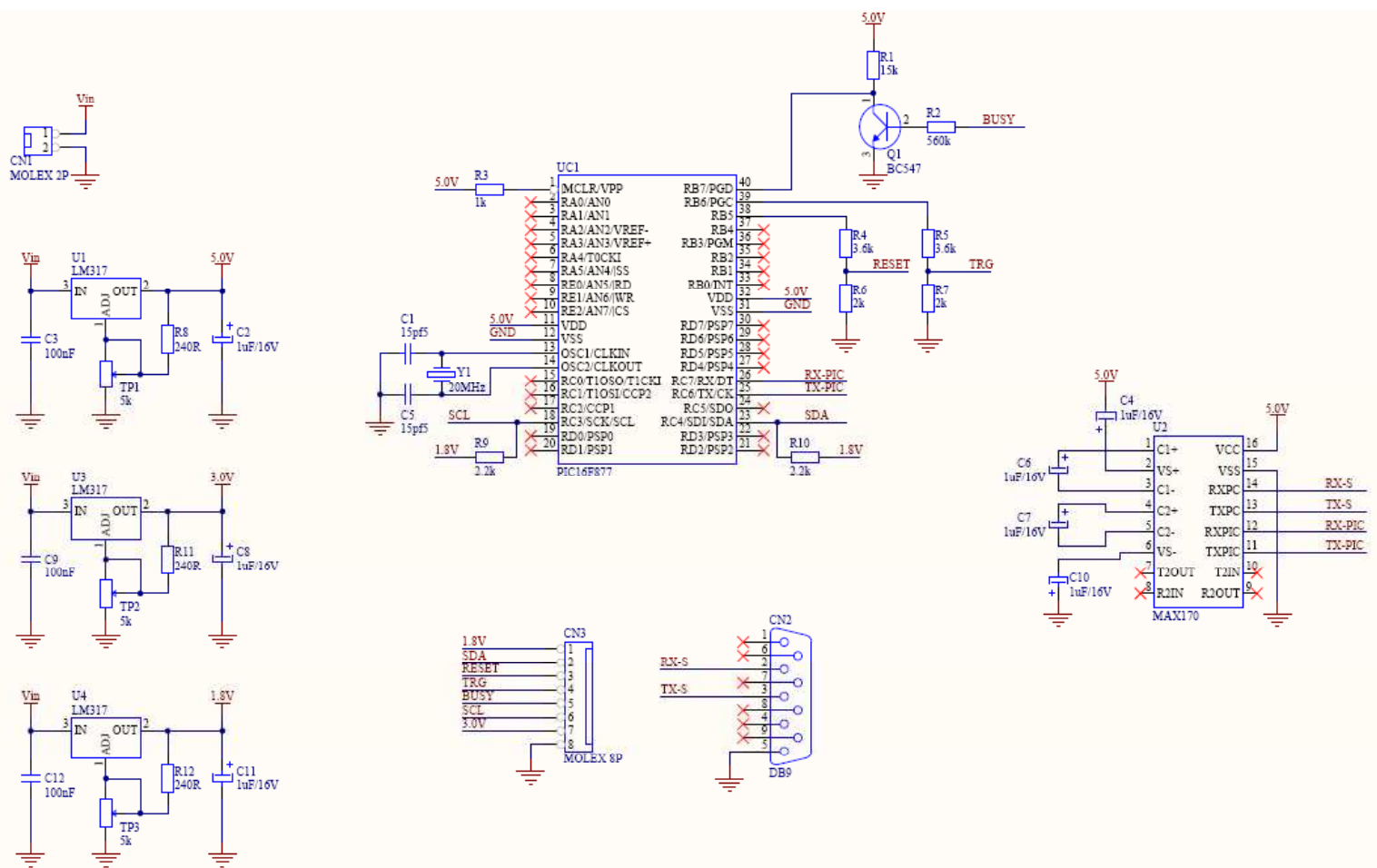

Figura 5.4 - Projeto da placa principal

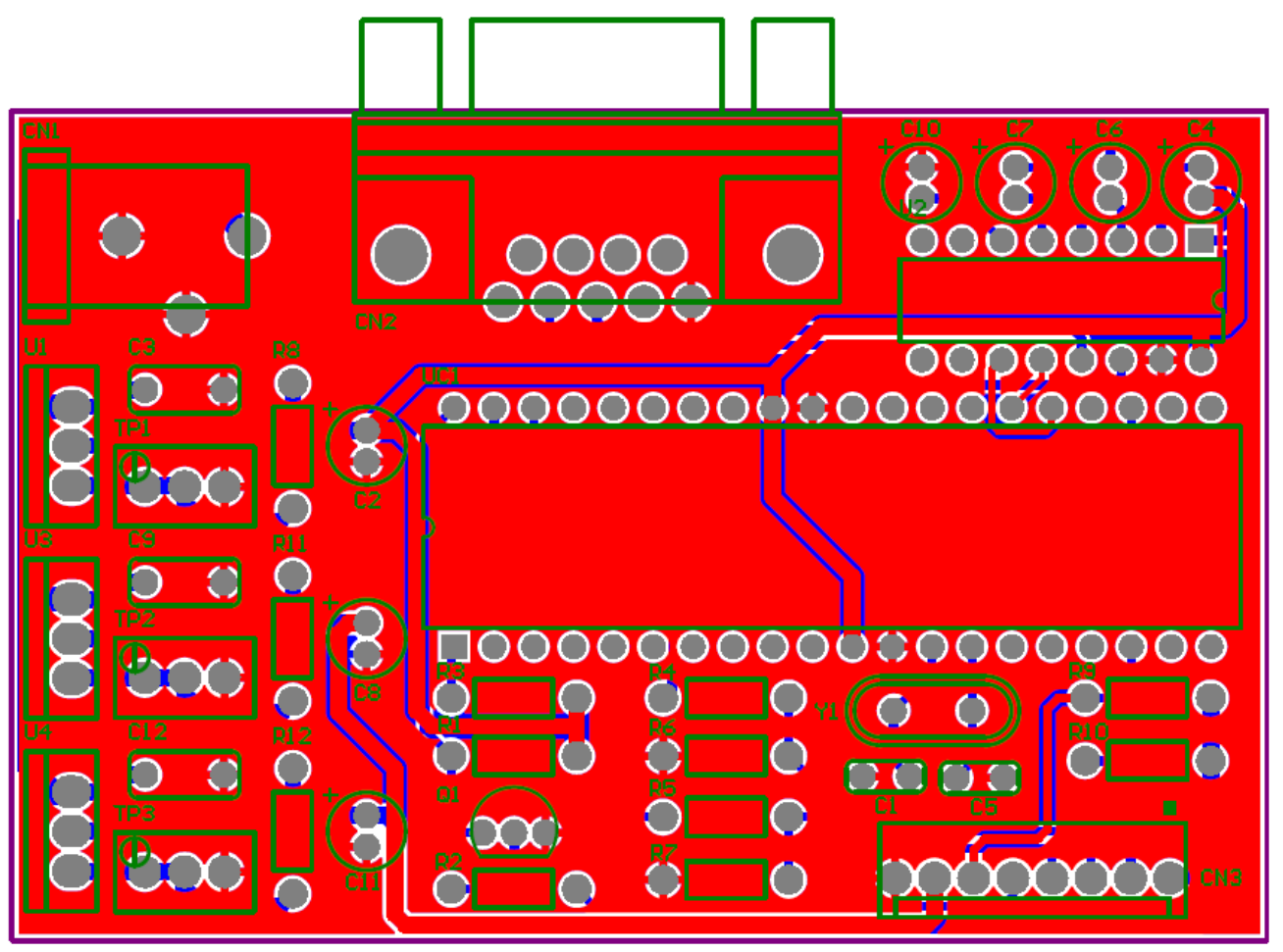

Figura 5.5 - Layout da placa principal 


\subsubsection{Diagrama da placa do sensor}

Na Figura 5.6 o diagrama da placa do sensor é apresentada. O circuito possui o sensor AMI601 e alguns capacitores colocados na alimentação para reduzir acoplamentos e ruídos. Na Figura 5.7 é apresentado o layout final da placa do sensor.
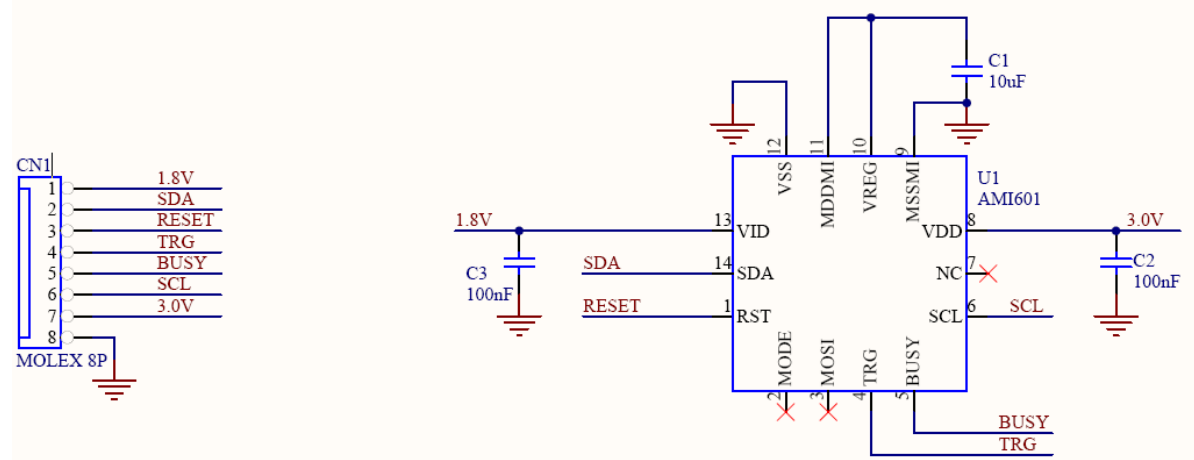

Figura 5.6 - Projeto da placa do sensor

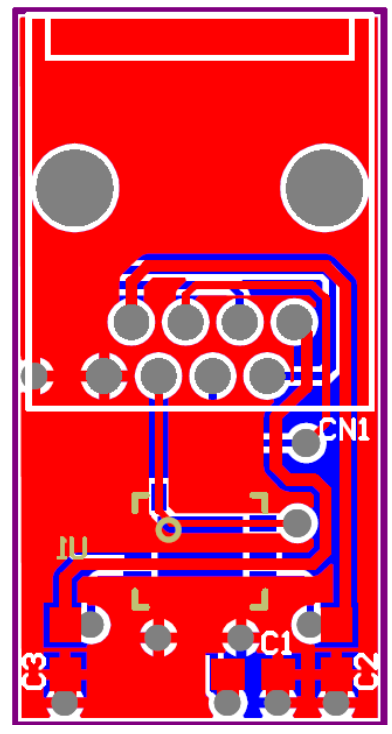

Figura 5.7 - Layout da placa do sensor

\subsubsection{Microcontrolador}

O PIC16F877A (Figura 5.8), microcontrolador da Microchip ${ }^{26}$, foi utilizado devido à familiaridade do autor com tal componente.

\footnotetext{
${ }^{26}$ http://www.microchip.com.
} 
O microcontrolador é um componente eletrônico programável utilizado no controle de processos lógicos; responsável por gerenciar todo o circuito, já que possui a capacidade de armazenar um software de pequeno porte. Assim, o programador consegue controlar e definir suas entradas e saídas.

A finalidade do microcontrolador no protótipo é realizar a comunicação via protocolo $I 2 C^{27}$ com o sensor AMI601, obtendo os dados dos 6 sensores que compõem o AMI601 e configurando parâmetros como ganhos e offsets dos amplificadores de cada um desses sensores. Dessa forma, o microcontrolador atua como uma ponte entre o computador e o sensor AMI601, pois além de enviar os dados obtidos do sensor pela serial, também permite que comandos oriundos da serial sejam enviados ao sensor. $\mathrm{O}$ Apêndice A apresenta detalhes sobre tal ponte e o código assembly implementado.

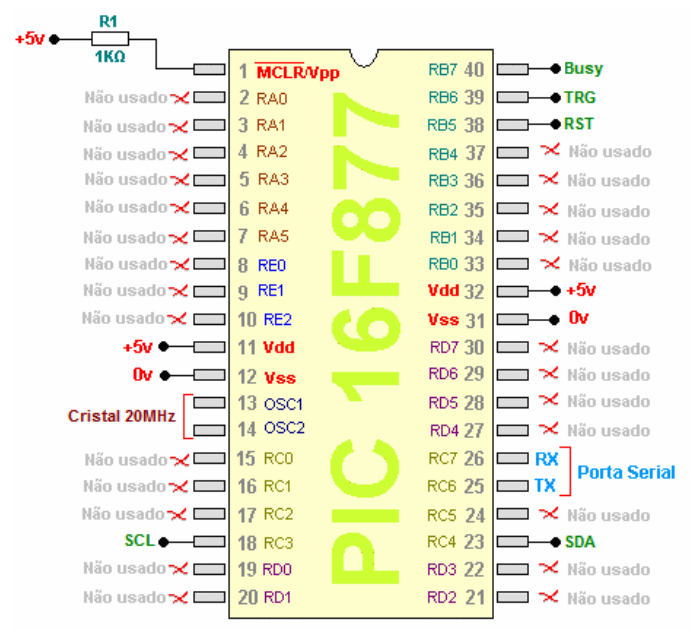

Figura 5.8 - Descrição dos pinos do PIC16F877A usados no projeto (http://www.rogercom.com)

Os microcontroladores PIC possuem em uma única pastilha de silício os componentes necessários ao controle de um processo, sendo provido internamente de memória de programa, memória de dados, portas de entrada e/ou saídas paralela, timer's, controladores, comunicação serial, PWM`s, conversores A/D, etc.

Os pinos 1,11 e 32 são alimentados com tensão de $5 \mathrm{~V}$ e os pinos 12 e 31 são ligados ao terra (GND). Os pinos 25 e 26 do PIC são ligados,

\footnotetext{
${ }^{27}$ http://i2c-bus.org.
} 
respectivamente, aos pinos $11(\mathrm{TX})$ e 12(RX) do MAX 232 (comunicação serial). Os pinos 13 e 14 do PIC, são respectivamente, a entrada e a saída do oscilador de cristal de $20 \mathrm{MHz}$. O circuito do oscilador é usado para fornecer um relógio (clock) ao microcontrolador, para que o mesmo possa executar um programa ou as instruções de um programa. O oscilador é ligado a dois capacitores cerâmicos.

Os pinos 18 (SCL), 23 (SDA), 38 (RST), 39 (TRG) e 40 (BUSY) do PIC são conectados com o conector de 8 pinos que tem ligação com o sensor AMI601.

\subsubsection{MAX232}

O MAX232 é o componente responsável por converter sinais RS232/TTL, utilizado para fazer a conexão entre o microcontrolador e o computador através da porta serial.

A comunicação serial RS232 trabalha geralmente com tensões simétricas de $+12 \mathrm{~V}$ e $-12 \mathrm{~V}$, podendo danificar o microcontrolador, pois ele trabalha com nível TTL de 0 a $5 \mathrm{~V}$. O MAX232 foi utilizado, para possibilitar a comunicação do microcontrolador com o computador via a porta serial. Na Figura 5.9 é apresentado a interligação do PIC com o computador, tendo como intermediário o MAX232. Na Figura 5.10 são apresentados os pinos do conector DB9.

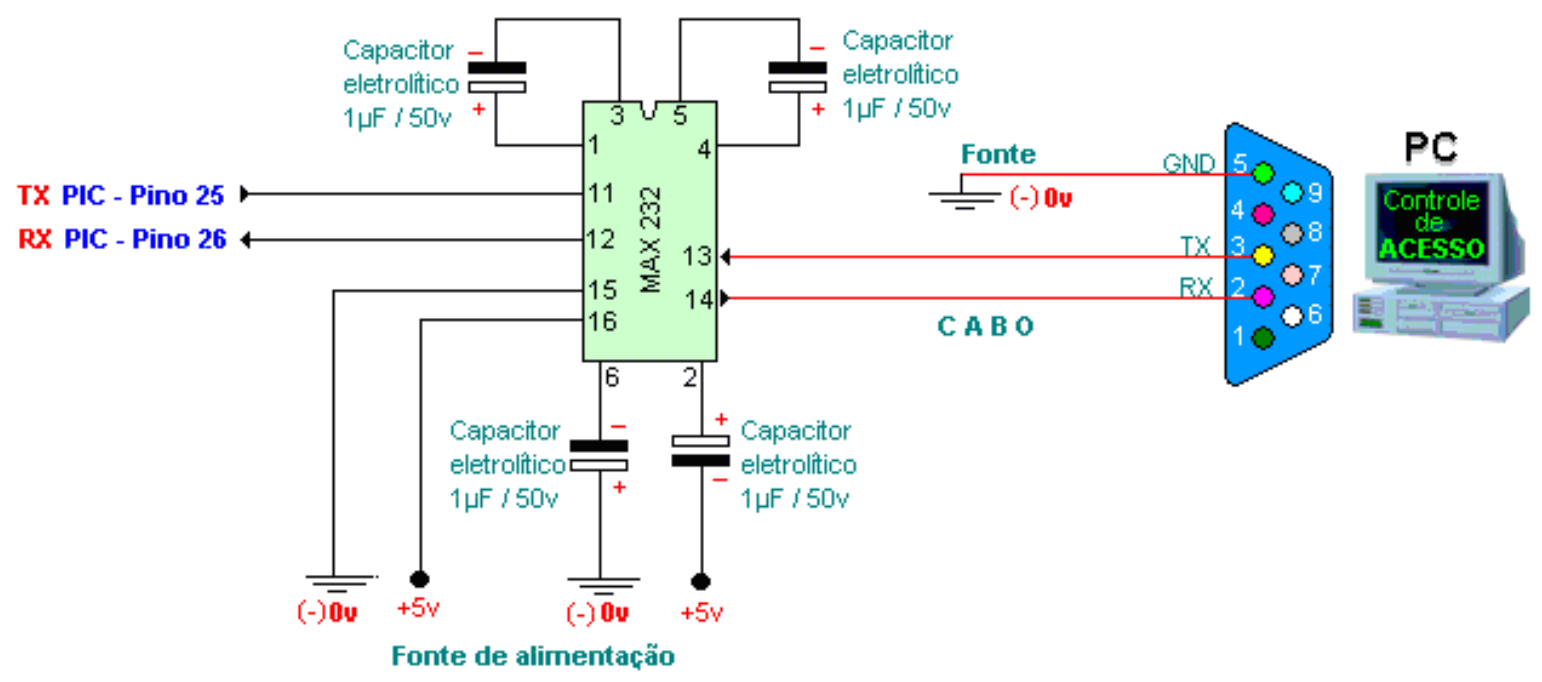

Figura 5.9 - Conversor de sinais RS232/TTL (http://www.rogercom.com) 
Os pinos 11 e 12 do MAX232 são ligados respectivamente aos pinos 25(TX) e 26(RX) do PIC16F877A. O cabo serial ligado ao computador é composto de 3 fios $(R X, T X$ e $G N D$ ). Os pinos 2 e 3 do conector $D B 9$ (conector de 9 pinos que liga a placa controladora ao computador, através de um cabo serial) são conectados através do cabo serial, respectivamente, aos pinos 14 e 13 do MAX232. O pino 5 (GND) do conector é ligado ao terra da fonte de alimentação da placa controladora.

Os capacitores eletrolíticos são utilizados para configurar o funcionamento correto do MAX232; alguns deles trabalham com sua polaridade invertida.

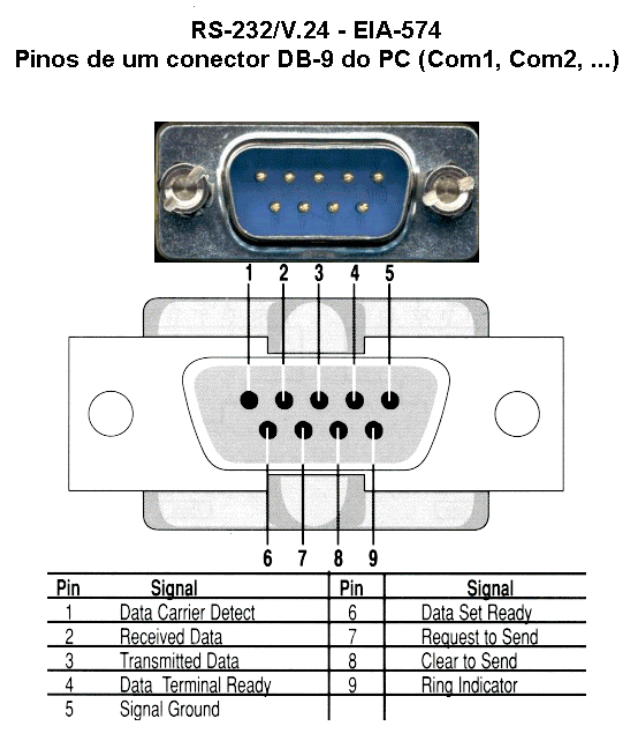

Figura 5.10 - Conector DB9 (http://www.rogercom.com)

\subsubsection{Sensor AMI601}

O AMI601 (Figura 5.11) é um sensor de controle de movimento que integra um sensor magnético de 3 eixos, um acelerômetro de 3 eixos e um microcontrolador em um mesmo circuito integrado, aumentando a precisão e velocidade de processamento. Ele inclui também sensor de temperatura, um conversor A/D (Analógico/Digital) e memória RAM (2KB) e ROM (16KB) onboard. 
A razão pela escolha desse sensor é que o mesmo apresenta alta precisão nas medidas de aceleração 28 e magnetismo ${ }^{29}$ quando comparado a dispositivos semelhantes, tamanho físico $(6 \times 5.2 \times 1.57 \mathrm{~mm})$ reduzido (fato que possibilita a construção de protótipos pequenos), correção dos valores mensurados pelos sensores internos devido a variação de temperatura e a existência de um conversor digital interno dos sinais analógicos que evita muitos dos problemas relacionados ao condicionamento de sinais analógicos.

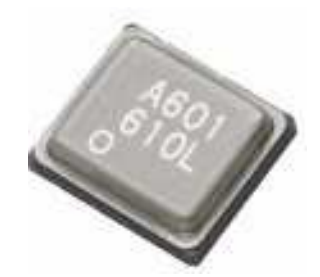

Figura 5.11 - Sensor AMI601 (http://www.aichi-mi.com)

\subsubsection{Aquisição de dados do sensor ami601}

A aquisição de dados do sensor AMI601 é composto por uma série de etapas. Em primeiro lugar é necessário estabelecer uma comunicação com o sensor via protocolo $\mathrm{I}^{2} \mathrm{C}$. Posteriormente são enviados ao sensor comandos adequados para sua configuração e obtenção dos valores mensurados. Finalmente tais dados são enviados ao computador através da comunicação serial.

$\mathrm{O}$ código assembly produzido é um software executado em um microcontrolador PIC16F877A conectado a um sensor de movimento AMI601 e a um microcomputador. O código permite que o computador se comunique (obtendo e ajustando valores) com o sensor AMI601 via comunicação serial (RS232).

O programa que é executado no microcontrolador executa 50 leituras de posicionamento por segundo, obtendo os dados primitivos do sensor AMI601

\footnotetext{
${ }^{28}$ A sensibilidade de aceleração é de 400 bit/g e a faixa de medidas possíveis de \pm 2 g. A faixa de aceleração é adequada ao objetivo do projeto, visto que a aceleração da gravidade a ser mensurada está na faixa de $\pm 1 \mathrm{~g}$. ${ }^{29}$ A sensibilidade do magnetismo é de $10 \mathrm{bit} / \mu \mathrm{T}$ (bits por micro Tesla) e uma faixa de medidas possíveis de \pm $200 \mu \mathrm{T}$. A faixa do magnetismo é adequado ao objetivo do projeto, visto que o magnetismo terrestre a ser mensurado está na faixa de 30 a $60 \mu \mathrm{T}$.
} 
(via protocolo de comunicação $\mathrm{I}^{2} \mathrm{C}$ ). Os dados são transmitidos no formato $N M E A^{30}$ para o computador através da comunicação serial (RS232). O sensor AMI601 permite diversas configurações tais como ajuste dos ganhos de amplificadores. Para executar essas configurações o computador envia strings no formato NMEA ao microcontrolador, que por sua vez repassa tal comando ao sensor AMI601. No Apêndice A são apresentados detalhes do código assembly.

\subsection{Componentes de hardware construídos}

Além da construção de todos os componentes de hardware referentes a utilização do sensor AMI601, descritos nas seções anteriores, outros componentes de hardware também foram construídos e utilizados na construção de alguns dispositivos de interação. Nas Figuras 5.12, 5.13, 5.14 e 5.15 são apresentados alguns componentes de hardware, utilizando a simbologia adotada pelo ICon. Esses componentes integram a camada Rawto-Primitive-Data da arquitetura $A M C E$, disponibilizando os dados primitivos capturados pelos sensores através de eventos em alto nível.

Na Figura 5.12 é apresentado o componente de hardware ADXL Breakout Board que possui uma entrada implícita (comunicação serial com o sensor ADXL) e duas saídas relativas a aceleração mensurada em dois eixos ortogonais $(x$ e $y$ ). As saídas são do tipo numérico double, e a sua unidade de medida é o G (gravidade). O componente pode ser utilizado em várias aplicações, como por exemplo aquelas que tenham interesse em medir inclinações de corpos ou vibrações. O componente foi utilizado na implementação do SBIMCards descrito em Santos et al (2006 a).

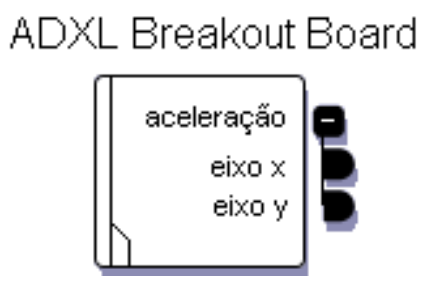

Figura 5.12 - Componente ADXL Breakout Board

\footnotetext{
${ }^{30}$ http://www.nmea.org/pub/0183.
} 
Na Figura 5.13 é apresentado o componente de hardware IMU Combo Board que possui uma entrada implícita (comunicação serial com o sensor IMU), duas saídas relativas a aceleração mensurada em dois eixos ortogonais $(x$ e $y)$ e uma saída relativa à velocidade angular mensurada em um terceiro eixo perpendicular ao plano formado pelos eixos dos acelerômetros. As saídas são do tipo numérico double. A unidade de medida da aceleração é o $\mathrm{G}$ (gravidade) e a da velocidade angular é graus/segundo ( $/ \mathrm{s})$.

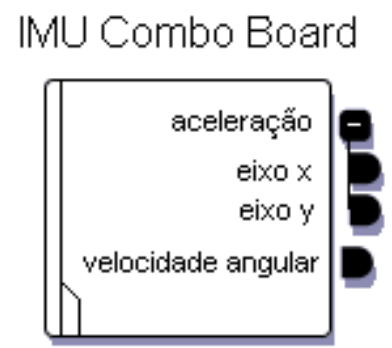

Figura 5.13 - Componente IMU Combo Board

Na Figura 5.14 é apresentado o componente de hardware OS1x00 que possui uma entrada implícita (comunicação serial com o sensor OS1x00), três saídas relativas aos ângulos de Euler (heading, roll e pitch) e uma saída relativa à temperatura mensurada pelo sensor. As saídas são do tipo numérico double. A unidade de medida dos ângulos é o grau $\left(^{\circ}\right)$, sendo que as faixas de valores mensuradas pelo heading é o intervalo $\left[0^{\circ}, 360^{\circ}\right]$, pelo roll o intervalo $\left[-90^{\circ}, 90^{\circ}\right]$ e pelo pitch o intervalo $\left[-90^{\circ}, 90^{\circ}\right]$. A unidade de medida da temperatura é o grau Celsius $\left({ }^{\circ} \mathrm{C}\right)$.

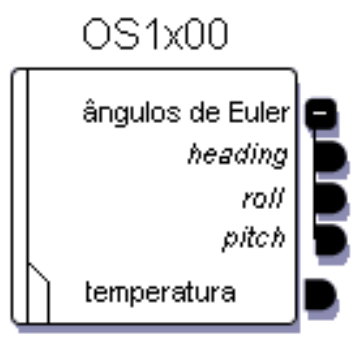

Figura 5.14 - Componente OS1x00 
Na Figura 5.15 é apresentado o componente de hardware AMI601 que possui uma entrada implícita (comunicação serial com o sensor AMI601), três saídas relativas à aceleração mensurada em três eixos ortogonais $(x, y$ e $z)$, três saídas relativas ao campo magnético mensurado em três eixos ortogonais $(x, y$ e $z)$, e uma saída referente à temperatura mensurada pelo sensor. As saídas são do tipo numérico double. A unidade de medida relativas à aceleração é o grau ( ${ }^{\circ}$ ), relativa ao campo magnético é o Gauss, e relativa à temperatura o grau Celsius $\left({ }^{\circ} \mathrm{C}\right)$.

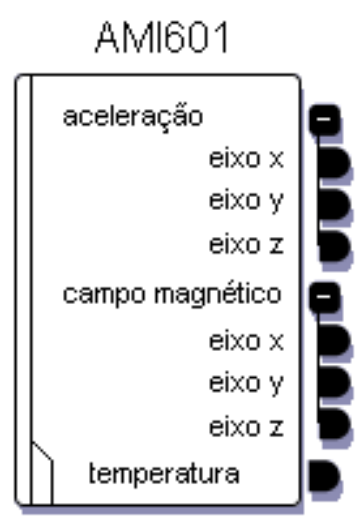

Figura 5.15 - Componente AMI601

\subsection{SBIMOUSE}

Todos os sensores utilizados comunicam-se com o computador via a interface serial (ou USB, com o auxílio de conversores adequados). Portanto são necessários componentes que realizam a comunicação serial. Isso foi feito utilizando-se a linguagem de programação JAVA e a API javax.comm ${ }^{31}$, que oferece um conjunto de abstrações para a comunicação serial ou paralela. Além disso, a implementação de outros componentes que envolvem interfaces gráficas de usuários ou processamento também foram construídas, e uma descrição mais detalhada é feita nas próximas seções.

\footnotetext{
${ }^{31}$ http://java.sun.com/products/javacomm.
} 


\subsubsection{Configuração do sensor AMI601}

O sensor AMI601 possui um conjunto de configurações que podem ser realizadas para uma obtenção precisa do campo magnético do ambiente em que for instalado. Para possibilitar essa configuração, uma interface gráfica em Java foi especificada, programada e implementada para permitir que o usuário realize tais configurações quando necessário. Os detalhes sobre a configuração do sensor AMI601 são apresentados no Apêndice B.

\subsubsection{Calibração do sensor AMI601}

O processo de calibração é necessário para se obter precisão dos campos magnéticos mensurados. Quando os valores dos sensores apresentam anormalidades, por exemplo, por haver um forte campo no ambiente, magnetizando os terminais dos componentes eletrônicos que estão próximos aos elementos do sensor, a calibração é necessária para acabar com estas interferências.

Este processo foi implementado através da linguagem Java com o objetivo de orientar o usuário, junto com figuras ilustrativas, a posicionar e rotacionar o sensor para cada etapa de calibração. Os detalhes sobre o processo de calibração do sensor AMI601 são apresentados no Apêndice C.

\subsubsection{Obtenção dos ângulos de Euler}

O componente Ângulos de Euler integra a camada Basic-Input-Operations Library da arquitetura AMCE.

Estudos foram realizados para determinar como obter os ângulos de Euler (heading, roll e pitch) a partir dos dados primitivos de aceleração (três eixos ortogonais) e campo magnético (três eixos ortogonais) fornecidos pelos sensores adquiridos. Shelburne e Williston (2006) descrevem, em sua patente, um método para obtenção de tais ângulos. Os detalhes sobre o modelo matemático utilizado são apresentados no Apêndice D.

$\mathrm{Na}$ Figura 5.16 esse componente é apresentado. Como pode ser observado, as entradas do componente são os valores primitivos de aceleração ( 3 eixos, mensurados em G) e campo magnético (3 eixos, 
mensurados em Gauss), e as saidas são os ângulos de Euler (heading, roll e pitch) calculados a partir dos dados de entrada. A unidade de medida de tais ângulos é o grau $\left({ }^{\circ}\right)$, sendo que as faixas de valores mensuradas pelo heading pertence ao intervalo $\left[0^{\circ}, 360^{\circ}\right]$, pelo roll ao intervalo $\left[-90^{\circ}, 90^{\circ}\right]$ e pelo pitch ao intervalo $\left[-90^{\circ}, 90^{\circ}\right]$.

As entradas do componente podem ser fornecidas por outros componentes como por exemplo, o componente AMI601.

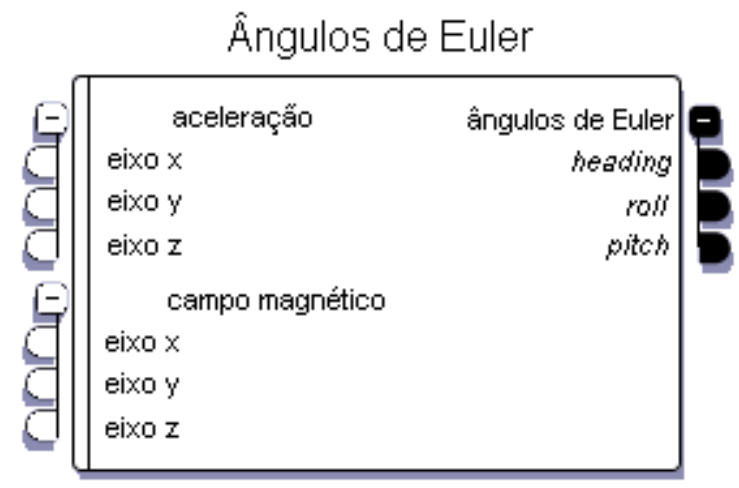

Figura 5.16 - Componente para transformação de dados primitivos de aceleração e campos magnéticos em ângulos de Euler

\subsection{Implementação do SBIMouse}

O componente SBIMOUSE integra a camada SBIDevice da arquitetura AMCE.

Para gerar eventos para o Sistema Operacional que controlem a ponteira do mouse e permita controlar os cliques com os diversos botões, a API Java java.awt.Robot ${ }^{32}$ (Figura 5.17) foi utilizada, criando um componente de software capaz de controlar a ponteira do mouse e os cliques a partir dos seus eventos de entrada.

\footnotetext{
${ }^{32}$ http://java.sun.com/javase/6/docs/api/java/awt/Robot.html.
} 


\begin{tabular}{|c|}
\hline java.swt. Robot \\
\hline 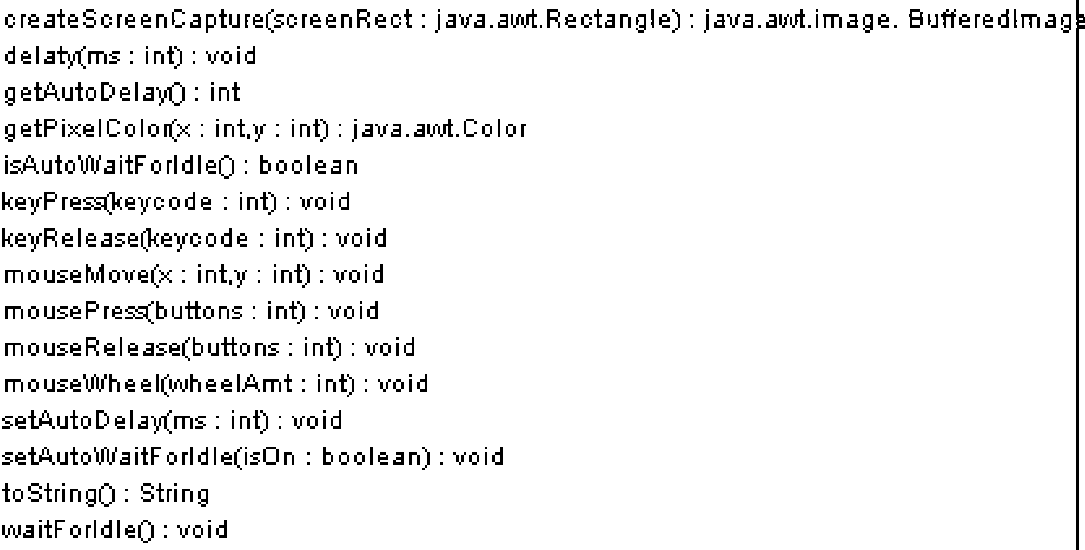 \\
\hline
\end{tabular}

Figura 5.17 - Classe java.awt.Robot

$\mathrm{Na}$ Figura 5.18 o componente SBIMOUSE é apresentado. Para determinação de cada posição da ponteira do mouse a entrada $p$ (coordenadas $x$ e $y$ do tipo int) é utilizada. Para efetuar os cliques em qualquer um dos três botões, a entrada but (booleano) é utilizada. Como saídas, o componente apresenta a posição atual da ponteira do mouse, controla a posição da ponteira do mouse na tela e os cliques.

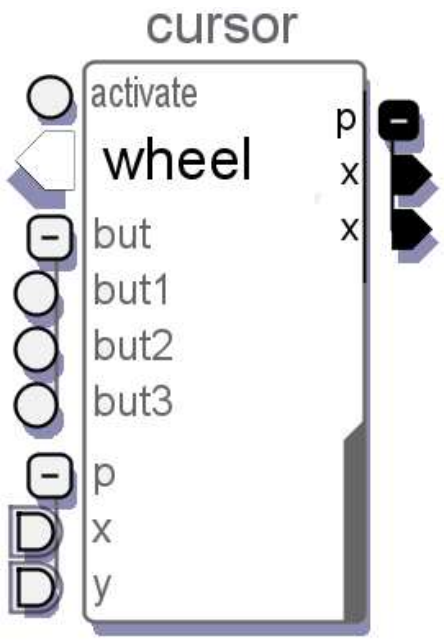

Figura 5.18 - Componente SBIMouse 


\subsection{O MOUSE RELATIVO ASSISTIVO}

\subsubsection{Mouses absolutos versus mouses relativos}

Existem vários dispositivos comerciais para controle do cursor do mouse, dentre os quais duas categorias podem ser identificadas: a primeira formada pelo conjunto de elementos, cujo o movimento do cursor na tela fica associado à movimentação do dispositivo, mas não a sua posição espacial. Tal categoria é denominada de apontamento relativo. Já a segunda categoria, cuja a posição do cursor na tela está associada a posição espacial do dispositivo, é denominada de categoria de apontamento absoluto (Evans \& Blenkhorn, 1999).

Para ilustrar os conceitos podem ser citados dois mouses controlados pela movimentação da cabeça do usuário. Se o dispositivo implementado for um mouse absoluto, cada posição da ponteira do mouse estará associada a uma posição espacial da cabeça. Assim cada posição espacial da cabeça, determina um único pixel da tela onde o cursor deve estar localizado. Dessa forma, um possivel mapeamento seria posicionar o cursor no centro da tela, quando a cabeça também estivesse centralizada (sem giros de negação, afirmação e inclinações), e alterar a posição do cursor em função de novas posições da cabeça.

Se o dispositivo implementado for um mouse relativo, o cursor não se desloca quando a posição da cabeça do usuário encontra-se em uma posição padrão (configurável). Deslocamentos da cabeça, em relação a posição padrão, implicam no deslocamento do cursor na tela, que só cessará quando o usuário retornar a cabeça a posição padrão. Dessa forma, se o usuário desejar deslocar o cursor no eixo $x$ para a esquerda, ele deverá simplesmente deslocar sua cabeça, na direção do movimento de negação para a esquerda, assim o cursor começara a se deslocar no eixo $x$ para a esquerda, sendo que a velocidade de tal deslocamento será proporcional à inclinação da cabeça, e a medida que o cursor se aproxima da posição alvo, o usuário deve ir retornando a posição da cabeça a posição padrão, para que a movimentação do cursor pare. 


\subsubsection{O desenvolvimento do mouse Relativo}

Para o desenvolvimento do mouse relativo assistivo, cujo o modelo de operação é descrito nas próximas seções, os componentes (OS1x00, AMI601, ângulos de Euler e SBIMouse) apresentados nas seções anteriores foram utilizados, bastando para o desenvolvedor simplesmente mapear os eventos gerados para os componentes adequados.

Nas Figuras 5.19 e 5.20 é ilustrado a construção de tal dispositivo através de duas configurações: a primeira explorando o sensor AMI601 (mais preciso e de tamanho diminuto), e a segunda o sensor OS1x00.

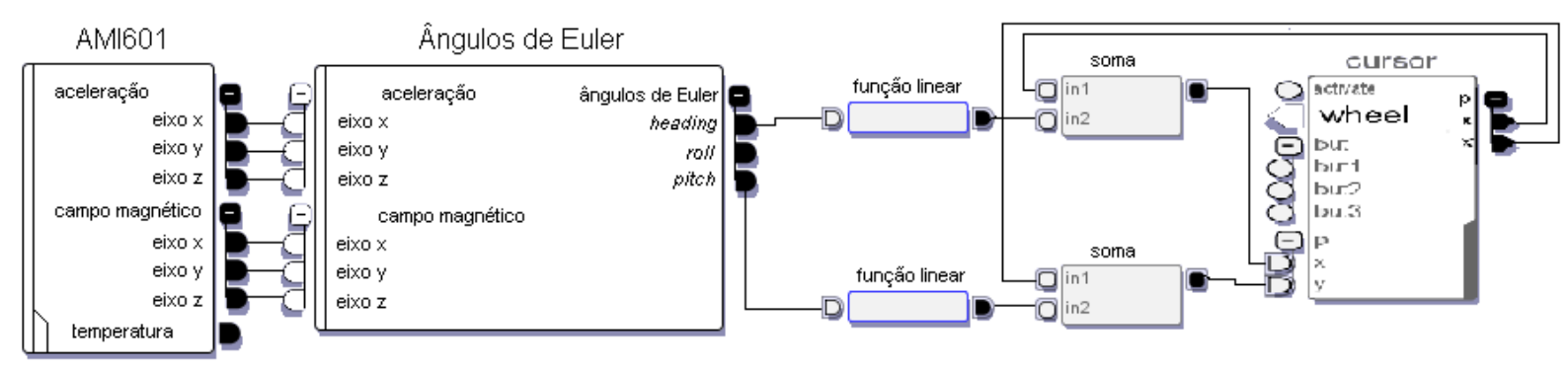

Figura 5.19 - Mouse Assistivo com o AMI601

Na Figura 5.19 é apresentada a implementação do mouse relativo assistivo utilizando o sensor AMI601. Como pode ser observado, após a transformação dos valores primitivos do sensor em ângulos de Euler, o heading é utilizado para controlar a posição do eixo $x$ da ponteira do mouse, enquanto o pitch é utilizado para controlar a posição do eixo $y$, porém isso não é feito diretamente, um mapeamento é necessário.

Como a saída heading é um double que pertence ao intervalo $[0,360]$ e a entrada $x$ do componente SBIMouse é dada em pixel, uma transformação é requerida. O que é feito, é uma transformação linear de heading, de modo que o intervalo $[0,360]$ seja transformado em um intervalo [-b,b], de tal forma que quando a posição da cabeça do usuário encontra-se na posição padrão, a saída da transformação linear é zero. A constante b determina a quantidade de pixels que a ponteira do mouse será deslocada, quando ocorrer um deslocamento de 180 graus em relação a posição padrão. Portanto, a saída da transformação linear determina o quanto o cursor deverá ser deslocado no eixo x. Porém, o componente SBIMouse possui como 
entrada a posição absoluta do cursor (em pixels $x$ e $y$ ), por isso é necessário somar a posição atual do cursor (saída do componente SBIMouse) ao deslocamento desejado.

O mesmo mapeamento descrito para heading é necessário para o pitch.

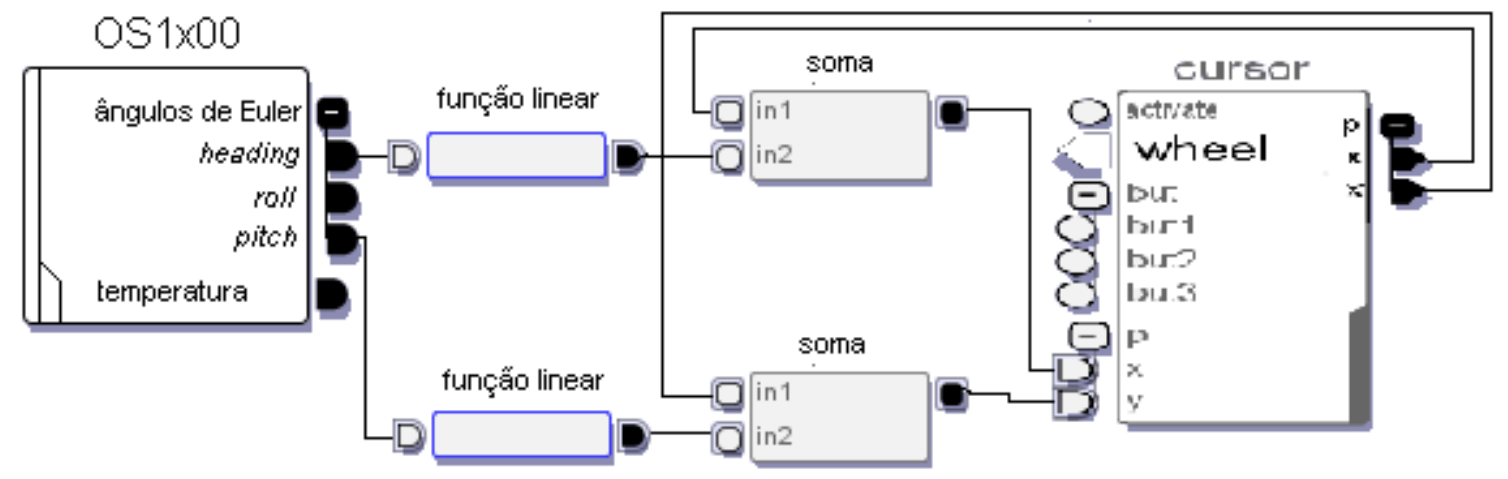

Figura 5.20 - Mouse Assistivo com o OS1x00

Na Figura 5.20 é apresentada a implementação do mouse relativo assistivo utilizando o sensor OS1x00. Como pode ser observado, todo o mapeamento se manteve, modificando-se apenas o componente que gera os ângulos de Euler.

Um mouse absoluto assistivo também foi implementado com os dois sensores, modificando-se apenas o mapeamento que interliga os ângulos de Euler ao controle do cursor. Testes mostraram que os sensores utilizados não apresentam precisão adequada, para esse tipo de implementação.

\subsubsection{Controle do cursor do mouse relativo}

O mouse relativo assistivo é um dispositivo que controla todo o movimento da ponteira do mouse no monitor, usando o movimento da cabeça e permitindo o clique esquerdo, direito, duplo clique entre outros através de um programa auxiliar. Para se ter uma melhor visão do que é o mouse assistivo observe a Figura 5.21 e a explicação de cada ponto apresentado. 


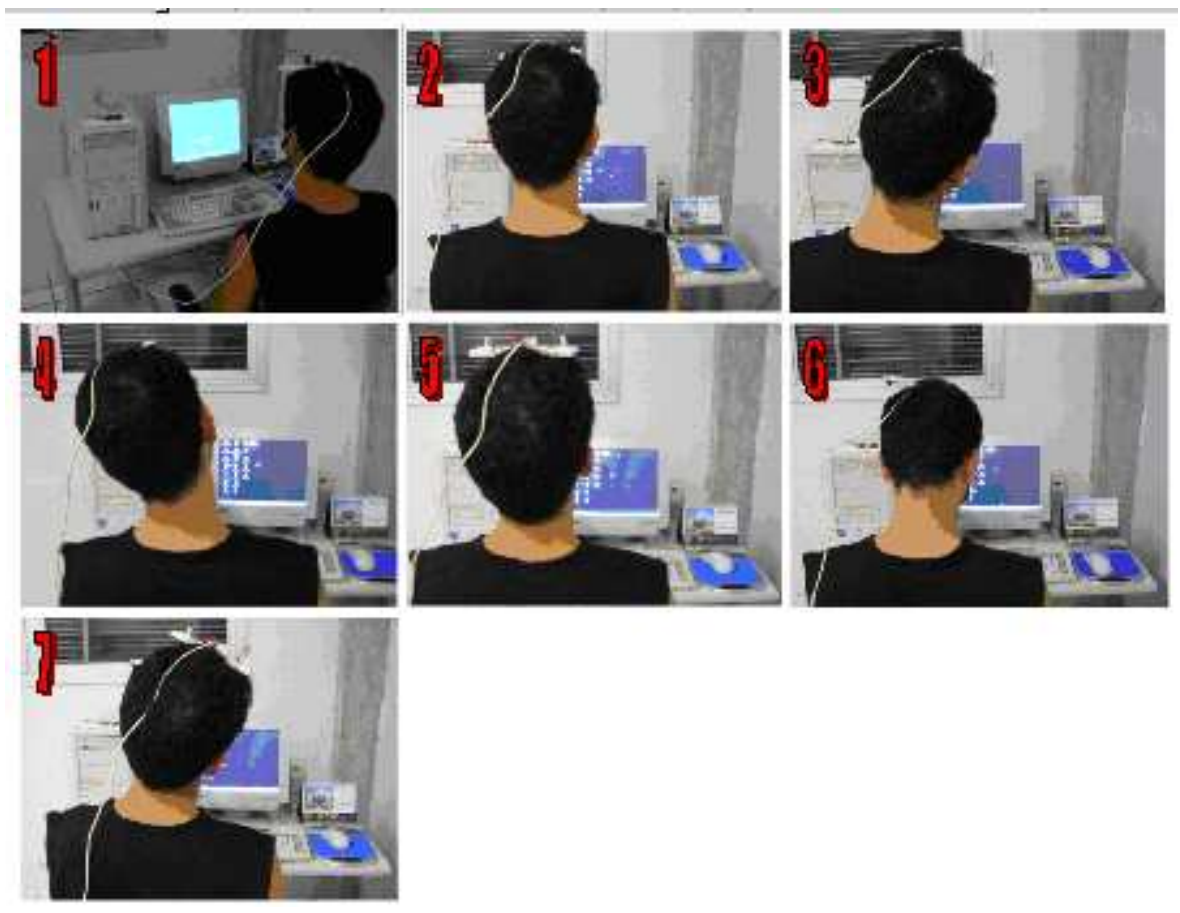

Figura 5.21 - Utilização do mouse relativo assistivo

A seguir, a explicação de cada ponto destacado na Figura 5.21:

- Ponto 1, ilustra o usuário utilizando o dispositivo.

- Ponto 2, ilustra a posição considerada como ponto 0 (zero), na qual o sistema não atua, ou seja, a ponteira do mouse não se desloca (este ponto pode ser ajustado para qualquer outra posição).

- Ponto 3, ilustra o sentido e direção da inclinação da cabeça necessária para o deslocamento da ponteira do mouse no eixo $\mathrm{x}$, da esquerda para a direita, ressaltando-se que a velocidade de deslocamento da ponteira do mouse é diretamente proporcional ao ângulo de inclinação.

- $\quad$ Ponto 4, ilustra o sentido e direção da inclinação da cabeça necessária para o deslocamento da ponteira do mouse no eixo $\mathrm{x}$, da direita para a esquerda.

- Ponto 5, ilustra o sentido e direção da inclinação da cabeça necessária para o

deslocamento da ponteira do mouse no eixo y, de cima para baixo. 
- Ponto 6, ilustra o sentido e direção da inclinação da cabeça necessária para o deslocamento da ponteira do mouse no eixo y, de baixo para cima.

- Ponto 7, ilustra a combinação da inclinação da cabeça em ambos os eixos, que possibilita o deslocamento da ponteira do mouse, simultaneamente no eixo $x$ e $y$.

\subsubsection{Controle dos cliques do mouse}

Os cliques do mouse podem ser realizados em qualquer lugar do ambiente utilizando uma técnica conhecida como seleção por repouso. Tal técnica efetua um clique esquerdo com o botão do mouse depois que a ponteira do mouse fica parada durante um determinado tempo (configurável).

Através da interface do programa é possivel realizar outras operações além do clique esquerdo. Operações como: arrastar com botão esquerdo, arrastar com o botão direito, arrastar com o botão central, duplo clique, clique direito e clique central são possíveis, bastando selecionar o modo de operação na barra de ferramentas. Após a nova operação ser realizada, o sistema retorna automaticamente para o modo padrão de um simples clique com o botão esquerdo.

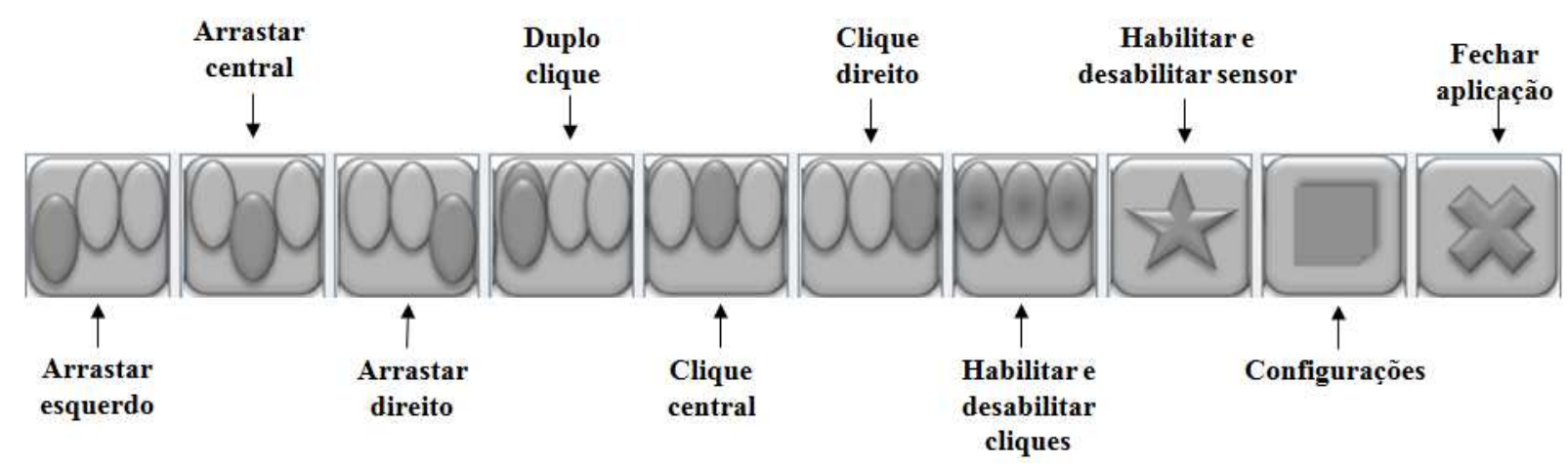

Figura 5.22 - Interface para efetuar cliques com o mouse

Como apresentado na Figura 5.22, a interface apresenta botões associados com as funções acima descritas. Para ilustrar uma operação, 
suponha que o usuário deseje arrastar um ícone da área de trabalho para um outro local. Para realizar tal operação, o usuário deve:

1. Mover a ponteira do mouse para o botão da barra de ferramentas adequado (arrastar com o esquerdo).

2. Repousar a ponteira do mouse sobre tal botão pelo tempo configurado, para que o sistema efetue o modo padrão, que é um simples clique com o esquerdo e selecione o novo modo de operação (arrastar com o esquerdo).

3. Mover a ponteira do mouse até o ícone alvo a ser arrastado.

4. Repousar a ponteira do mouse sobre tal ícone pelo tempo configurado, para que o sistema efetue o modo selecionado, que nesse caso é manter o botão esquerdo pressionado.

5. Mover a ponteira do mouse e conseqüentemente o ícone, para o novo local.

6. Repousar a ponteira do mouse sobre o novo local, para que o sistema "solte" o botão esquerdo. Após isso, o sistema retorna para o modo padrão de um único clique com o botão esquerdo.

\subsection{CONSIDERAÇÕES FINAIS}

Neste capitulo foram descritas as principais atividades de desenvolvimento dos principais componentes de hardware e software. Também foram apresentados em detalhes o desafios de se construir novos dispositivos de interação sem o apoio de nenhuma infraestrutura ou reuso de componentes. Finalmente, o mouse assistivo desenvolvido é apresentado em detalhes, explicitando como a disponibilização de componentes em alto nível facilitam o desenvolvimento e prototipação de novos dispositivos de interação. 


\section{CONCLUSÕES}

No presente trabalho foi apresentada a arquitetura $A M C E$, constituída por um conjunto de camadas (e componentes) de hardware e software que delimitam alguns dos problemas recorrentes na construção de dispositivos de interação físicos, incluindo a necessidade da abstração do hardware, da abstração dos conceitos físicos inerentes aos sensores utilizados, da adaptabilidade de entrada e do controle externo das aplicações.

\subsection{CONTRIBUIÇÕES}

Dentre os principais resultados e contribuições resultantes da conclusão dos objetivos propostos estão:

- Definição da arquitetura $A M C E$ que separa de forma clara os desafios ao se construir novos dispositivos de interação físicos. Arquitetura que possibilita a criação de frameworks que podem facilitar o desenvolvimento de tais dispositivos;

- Criação de componentes de hardware que abstraem o uso de acelerômetros, giroscópios, sensores magnéticos e bússolas eletrônicas. Fornecendo através de eventos de alto nivel valores de aceleração, velocidade angular e de campo magnético detectados pelos sensores;

- Criação de componentes de software que transformam valores primitivos de aceleração e campo magnético em ângulos de Euler (heading, roll e pitch);

- Criação de componentes de software que geram para o Sistema Operacional eventos semelhantes aos fornecidos por um mouse;

- Implementação de um mouse funcional, utilizando acelerômetros e bússolas eletrônicas, que pode ser utilizado por usuários tetraplégicos, que possuam controle fino dos movimentos da cabeça e ausência de deficiências visuais. 


\subsection{TRABALHOS FUTUROS}

Uma possivel continuidade desse trabalho pode se dar nos seguintes aspectos:

1. Construção de um framework que possibilite a formulação de novos dispositivos de interação física através de uma interface visual, unindo dessa forma as vantagens dos Phidgets e ICon;

2. Avaliação de como a disponibilização de:

- $\quad$ Sensores e/ou atuadores, com todas as abstrações feitas, por exemplo, pelos Phidgets.

- Componentes de software reusáveis de interação como aqueles que geram eventos de mouse e/ou teclado, ou controlam partes específicas de uma aplicação entre outros.

- O poder de um framework como o ICon.

podem diminuir os custos da implementação/avaliação de novas formas de interação.

3. Construção de uma biblioteca de hardware e software que apresente os sensores/atuadores disponiveis no mercado, funções de processamento como por exemplo reconhecimento de gestos, e também funções de controle como mouse e teclado;

4. Reconhecimento de gestos baseados em sinais de aceleração e campo magnético, utilizando por exemplo cadeias de Markov e/ou máquina de estado finito.

5. Criação de novos dispositivos de interação, como por exemplo, novos modelos de mouse e teclado. 


\section{Glossário}

Acelerômetro: Um sensor que mensura aceleração, tanto estática (referente ao campo gravitacional terrestre), quanto dinâmica (movimentos).

API: Application Programming Interface (Interface de Programação de Aplicativos) é um conjunto de rotinas e padrões estabelecidos por um software para utilização de suas funcionalidades por programas aplicativos, isto é, programas que não querem envolver-se em detalhes da implementação de software, mas apenas usar seus serviços.

Bússola eletrônica: Um instrumento navegacional para encontrar direções sobre a Terra (referência campo magnético terrestre).

Dial Resistor: Um potenciômetro cuja a variação da resistência elétrica ocorre através do deslocamento angular de um elemento de ajuste.

Encoder: Um sensor capaz de mensurar o número de rotações de um determinado eixo. Os Phidgets apresentam um encoder que disponibiliza o número de rotações as aplicações através de um valor numérico. A cada 360 graus de rotação, tal encoder retorna 80 pontos as aplicações.

GUI: Graphical User Interface (Interface Gráfica de Usuário) é um mecanismo de interação entre usuário e um sistema de computador. Com um mouse ou teclado o usuário é capaz de selecionar símbolos associados a funções de software e manipulá-los de forma a obter algum resultado prático. Esses símbolos são chamados normalmente de widgets e são agrupados em kits.

Potenciômetro: Componente elétrico que possui resistência elétrica variável. 
Push button: Uma chave elétrica operada pelo acionamento (pressão) de seu contato. Quando acionada abre ou fecha o contato elétrico, retornando ao estado original quando não mais acionada.

Sensor de distância: Um sensor capaz de mensurar a distância de corpos em relação a ele. Os Phidgets apresentam um sensor que mensura distâncias de $70 \mathrm{~cm}$ a $10 \mathrm{~cm}$. A distância é disponibilizada as aplicações, através de um valor numérico (intervalo de 0 a 500) que é inversamente proporcional a distância do corpo.

Sensor de força: Um sensor capaz de mensurar a força aplicada sobre ele. Os Phidgets apresentam um sensor de força, utilizado como dispositivo de entrada, semelhante a um push button. A força aplicada a tal botão é disponibilizada as aplicações, através de um valor numérico que representa a intensidade da força aplicada ao sensor. Quando nenhuma força é aplicada o valor é zero e quando a máxima força (4 kgf) é aplicada ao sensor, o valor mensurado é 1000 .

Sensor de luz: Um sensor capaz de mensurar a intensidade de luz que incide sobre ele. Os Phidgets apresentam um sensor de luz, utilizado como dispositivo de entrada. A intensidade de luz mensurada pelo sensor é disponibilizada as aplicações, através de um valor numérico que representa a intensidade de luz incidente sobre o sensor. No escuro, o valor mensurado é zero, quando a intensidade da luz aumenta, tal valor também é incrementado, sendo o valor máximo 1000.

Sensor de movimento: Um sensor capaz de determinar movimentos de corpos. Os Phidgets apresentam um sensor de movimento que utiliza raios infravermelhos. Quando não há movimentos tal sensor apresenta um valor na faixa de 500, valores fora do intervalo [400, 600], implicam no movimento de corpos. 
Sensor de pressão: Um sensor capaz de mensurar pressão de gases. Os Phidgets apresentam um sensor de pressão, capaz de mensurar pressões entre 20 a $250 \mathrm{Kpa}$.

Servomotor: Motor elétrico, cuja características de dinâmica, controle de rotação, torque constante e precisão de posicionamento são necessárias.

Slider resistor. Um potenciômetro cuja a variação da resistência elétrica ocorre através do deslocamento linear de um elemento de ajuste. Os Phidgets apresentam um slider resistor. A resistência elétrica mensurada é disponibilizada as aplicações através de um valor numérico. Quando o elemento móvel encontra-se em uma das extremidades, o valor mensurado é zero, enquanto que na extremidade oposta é 1000.

Toggle button: Uma chave elétrica que alterna entre dois estados. Quando acionada (pressão) abre ou fecha o contato elétrico, e só mudará de estado caso acionada novamente.

Universal Serial Bus: (USB) é um tipo de conexão Plug and Play que permite a conexão de periféricos sem a necessidade de desligar o computador.

Widget: Elemento de interface que um usuário de computador utiliza para interagir, tais como: janelas ou caixas de texto. Widgets são algumas vezes qualificados como virtuais para distingui-los das suas contrapartes físicas, por exemplo, botões virtuais que podem ser clicados com o cursor do mouse, em contraste com botões fîsicos que podem ser pressionados com um dedo. Widgets são freqüentemente encapsulados em toolkits widgets. Programadores utilizam widgets para construir interfaces gráficas de usuário (GUIs). 
Wireless: Expressão genérica que designa sistemas de telecomunicações nos quais as ondas eletromagnéticas como as de rádio são utilizadas no transporte dos sinais. 


\section{Referências Bibliográficas}

(Assistive Technology Act, 1988)

(Ballagas et al., 2003)

(Beaudouin-Lafon, 2004)

(Beckhaus \& Kruijff, 2004)

(Chen, 2001)
EUA. Assistive Technology Act of 1988. Public Law 105394, 105th Congress, November 13, 1988. Disponível online

em http:/ /www.section508.gov/docs / AT1998.html . Visitado em fevereiro de 2008.

BALlAGAS, R., Ringel, M., STONE, M., and BORCHERS, J. 2003. iStuff: a physical user interface toolkit for ubiquitous computing environments. In Proceedings of the SIGCHI Conference on Human Factors in Computing Systems (Ft. Lauderdale, Florida, USA, April 05 - 10, 2003). CHI '03. ACM Press, New York, NY, p. 537-544.

BEAUDOUIN-LAFON, M. 2004. Designing interaction, not interfaces. In Proceedings of the Working Conference on Advanced Visual interfaces (Gallipoli, Italy, May 25 28, 2004). AVI '04. ACM Press, New York, NY, p. 15-22. BECKHAUS, Steffi; KRUIJFF, Ernst. Unconventional human computer interfaces. In Proceedings of the Conference on SIGGRAPH 2004 Course Notes. Los Angeles, CA, artigo n¹8, 2004, 209 p. Disponível em http://delivery.acm.org/10.1145/1110000/1103918/cs17.p df?key1=1103918\&key2=8701227411\&coll=GUIDE\&dl $=\mathrm{GUIDE} \& \mathrm{CFID}=68611358 \& \mathrm{CFTOKEN}=95952657$

CHEN, Y. L. 2001. Application of tilt sensors in humancomputer mouse interface for people with disabilities. In IEEE Transactions on Neural Systems and Rehabilitation Engineerin, 2001.. p. 289-294. 
(Dai et al., 2004)

(Dragicevic \& Fekete, 2004)

(Dragicevic \& Fekete, 2001)

(Edwards et al., 2003)

(Evans \& Blenkhorn, 1999)

(Gellersen et al., 2004)

(Grauman et al., 2001)
DAI, Liwei; GOLDMAN, Rich; SEARS, Andrew; Jeremy Lozier. Speech-based cursor control: a study of grid-based solutions. In Proceedings of the 6th international ACM SIGACCESS Conference on Computers and Accessibility. Atlanta, GA, USA, p. 94-101, 2004.

DRAGICEVIC, P. and FEKETE, J. 2004. The Input Configurator toolkit: towards high input adaptability in interactive applications. In Proceedings of the Working Conference on Advanced Visual interfaces (Gallipoli, Italy, May 25 - 28, 2004). AVI '04. ACM Press, New York, NY, p. 244-247.

DRAGICEVIC, P. \& FEKETE J. D. 2001. Input Device Selection and Interaction Configuration with ICON. In Proceedings of HCI 2001 and IHM 2001, People and Computer XV - Interaction without frontier (Lille, France, September 2001). Spring Verlag. p. 543-558.

EDWARDS, W.; BELLOTI, V.; DEY, A.; NEWMAN, M. Stuck in the middle: The challenges of user-centered design and evaluation for infrastructure. CHI Letters, 5(1):297-304.

EVANS, G. \& BLENKHORN, P. 1999. A Head Operated Joystick - Experience with Use. In Proceedings of the CSUN Conference on Technology and Persons with disabilities 1999, California State University, Northridge. GELLERSEN, H., KORTUEM, G., SCHMIDT, A, BEIGL, M. 2004. Physical Prototyping with Smart-Its. IEEE Pervasive Computing, vol. 3, no. 3, pp. 74-82, JulSept, 2004.

GRAUMAN, K., BETKE, M., GIPS, J., BRADSKI, G. 2001. Communication via eye blinks detection and duration in real time. In Proceedings of IEEE Computer Society Conference on Computer Vision and Pattern Recognition. p. 1010-1017. 
(Greenberg \& Fitchett, 2001)

(Greenberg \& Boyle, 2002)

(Greenberg, 1993)

(Guan et al., 2005)

(Holmquist, 2006)

(Holmquist et al., 2004)

(Hornof et al., 2004)

(Huot et al., 2004)
GREENBERG, S. and FITCHETT, C. 2001. Phidgets: easy development of physical interfaces through physical widgets. In Proceedings of the 14th Annual ACM Symposium on User interface Software and Technology (Orlando, Florida, November 11 - 14, 2001). UIST '01. ACM Press, New York, NY, p. 209-218.

GREENBERG, S. and BOYLE, M. 2002. Customizable physical interfaces for interacting with conventional applications. In Proceedings of the 15th Annual ACM Symposium on User interface Software and Technology (Paris, France, October 27 - 30, 2002). UIST '02. ACM Press, New York, NY, p. 31-40.

GREENBERG, S. 1993 The Computer User As Toolsmith: the Use, Reuse, and Organization of Computer-Based Tools. Cambridge University Press.

GUAN, J., CHEN, Y., LIN, J. 2005. Designing a dual page virtual keyboard for mental speller. In Proceedings of the First Internation Conference on Neural Interface and Control, p. 55-59.

HOLMQUIST, L. E. 2006. Sketching in hardware. interactions 13, 1 (Jan. 2006), p. 47-60.

Holmquist, L. E., Gellersen, H., Kortuem, G., Schmidt, A., Strohbach, M., Antifakos, S., Michahelles, F., Schiele, B., Beigl, M., and Mazé, R. 2004. Building Intelligent Environments with Smart-Its. IEEE Comput. Graph. Appl. 24, 1 (Jan. 2004), p. 56-64. HORNOF, Anthony; CAVENDER, Anna; HOSELTON, Rob. Eyedraw: a system for drawing pictures with eye movements. In Proceedings of the 6th international ACM SIGACCESS Conference on Computers and Accessibility. Atlanta, GA, USA, p. 86-93, 2004.

HUOT, S., Dumas, C., DRAGICEVIC, P., FEKETE, J., and HÉGRON, G. 2004. The MaggLite post-WIMP 
(Kabadayi et al., 2006)

(Kim \& Cho, 2002)

(Klemmer et al., 2004)

(Mcgrenere et al., 2002)

(MCT, 2005) toolkit: draw it, connect it and run it. In Proceedings of the 17th Annual ACM Symposium on User interface Software and Technology (Santa Fe, NM, USA, October 24 - 27, 2004). UIST '04. ACM Press, New York, NY, p. 257-266.

KABADAYI, S., PRIDGEN, A., and Julien, C. 2006. Virtual Sensors: Abstracting Data from Physical Sensors. In Proceedings of the 2006 international Symposium on on World of Wireless, Mobile and Multimedia Networks (June 26 - 29, 2006). International Workshop on Wireless Mobile Multimedia. IEEE Computer Society, Washington, DC, p. 587-592.

Y. wook Kim and J. hyun Cho. A novel development of head-set type computer mouse using gyro sensors for the handicapped. In 2nd Annual International IEEE-EMBS Special Topic Conference on Microtechnologies in Medicine \& Biology, p. 356-359, 2002.

Klemmer, S. R., LI, J., LIN, J., and LANDAY, J. A. 2004. Papier-Mache: toolkit support for tangible input. In Proceedings of the SIGCHI Conference on Human Factors in Computing Systems (Vienna, Austria, April 24 - 29, 2004). CHI '04. ACM Press, New York, NY, p. 399406.

MCGRENERE, J., BAECKER, R. M., and BOOTH, K. S. 2002. An evaluation of a multiple interface design solution for bloated software. In Proceedings of the SIGCHI Conference on Human Factors in Computing Systems: Changing Our World, Changing Ourselves (Minneapolis, Minnesota, USA, April 20 - 25, 2002). CHI '02. ACM Press, New York, NY, p. 164-170.

Ministério da Ciência e Tecnologia. WWW: Disponível on-line em: http://www.mct.gov.br. Visitado em fevereiro 2008. 
(Nakajima, 2006)

(Olwal \& Feiner, 2004)

(Phidgets, 2008)

(Pimentel et al., 2005)

(Portal Nacional de Tecnologia Assistiva, 2008)

(Santos et al., 2006a)

(Santos et al., 2006b)
NAKAJIMA, T. 2006. How to reuse exisiting interactive applications in ubiquitous computing environments? In Proceedings of the 2006 ACM Symposium on Applied Computing (Dijon, France, April 23 - 27, 2006). SAC '06. ACM Press, New York, NY, p. 1127-1133. DOI= http://doi.acm.org/10.1145/1141277.1141546

OLWAL, A. and FEINER, S. 2004. Unit: modular development of distributed interaction techniques for highly interactive user interfaces. In Proceedings of the 2nd International Conference on Computer Graphics and Interactive Techniques in Australasia and South East Asia (Singapore, June 15 - 18, 2004). S. N. Spencer, Ed. GRAPHITE '04. ACM Press, New York, NY, p. 131-138. Phidgets Home Page. WWW: Disponível on-line em: http://www.phidgets.com. Visitado em fevereiro de 2008. PIMENTEL, Maria da Graça Campos; ELEUTÉRIO, Pedro Monteiro da Silva; SANTOS, Felipe Silva; TEIXEIRA, Cesar Augusto Camillo. A Synchronous Communication Service API using J2EE and JMS. In: Simpósio Brasileiro de Sistemas Multimídia e Hipermídia, 2005, Poços de Caldas. Proceedings: posters, 2005. v. 1. p. 1-3.

Portal Nacional de Tecnologia Assistiva Homepage. WWW: Disponível on-line em: http://www.assistiva.org.br. Visitado em fevereiro 2008. SANTOS, F. S., PIMENTEL, M. G., and TEIXEIRA, C. A. 2006. An architecture to improve the generalization of interacting device developments for accessibility. In Proceedings of the 12th Brazilian Symposium on Multimedia and the Web (Natal, Rio Grande do Norte, Brazil, November 19 - 22, 2006). WebMedia '06, vol. 192. ACM Press, New York, NY, p. 53-60.

SANTOS, F. S., PIMENTEL, M. G., and TEIXEIRA, C. 
(Santos et al., 2004)

(Shelburne \& Williston, 2006)

(Steriadis, 2003)

(Truong \& Abowd, 2004)

(Wang \& Mankoff, 2003)
A. 2006. Customization of sensor-based input devices. In Proceedings of the Brazilian Symposium on Human Factors in Computing Systems (Natal, Rio Grande do Norte, Brazil, November 19 - 22, 2006). IHC'2006. v. 1 p. 5-8.

SANTOS, F. S.; SCHADEN, F. M.; OLIVEIRA, R. A.. Construção de Periféricos para Inclusão Digital de Pessoas com Necessidades Especiais Físicas. Trabalho de Conclusão de Curso, Faculdades COC, Ribeirão Preto Brasil, Dezembro 2004. 85 p. Disponível on-line em http://www.icmc.usp.br/ fss. Visitado em fevereiro de 2008.

Shelburne, C. P. T., Williston, S. W. A. Solid State Orientation Sensor with 360 degree measurement capability. United States Patent Application Publication. November 23,2006.

STERIADIS, Constatine E.; CONSTANTINOU, Philip. Designing human-computer interfaces for quadriplegic people. ACM Transactions on Computer-Human Interaction (TOCHI). New York, NY, USA, v. 10, i. 2, p. 87-118, 2003.

TRUONG, K. and ABOWD, G. 2004. Inca: A software infrastructure to facilitate the construction and evolution of ubiquitous capture \& access applications. In Proceedings of the 2004 International Conference on Pervasive Computing. Lins, Viena, Áustria, 2004, p. 140157.

WANG, J. and MANKOFF, J. 2003. Theoretical and architectural support for input device adaptation. In Proceedings of the 2003 Conference on Universal Usability (Vancouver, British Columbia, Canada, November 10 - 11, 2003). CUU '03. ACM Press, New York, NY, p. 85-92. 
(Wheeler \& Jorgensen, 2003)

WHEELER, K., JORGENSEN, C. 2003. Gestures as input: neuroelectric joysticks and keyboards. In IEEE Pervasive Computing, 2(2): p. 56-61. 


\section{Apêndice A - Driver Assembly AMI601}

Para possibilitar a comunicação de um computador com o sensor AMI60 $1^{33}$, é necessário a implementação de um módulo de hardware capaz de realizar a comunicação via protocolo $\mathrm{I}^{2} \mathrm{C}^{34}$ (AMI601) e via serial (computador). O microcontrolador PIC16F877A é adequado para tal função, pois possui módulos internos de hardware que possibilitam tais implementações.

O "driver" assembly AMI601 é um software executado em um microcontrolador PIC16F877A conectado a um sensor de movimento AMI601.

O "driver" é programado para executar 50 leituras de posicionamento por segundo do sensor AMI601. Posteriormente, tais dados são transmitidos no formato $\mathrm{NMEA}^{35}$ para o computador. Além disso, o sensor AMI601 permite diversas configurações tais como ganho de amplificador e ajustes. Para executar estas configurações, o computador envia uma string no formato NMEA pela serial, conforme a Tabela A.1:

Tabela A.1 - Comandos aceitos pelo microcontrolador

\begin{tabular}{|l|l|}
\hline Comando & String \\
\hline Configurar o ganho dos amplificadores & $\$ A G, \mathrm{X} 1, \mathrm{X} 2, \mathrm{X} 3, \mathrm{X} 4, \mathrm{X} 5, \mathrm{X} 6^{*} \mathrm{CC}<\mathrm{CR}><\mathrm{LF}>$ \\
\hline Configurar o ajuste grosseiro dos amplificadores & $\$ \mathrm{OC}, \mathrm{X} 1, \mathrm{X} 2, \mathrm{X} 3, \mathrm{X} 4, \mathrm{X} 5, \mathrm{X} 6^{*} \mathrm{CC}<\mathrm{CR}><\mathrm{LF}>$ \\
\hline Configurar o ajuste fino dos amplificadores & $\$ \mathrm{OF}, \mathrm{X} 1, \mathrm{X} 2, \mathrm{X} 3, \mathrm{X} 4, \mathrm{X} 5, \mathrm{X} 6^{*} \mathrm{CC}<\mathrm{CR}><\mathrm{LF}>$ \\
\hline $\begin{array}{l}\text { Configurar o ajuste grosseiro dos amplificadores } \\
\text { não voláteis }\end{array}$ & $\$ \mathrm{OCNV}, \mathrm{X} 1, \mathrm{X} 2, \mathrm{X} 3, \mathrm{X} 4, \mathrm{X} 5, \mathrm{X} 6^{*} \mathrm{CC}<\mathrm{CR}><\mathrm{LF}>$ \\
\hline $\begin{array}{l}\text { Configurar o ajuste fino dos amplificadores não } \\
\text { voláteis }\end{array}$ & $\$ \mathrm{OFNV}, \mathrm{X} 1, \mathrm{X} 2, \mathrm{X} 3, \mathrm{X} 4, \mathrm{X} 5, \mathrm{X} 6^{*} \mathrm{Cc}<\mathrm{CR}><\mathrm{LF}>$ \\
\hline Retornar os valores dos ganhos & $\$ \mathrm{GAG}^{*} \mathrm{CC}<\mathrm{CR}><\mathrm{LF}>$ \\
\hline Retornar o firmware & $\$ \mathrm{GF}^{*} \mathrm{CC}<\mathrm{CR}><\mathrm{LF}>$ \\
\hline Retornar as origens & $\$ \mathrm{GO}^{*} \mathrm{CC}<\mathrm{CR}><\mathrm{LF}>$ \\
\hline Retornar os ajustes grosseiros & $\$ \mathrm{GOC}^{*} \mathrm{CC}<\mathrm{CR}><\mathrm{LF}>$ \\
\hline Retornar os ajustes finos & $\$ \mathrm{GOF}^{*} \mathrm{Cc}<\mathrm{CR}><\mathrm{LF}>$ \\
\hline Retornar sensibilidades das acelerações & $\$ \mathrm{GSM}^{*} \mathrm{CC}<\mathrm{CR}><\mathrm{LF}>$ \\
\hline Retornar sensibilidades dos magnetismos & $\$ \mathrm{GS}^{*} \mathrm{Cc}<\mathrm{CR}><\mathrm{LF}>$ \\
\hline Retornar a temperatura & $\$ \mathrm{GT}^{*} \mathrm{Cc}<\mathrm{CR}><\mathrm{LF}>$ \\
\hline Retornar o status & $\$ \mathrm{GS}^{*} \mathrm{Cc}<\mathrm{CR}><\mathrm{LF}>$ \\
\hline
\end{tabular}

\footnotetext{
${ }^{33} \mathrm{http} / / /$ www.aichi-mi.com.

${ }^{34}$ http://i2c-bus.org.

${ }^{35} \mathrm{http}: / /$ www.nmea.org/pub/0183.
} 
O "driver" também retorna os valores configurados no AMI601 para que o usuário seja capaz de visualizar os valores ajustados. Para realizar tal tarefa, basta enviar pela serial algum comando de retorno da Tabela A.1, que o "driver" retornara uma mensagem no formato NMEA (serial), segundo a Tabela A.2:

Tabela A.2 - Mensagens enviadas pelo microcontrolador

\begin{tabular}{|l|l|}
\hline Mensagem & Significado \\
\hline$\$ A G, \mathrm{X} 1, \mathrm{X} 2, \mathrm{X} 3, \mathrm{X} 4, \mathrm{X} 5, \mathrm{X} 6^{*} \mathrm{CC}<\mathrm{CR}><\mathrm{LF}>$ & Ganhos do amplificadores \\
\hline$\$ M, \mathrm{X} 1, \mathrm{X} 2, \mathrm{X} 3, \mathrm{X} 4, \mathrm{X} 5, \mathrm{X} 6^{*} \mathrm{CC}<\mathrm{CR}><\mathrm{LF}>$ & Valores de posicionamento \\
\hline$\$ O C, \mathrm{X} 1, \mathrm{X} 2, \mathrm{X} 3, \mathrm{X} 4, \mathrm{X} 5, \mathrm{X} 6^{*} \mathrm{CC}<\mathrm{CR}><\mathrm{LF}>$ & Valores dos ajustes grosseiros \\
\hline$\$ \mathrm{OF}, \mathrm{X} 1, \mathrm{X} 2, \mathrm{X} 3, \mathrm{X} 4, \mathrm{X} 5, \mathrm{X} 6^{*} \mathrm{CC}<\mathrm{CR}><\mathrm{LF}>$ & Valores dos ajustes finos \\
\hline$\$ S M, \mathrm{X} 1, \mathrm{X} 2, \mathrm{X} 3, \mathrm{X} 4, \mathrm{X} 5, \mathrm{X} 6^{*} \mathrm{CC}<\mathrm{CR}><\mathrm{LF}>$ & Sensibilidades dos magnetismos \\
\hline$\$ S A, \mathrm{X} 1, \mathrm{X} 2, \mathrm{X} 3^{*} \mathrm{CC}<\mathrm{CR}><\mathrm{LF}>$ & Sensibilidades das acelerações \\
\hline$\$ T, \mathrm{X}^{*} \mathrm{CC}<\mathrm{CR}><\mathrm{LF}>$ & Valor da temperatura \\
\hline$\$ F I, \mathrm{X} 1, \mathrm{X} 2, \mathrm{X} 3, \mathrm{X} 4, \mathrm{X} 5, \mathrm{X} 6^{*} \mathrm{CC}<\mathrm{CR}><\mathrm{LF}>$ & Informações do firmware \\
\hline$\$ S, \mathrm{X}^{*} \mathrm{CC}<\mathrm{CR}><\mathrm{LF}>$ & Status do AMI601 \\
\hline
\end{tabular}

\section{Especificação das strings aceitas:}

\section{AG - Amplifier Gain}

String aceita: $\left.\$ A G, X 1, \mathrm{X} 2, \mathrm{X} 3, \mathrm{X} 4, \mathrm{X} 5, \mathrm{X} 6{ }^{*} \mathrm{cc}<\mathrm{CR}\right\rangle\langle\mathrm{LF}\rangle$.

Faixa de valores de X1-X6: 0-63.

Descrição: Configura o ganho de cada amplificador interno do AMI601, sendo X1 a X6 o valor do ganho para cada canal. CC é o check sum, da string usado para detecção de erros. $\mathrm{O}$ check sum é a soma HEX X-OR dos caracteres entre \$ e *.

OC - Offset Coarse

String Aceita: $\$ \mathrm{OC}, \mathrm{X} 1, \mathrm{X} 2, \mathrm{X} 3, \mathrm{X} 4, \mathrm{X} 5, \mathrm{X} 6{ }^{*} \mathrm{cc}\langle\mathrm{CR}\rangle\langle\mathrm{LF}\rangle$.

Faixa de valores de X1-X6: 0-15.

Descrição: Configura o ajuste grosseiro de cada amplificador interno do AMI601, sendo X1 a X6 o valor do ajuste grosseiro para cada canal.

\section{OF - Offset Fine}

String Aceita: \$OF, X1, X2,X3,X4,X5,X6*cc $<\mathrm{CR}>\langle\mathrm{LF}>$.

Faixa de valores de X1-X6: 0-63.

Descrição: Configura o ajuste fino de cada amplificador interno do AMI601, sendo X1a X6 o valor do ajuste fino para cada canal.

OCNV - Offset Coarse Non Volatile

String Aceita: \$OCNV,X1,X2,X3,X4,X5,X6*c $\langle\mathrm{CR}\rangle\langle\mathrm{LF}\rangle$.

Faixa de valores de X1-X6: $0-15$.

Descrição: Configura o ajuste grosseiro não volátil de cada amplificador interno do AMI601, sendo X1 à X6 o valor do ajuste grosseiro para cada canal. 
OFNV - Offset Fine Non Volatile

String Aceita: \$OFNV,X1,X2,X3,X4,X5,X6*cc $<\mathrm{CR}\rangle\langle\mathrm{LF}\rangle$.

Faixa de valores de X1-X6: 0-63.

Descrição: Configura o ajuste fino não volátil de cada amplificador interno do AMI601, sendo X1 a X6 o valor do ajuste fino para cada canal.

GAG - Get Amplifier Gain

String Aceita: $\$ \mathrm{GAG}^{*} \mathrm{cc}<\mathrm{CR}>\langle\mathrm{LF}\rangle$.

Descrição: Obtém do "driver" os valores dos ganhos do AMI601.

GF - Get Firmware

String Aceita: $\$ \mathrm{GF}^{*} \mathrm{cc}\langle\mathrm{CR}\rangle\langle\mathrm{LF}\rangle$.

Descrição: Obtém do "driver" as informações do firmware do AMI601.

GO - Get Origins

String Aceita: $\$ \mathrm{GO} * \mathrm{cc}<\mathrm{CR}>\langle\mathrm{LF}\rangle$.

Descrição: Obtém do "driver" as informações das origens do AMI601.

GOC - Get Offset Coarse

String Aceita: $\left.\$ \mathrm{GOC}^{*} \mathrm{cc}<\mathrm{CR}><\mathrm{LF}\right\rangle$.

Descrição: Obtém do "driver" os valores dos ajustes grosseiros do AMI601.

GOF - Get Offset Fine

String Aceita: $\left.\$ \mathrm{GOF}^{*} \mathrm{cc}<\mathrm{CR}><\mathrm{LF}\right\rangle$.

Descrição: Obtém do "driver" os valores de ajustes finos do AMI601.

GSA - Get Sensitivity of Acceleration

String Aceita: $\$ \mathrm{GSA} * \mathrm{XX}<\mathrm{CR}>\langle\mathrm{LF}\rangle$.

Descrição: Obtém do "driver" os valores da sensibilidade da aceleração do AMI601.

GSM - Get Sensitivity of Magnetism

String Aceita: \$GSM*cc $<\mathrm{CR}><\mathrm{LF}>$.

Descrição: Obtém do "driver" os valores da sensibilidade do magnetismo do AMI601.

GT - Get Temperature

String Aceita: $\$ \mathrm{GSM}^{*} \mathrm{cc}<\mathrm{CR}><\mathrm{LF}>$.

Descrição: Obtém do "driver" a temperatura.

GS - Get Status

String Aceita: $\$ \mathrm{GSM}^{*} \mathrm{cc}<\mathrm{CR}><\mathrm{LF}>$.

Descrição: Obtém do "driver" o status do AMI601.

Descrição das strings enviadas pelo microcontrolador:

\$AG,X1,X2,X3,X4,X5,X6*ce $<\mathrm{CR}>\langle\mathrm{LF}>$

Significado: Ganho dos amplificadores.

Faixa de valores de X1-X6: 0-63.

Descrição: Valor do ganho de cada amplificador interno do AMI601. 
\$M,X1,X2,X3,X4,X5,X6*cc $<$ CR $><\mathrm{LF}>$

Significado: Valores mensurados pelos sensores internos do AMI601.

Faixa de valores de X1-X6: 0-4095.

Descrição: Valores de posicionamento do AMI601.

\$OC,X1,X2,X3,X4,X5,X6*cc $<\mathrm{CR}>\langle\mathrm{LF}>$

Significado: Ajuste grosseiro.

Faixa de valores de X1-X6: 0-15.

Descrição: Valores de ajuste grosseiro de cada amplificador interno do AMI601.

\$OF,X1,X2,X3,X4,X5,X6*cc $<\mathrm{CR}>\langle\mathrm{LF}\rangle$

Significado: Ajuste fino.

Faixa de valores de X1-X6: 0-63.

Descrição: Valores de ajuste fino de cada amplificador interno do AMI601.

$\$ \mathrm{SM}, \mathrm{X1}, \mathrm{X2}, \mathrm{X3}, \mathrm{X4}, \mathrm{X5}, \mathrm{X6} * \mathrm{cc}<\mathrm{CR}><\mathrm{LF}>$

Significado: Sensibilidade do magnetismo.

Faixa de valores de X1-X6: 0-4095.

Descrição: Valores de sensibilidade do magnetismo de cada amplificador interno do AMI601.

\$SA,X1,X2,X3*cc $<\mathrm{CR}>\langle\mathrm{LF}>$

Significado: Sensibilidade da aceleração.

Faixa de valores de X1-X3: 0-4095.

Descrição: Valores de sensibilidade da aceleração de cada amplificador interno do AMI601.

$\$ \mathrm{~T}, \mathrm{X}^{*} \mathrm{cc}<\mathrm{CR}>\langle\mathrm{LF}>$

Significado: Valor da temperatura.

Faixa de valores de $\mathrm{X}$ : 0-4095.

Descrição: Valor da temperatura.

\$FI,X1,X2,X3,X4,X5,X6*cc $<$ CR $><\mathrm{LF}>$

Significado: Firmware do AMI601.

Descrição: Informações sobre o firmware do AMI601.

$\$ \mathrm{~S}, \mathrm{X}^{*} \mathrm{cc}<\mathrm{CR}>\langle\mathrm{LF}>$

Significado: Status do sensor.

Descrição: Status do AMI601.

Bit $0=$ Phone Position $(0=$ aberto, $1=$ fechado $)$.

Bit 1 a $7=$ reservado 


\section{Apêndice B - Configuração do sensor AMI601}

No Apêndice A é apresentado um conjunto de configurações que o sensor AMI601 possui, entre elas estão os ajustes de ganhos e offsets dos amplificadores internos do sensor. Tais configurações existem para aumentar a precisão dos valores mensurados pelo sensor no ambiente em que o mesmo é instalado (o valor do campo magnético varia de lugar para lugar) e para evitar valores anormais.

Com os ajustes adequados, evita-se cortes e saturações dos amplificadores internos, que acarretariam em valores anormais (ou menos precisos) das medidas de aceleração e campo magnético mensuradas pelo AMI601.

A tarefa de ajustes dos ganhos e offsets precisa ser realizada pelo usuário, uma vez que deve ser feita no ambiente em que o sensor será utilizado. Para facilitar o trabalho de configuração, uma interface gráfica foi construída.

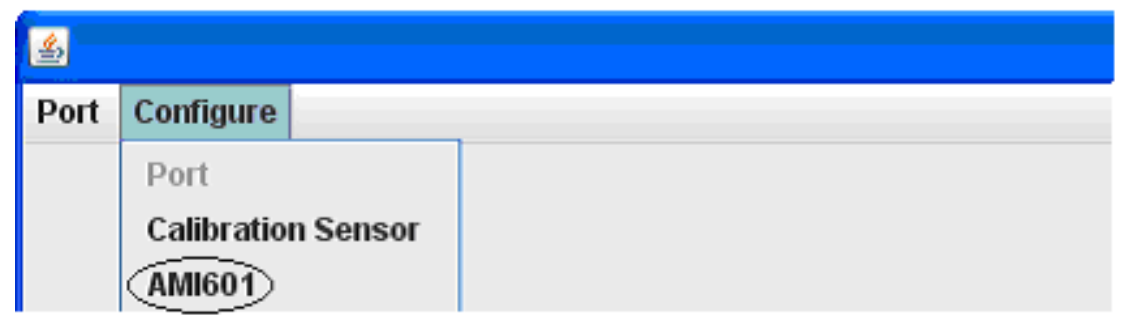

Figura B.1 - Configuração do sensor AMI601

Para configurar o sensor, o usuário seleciona o menu Configure, e em seguida seleciona a opção AMI601, como ilustrado na Figura B.1. 


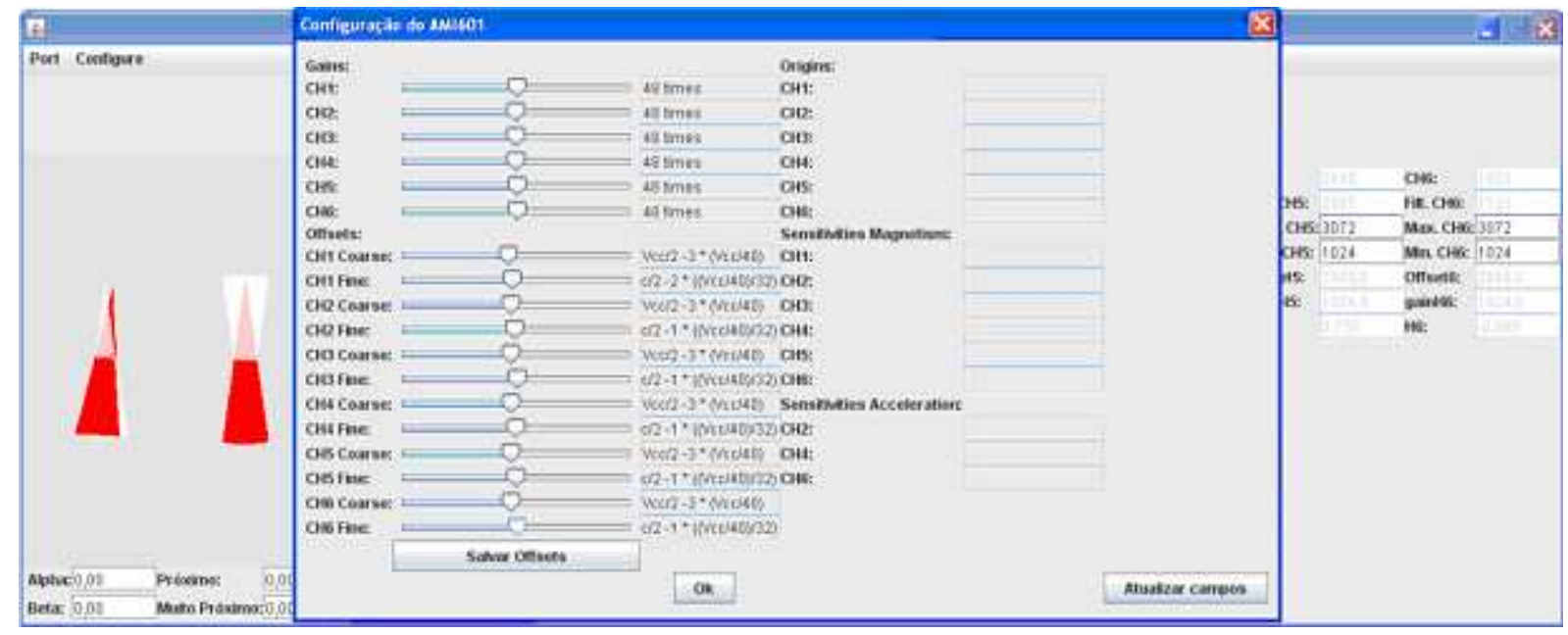

Figura B.2 - Ajuste de ganhos e offsets do sensor AMI601

A partir de então é possivel ajustar os ganhos e offsets de cada canal: basta arrastar as barras para esquerda (diminuir o valor) ou para direita (aumentar o valor) como ilustrado na Figura B.2.

Após o ajuste das configurações necessárias, o usuário clica no botão OK, finalizando a configuração do sensor. 


\section{Apêndice C - Calibração do Sensor AMI601}

O sensor AMI601 detecta campos magnéticos e aceleração através de 6 sensores internos (todos magnéticos). A calibração do sensor é necessária para se obter uma maior precisão das medidas de campo magnético.

Tal calibração é necessária quando os valores mensurados pelo sensor são anormais. Isso pode ocorrer por exemplo, se um forte campo magnetizar os terminais dos componentes eletrônicos próximos à placa do sensor. Neste caso, a calibração é necessária para eliminar a variação dos valores.

A tarefa de calibração precisa ser realizada pelo usuário, sempre que valores anormais forem observados. Para facilitar tal trabalho, uma interface gráfica foi construída.

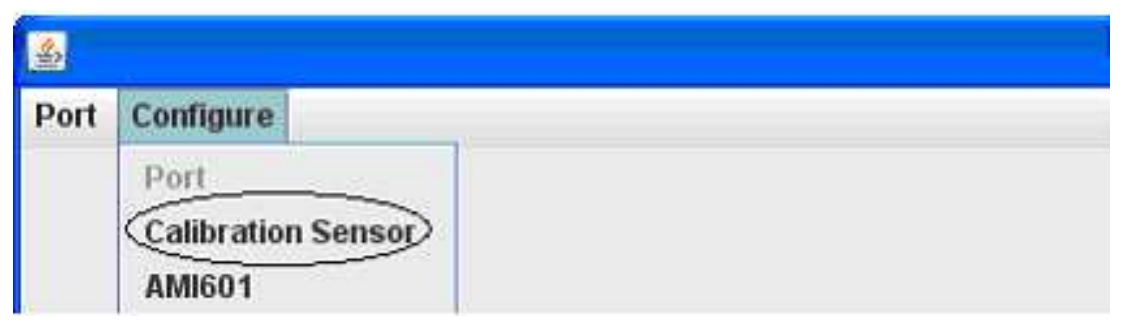

Figura C.1 - Iniciando o processo de calibração

Para iniciar o processo de calibração, o usuário seleciona o menu Configure e em seguida seleciona a opção Calibration Sensor, conforme Figura C.1.

O processo de calibração é dividido em 7 etapas, apresentadas a seguir:

Etapa 1. Posicionar o sensor na horizontal, conforme apresentado na Figura C.2.

Etapa 2. Rotacionar o sensor lentamente, para que não haja ruídos, como ilustrado na Figura C.3. Após a etapa 2, os ganhos e offsets do sensor magnético $\mathrm{CH} 1$ e $\mathrm{CH} 5$ são calibrados e os ganhos e offsets do acelerômetro $\mathrm{CH} 4$ e CH6 também.

Etapa 3. Posicionar o sensor na horizontal, conforme Figura C.4.

Etapa 4. Rotacionar o sensor lentamente, para que não haja ruídos, como ilustrado na Figura C.5. Após a etapa 4, os ganhos e offsets do sensor magnético $\mathrm{CH} 3$ e CH4 são calibrados. 
Etapa 5. Posicionar o sensor na horizontal, conforme apresentado na Figura C.6.

Etapa 6. Rotacionar o sensor lentamente, para que não haja ruídos, em ambos os eixos como ilustrado na Figura C.7. Após a etapa 6, os ganhos $\mathrm{CH} 2, \mathrm{CH} 4$ e $\mathrm{CH} 6$ dos acelerômetros são calibrados.

Etapa 7. Posicionar o sensor na horizontal conforme apresentado na Figura C.8. Nessa etapa a calibração está concluída.

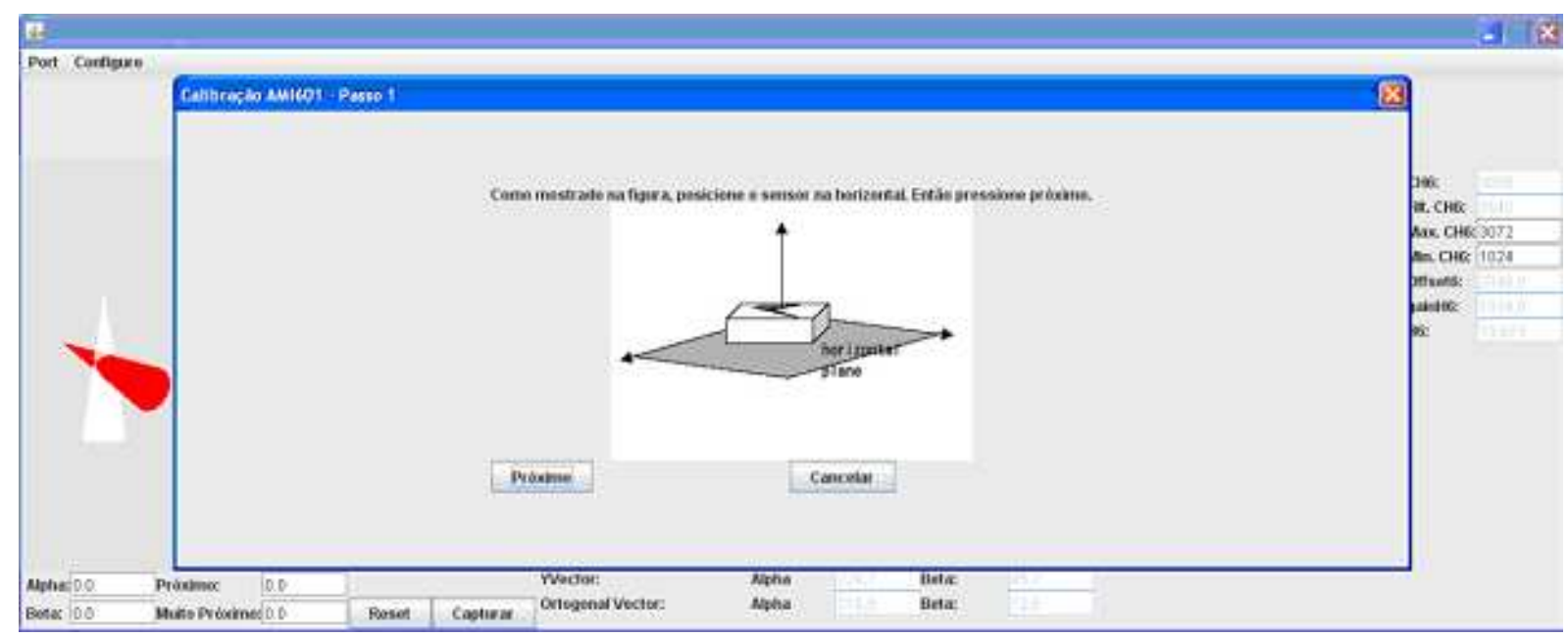

Figura C.2 - Calibração: posicionar sensor na horizontal

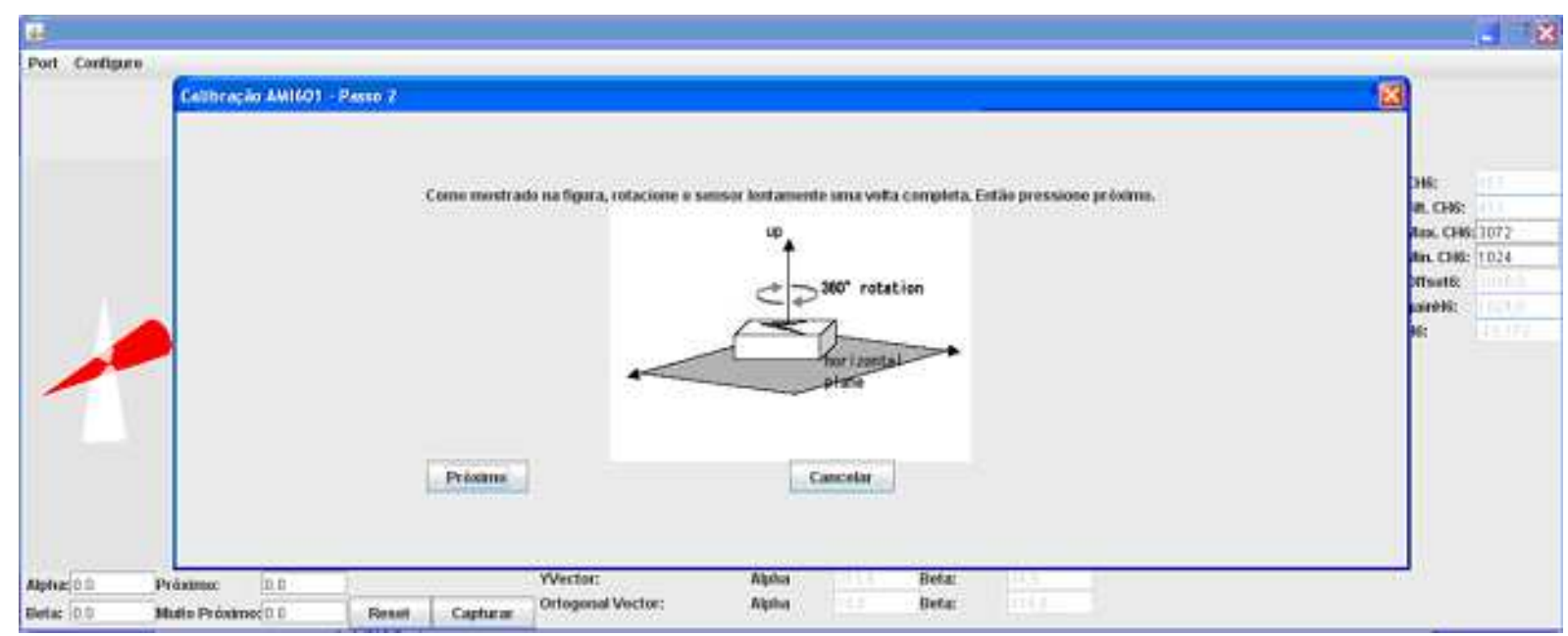

Figura C.3 - Calibração: rotacionar sensor na horizontal 


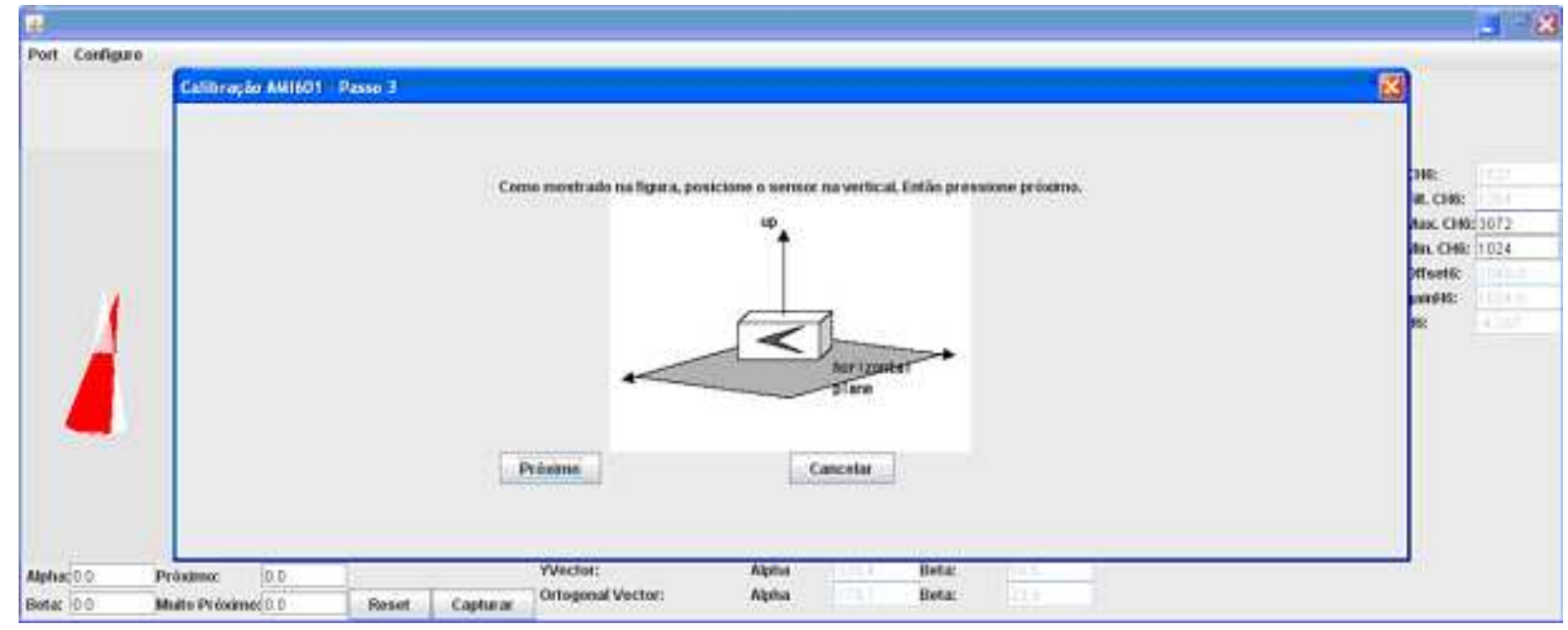

Figura C.4 - Calibração: posicionar sensor na vertical

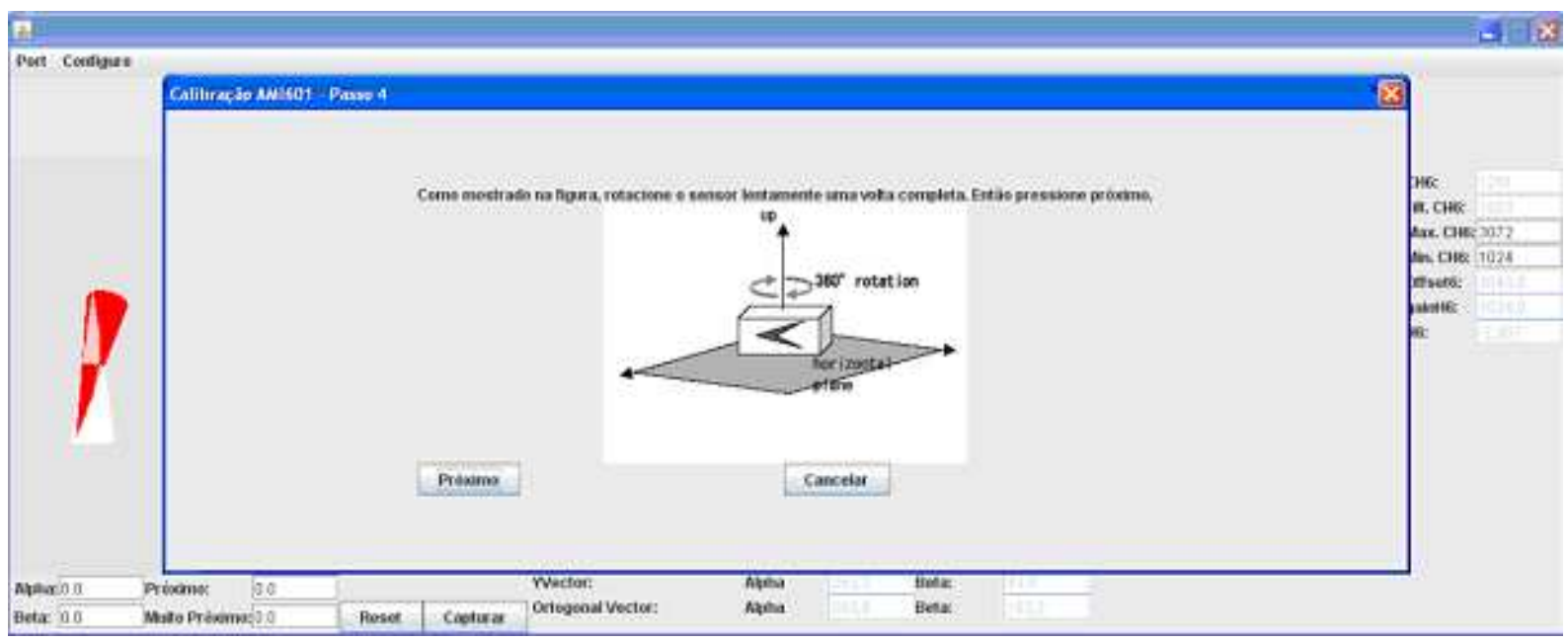

Figura C.5 - Calibração: rotacionar sensor na vertical

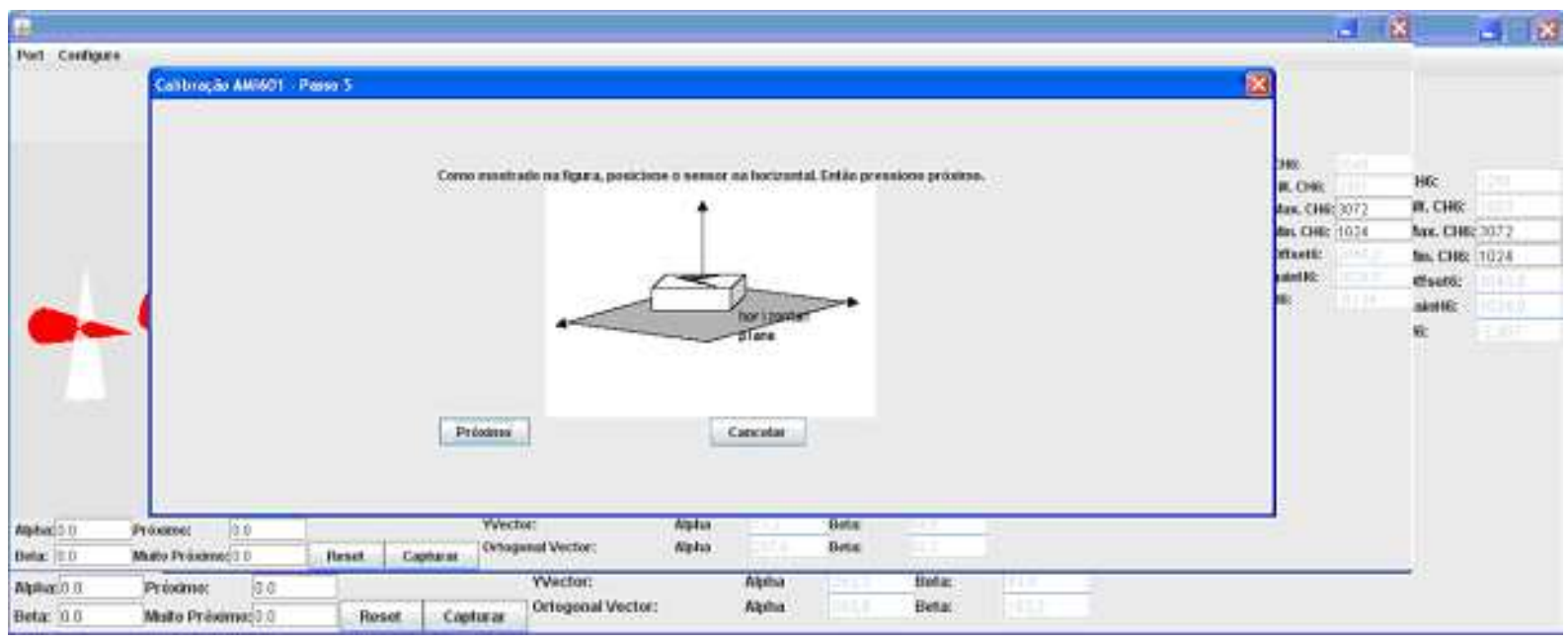

Figura C.6 - Calibração: posicionar sensor na horizontal 


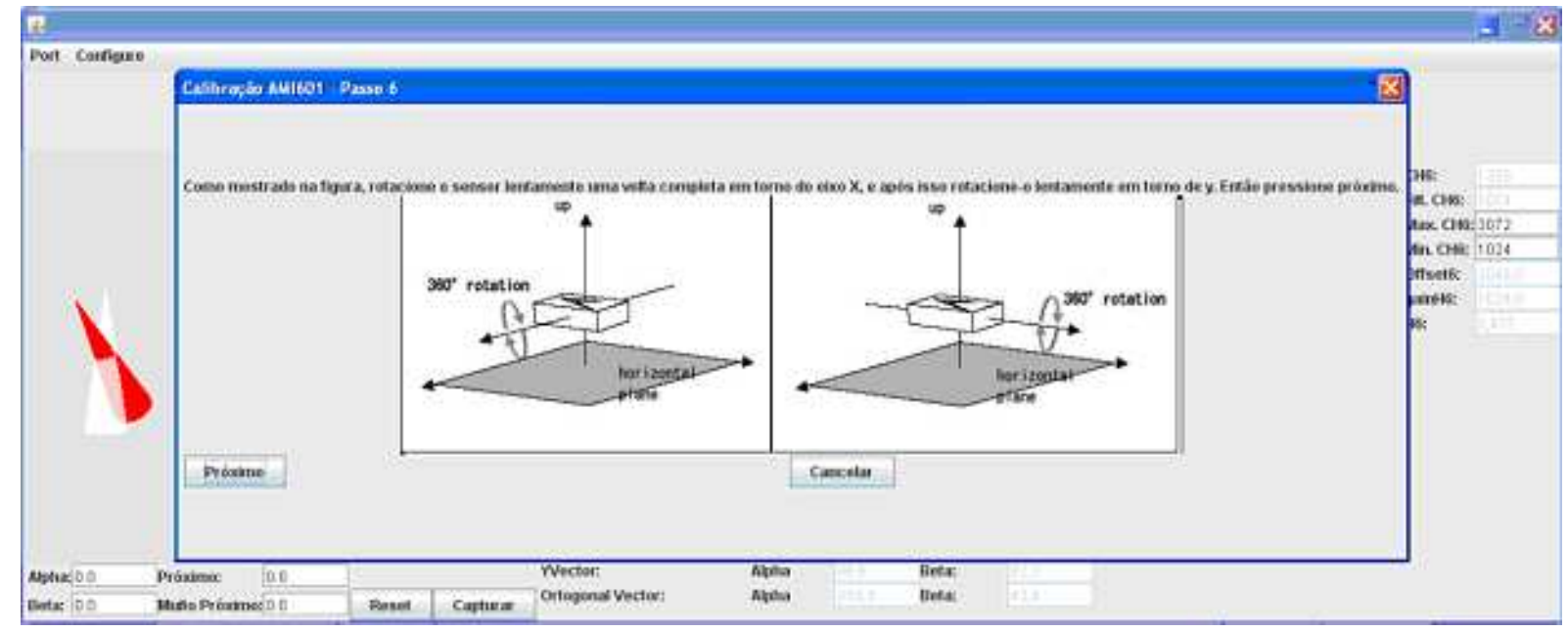

Figura C.7 - Calibração: rotacionar sensor em torno do eixo $x$ e $y$

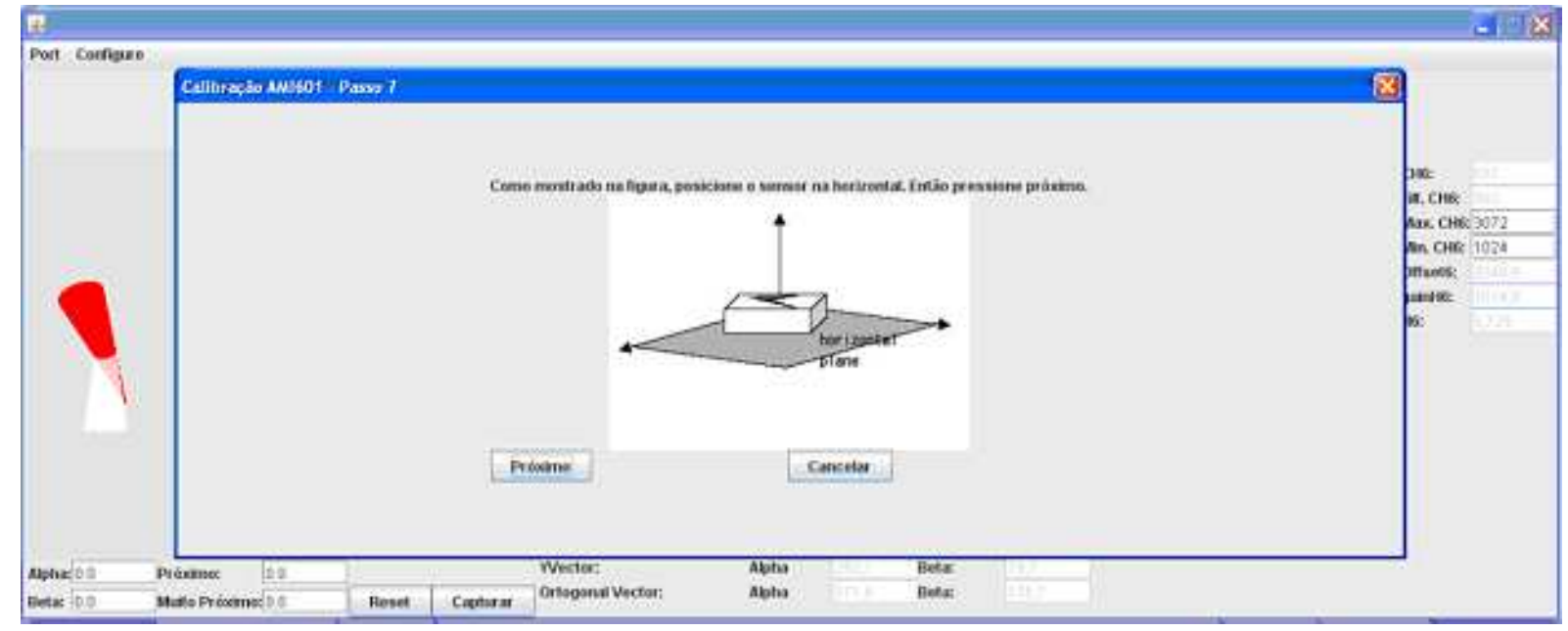

Figura C.8 - Calibração: posicionar sensor na horizontal 


\section{Apêndice D - Modelo matemático para obtenção dos ângulos de Euler}

A posição do sensor AMI601 no espaço é baseada em heading, roll e pitch (ângulos de Euler), que são os giros em torno dos eixos $z, x$ e $y$ respectivamente. O sensor $A M I 601$ não fornece diretamente heading, roll e pitch, mas $\operatorname{sim} \mathrm{A}_{\mathrm{x}}, \mathrm{A}_{\mathrm{y}}, \mathrm{A}_{\mathrm{z}}$ e $\mathrm{H}_{\mathrm{x}}, \mathrm{H}_{\mathrm{y}}, \mathrm{H}_{\mathrm{z}}$ através do acelerômetro de três eixos e do sensor magnético de três eixos, havendo a necessidade de conversão para os ângulos de Euler. A obtenção dos ângulos pitch e roll do acelerômetro é efetuada da seguinte forma: primeiramente é aplicado um filtro passa-baixa para amenizar ruídos devido a entradas inerciais dos acelerômetros; em seguida são calculados os ângulos utilizando os relacionamentos a seguir (ganhos e offsets são obtidos a partir do processo de calibração, descrito no Apêndice C):

$$
\begin{aligned}
& \mathrm{a}_{\mathrm{x}}=\left(\mathrm{a}_{\mathrm{xcru}}-\mathrm{a}_{\mathrm{xoffset}}\right)^{*} \mathrm{a}_{\mathrm{xgain}} \\
& \mathrm{a}_{\mathrm{y}}=\left(\mathrm{a}_{\mathrm{ycru}}-\mathrm{a}_{\mathrm{yoffset}}\right)^{*} \mathrm{a}_{\mathrm{ygain}} \\
& \mathrm{a}_{\mathrm{z}}=\left(\mathrm{a}_{\mathrm{zcru}}-\mathrm{a}_{\mathrm{zoffset}}\right)^{*} \mathrm{a}_{\mathrm{zgain}}
\end{aligned} \quad \text { Roll }=\arctan \frac{a_{y}}{\sqrt{a_{x}^{2}+a_{z}^{2}}} \quad \text { Pitch }=\arctan \frac{a_{x}}{a_{z}}
$$

A seguir é calculado o campo magnético da terra em seu plano de referência horizontal:

$$
\mathrm{m}_{\mathrm{x}}=\left(\mathrm{m}_{\mathrm{xcru}}-\mathrm{m}_{\text {xoffset }}\right) * \mathrm{~m}_{\mathrm{xgain}} \quad \mathrm{m}_{\mathrm{y}}=\left(\mathrm{m}_{\mathrm{ycru}}-\mathrm{m}_{\text {yoffset }}\right) * \mathrm{~m}_{\mathrm{ygain}} \quad \mathrm{m}_{\mathrm{z}}=\left(\mathrm{m}_{\mathrm{zcru}}-\mathrm{m}_{\text {zoffset }}\right) * \mathrm{~m}_{\text {zgain }}
$$

Para projetar a leitura do sensor (no plano horizontal da referência da terra), os seguintes relacionamentos são utilizados:

$$
\begin{aligned}
\mathrm{m}_{\mathrm{y}}{ }^{\prime}=\mathrm{m}_{\mathrm{y}}{ }^{\prime} \cos (\text { roll })+\mathrm{m}_{\mathrm{z}}{ }^{\prime} \sin (\text { roll })->\quad \mathrm{m}_{\mathrm{y}}=\mathrm{m}_{\mathrm{y}}{ }^{\prime}{ }^{\prime}>\quad \mathrm{m}_{\mathrm{z}}{ }^{\prime}=\mathrm{m}_{\mathrm{z}}{ }^{\prime} \cos (\text { roll })+\mathrm{m}_{\mathrm{y}}{ }^{\prime} \sin (\text { roll })->\quad \mathrm{m}_{\mathrm{x}}{ }^{\prime}=\mathrm{m}_{\mathrm{x}}{ }^{\prime}{ }^{\prime}> \\
\mathrm{m}_{\mathrm{x}}=\mathrm{m}_{\mathrm{x}}{ }^{\prime} \cos (\text { pitch })-\mathrm{m}_{\mathrm{z}}{ }^{\prime} \sin (\text { pitch })
\end{aligned}
$$

Finalmente, yaw, também chamado de heading, pode ser calculado:

$$
Y a w=\arctan \frac{m_{x}}{m_{y}}
$$




\section{Anexo A - Diagrama de Classes Phidgets}

Phidgets (2008) são um conjunto de sensores e atuadores controlados pelo computador. Usando a USB como base para todos eles, a complexidade do hardware é abstraída através de uma robusta API que expõe as funcionalidades dos dispositivos. Aplicações podem ser desenvolvidas rapidamente em .NET, Visual Basic, VBA, LabView, Java, Delphi e $\mathrm{C}++$. Neste anexo, são apresentados os diagramas ${ }^{36}$ das principais classes da hierarquia Phidgets.

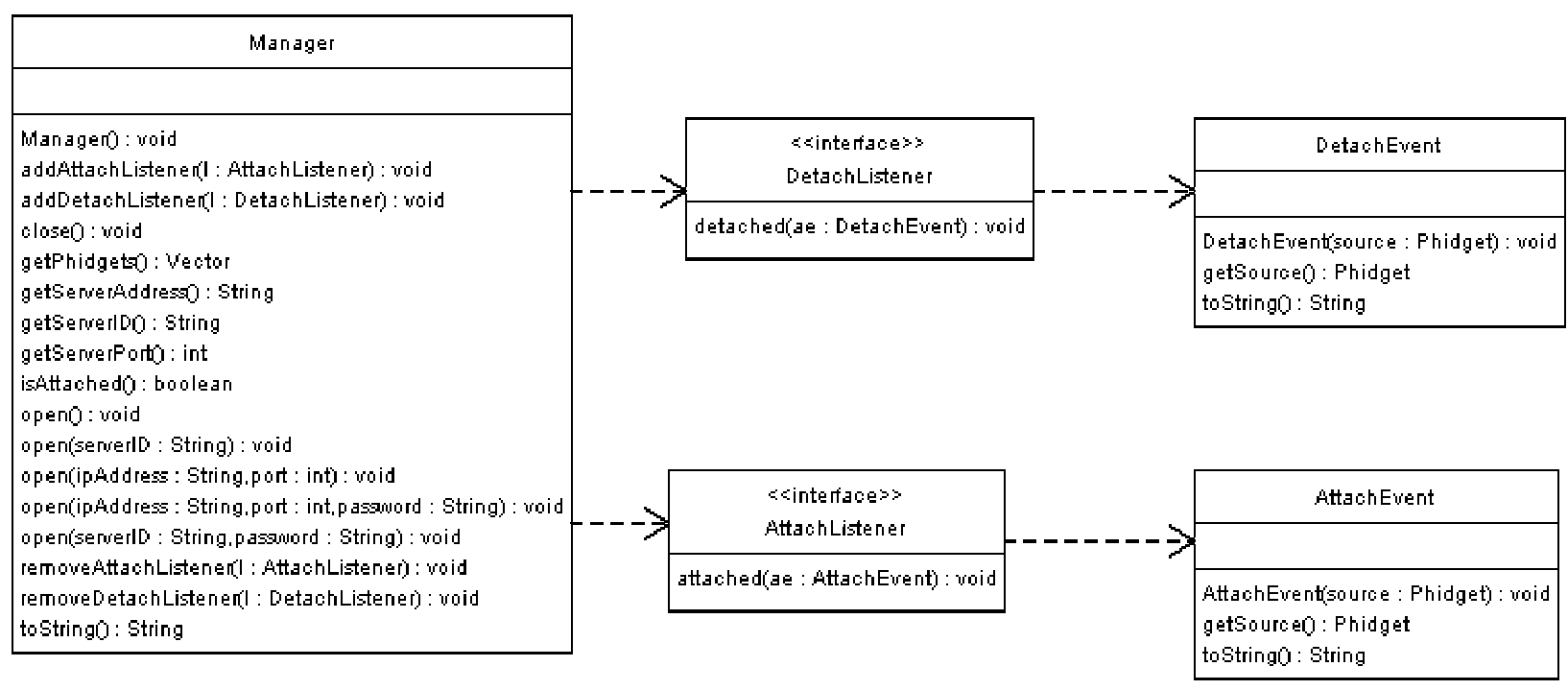

Figura D.1 - Gerenciador de Conexões Phidgets

Na Figura D.1 são apresentadas as classes responsáveis pela gerencia de conexões dos Phidgets ao computador. Através dos eventos AttachEvent e DetachEvent o programador pode gerenciar quais Phidgets são adicionados ou removidos do sistema, e obter uma referência a tais objetos.

\footnotetext{
${ }^{36}$ Diagramas criados a partir do JAVADOC das classes Phidgets.
} 


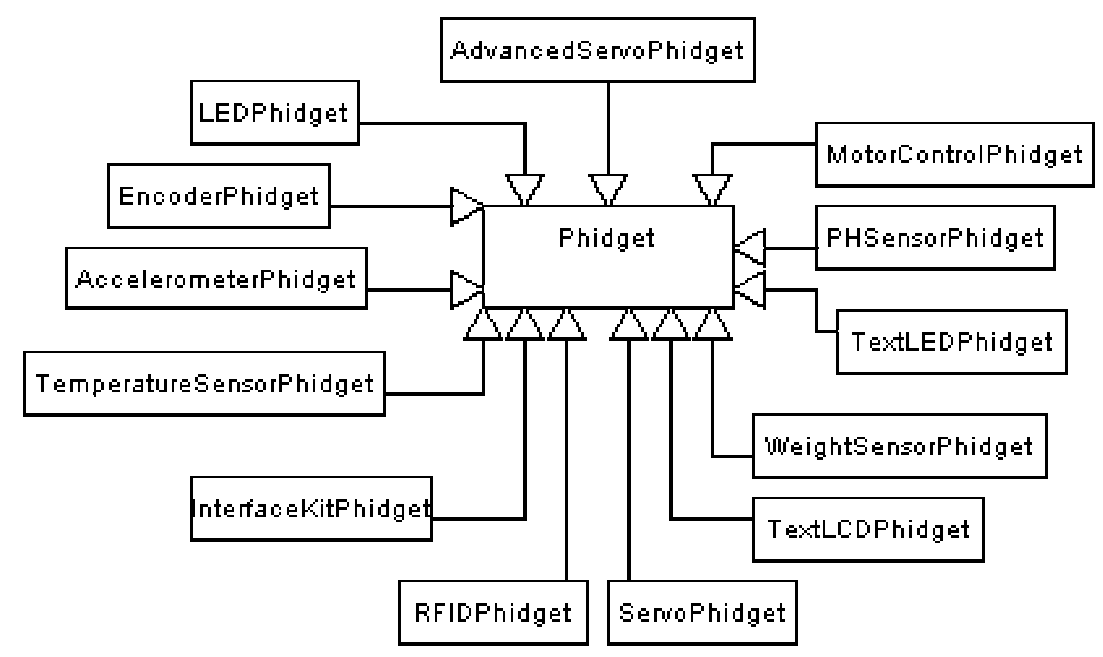

Figura D.2 - Hierarquia Phidgets

Na Figura D.2 são apresentados um conjunto de dispositivos físicos oferecidos pelos Phidgets. Todos eles herdam da classe principal Phidget, que agrega os pontos comuns a todos os dispositivos físicos.

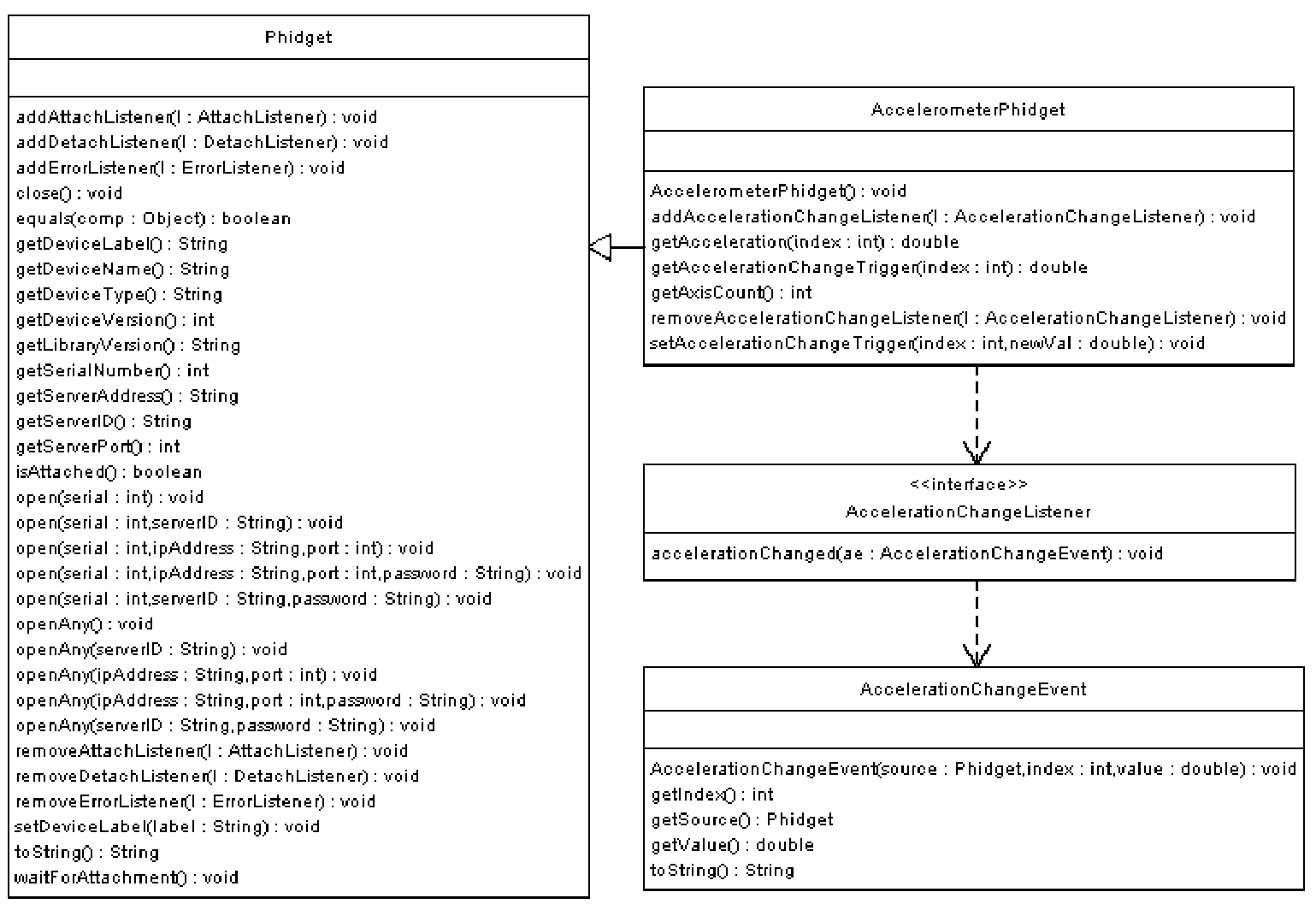

Figura D.3 - Acelerômetro Phidget 
Na Figura D.3 é apresentada a hierarquia de classes de um acelerômetro. Como todo Phidget, a classe AccelerometerPhidget estende a classe principal Phidget. O programador pode obter os valores de aceleração através da invocação do método getAcceleration(index: int), que retorna o valor da aceleração mensurada em um determinado eixo do acelerômetro (argumento do método). Outra forma de se obter a aceleração é criar um objeto listener. Através desse listener, toda vez que o valor da aceleração variar uma determinada quantidade (configurável) um evento é disparado, contendo todas as informações relevantes.

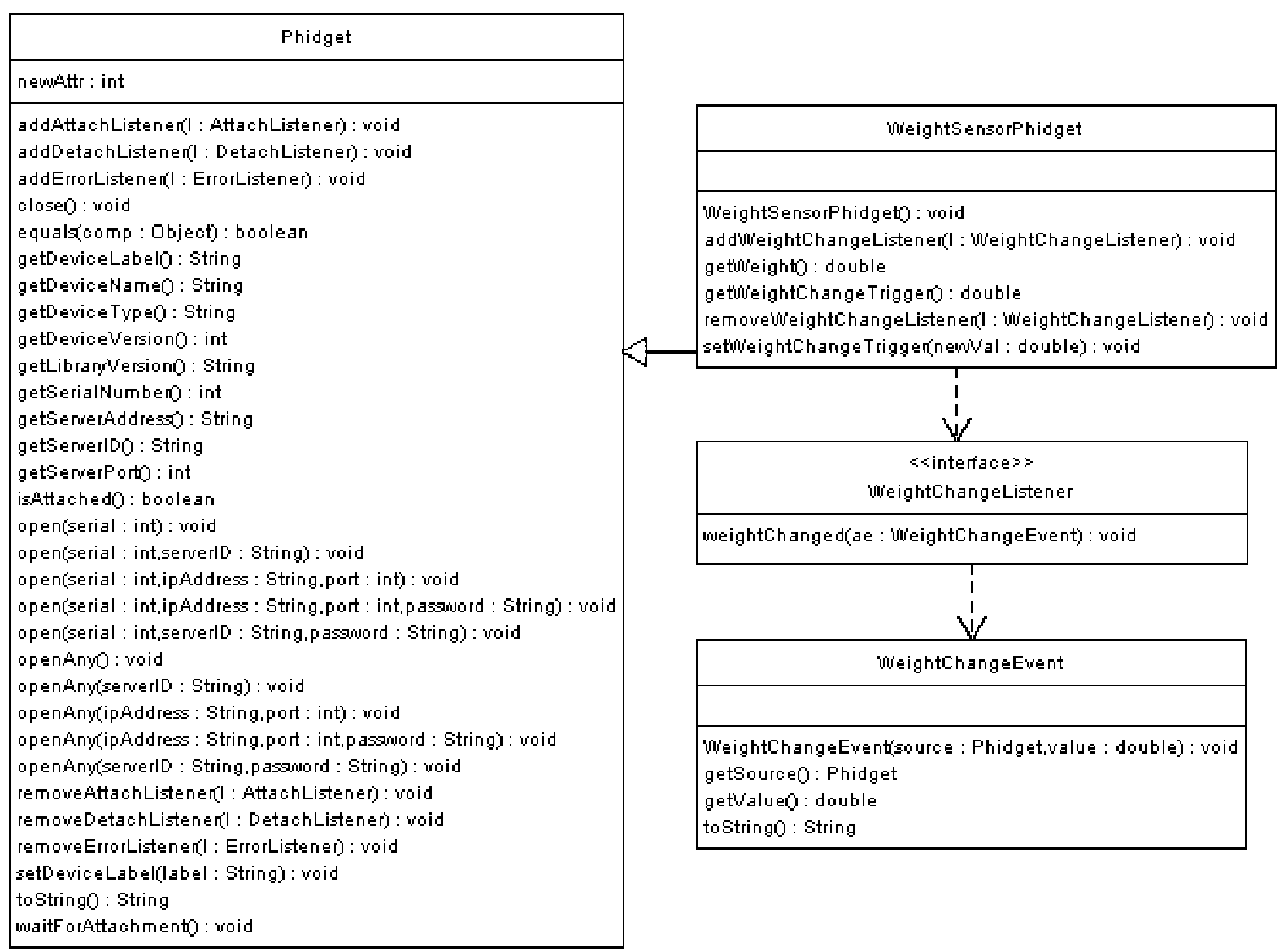

Figura D.4 - Sensor de Massa Phidget

Na Figura D.4 é apresentada a hierarquia de classes de um sensor de massa. 


\section{ANEXO B - Diagrama de Classes ICon}

\begin{tabular}{|l|}
\multicolumn{1}{|c|}{ ccinteriacess } \\
Device
\end{tabular}

Figura E.1 - Interface Device

\begin{tabular}{|l|}
\hline $\begin{array}{c}\text { Ceinterfacess } \\
\text { Processor }\end{array}$ \\
\hline $\begin{array}{l}\text { inito: woid } \\
\text { updateo: woid }\end{array}$ \\
\hline
\end{tabular}

Figura E.2 - Interface Processor

\begin{tabular}{|c|}
\hline Slot \\
\hline $\begin{array}{l}\text { description : String } \\
\text { dynamic : boolean } \\
\text { help : String } \\
\text { mutable : boolean } \\
\text { name : String } \\
\text { owner : Device } \\
\text { zupertype : int } \\
\text { type : int }\end{array}$ \\
\hline 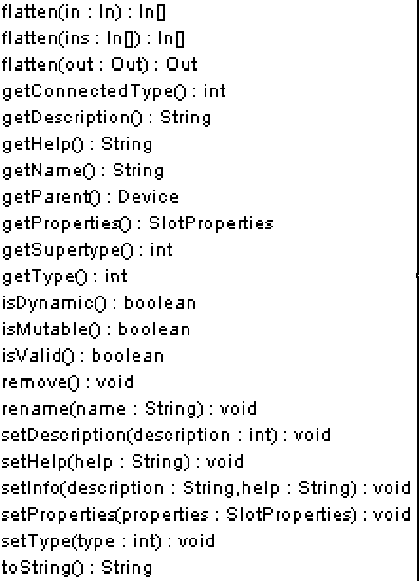 \\
\hline
\end{tabular}

In(owner : Device, name : String,type : int, obligaton: : boolean) : woid

In(owner : MutableDevice, name: String,supertype : int,obligatony : boolean, mutable : boolean) : woid

In'owner : Mutablebevice,name : Strings,supert/pe : int,obligaton: boolean,mutable : boolean,dynamic : booleani : void

getEooleanvalue0 : boolean

getConnectedo: Dut

getConnected Typeo: int

getDoublevalue 0 : double

getIntvalue 0 : int

getobjectvalue0: Object

getStringValue0: String

hassignalo: boolean

hasValue0 : boolean

isconnectedo: boolean

isobligatono: boolean

isualido: boolean

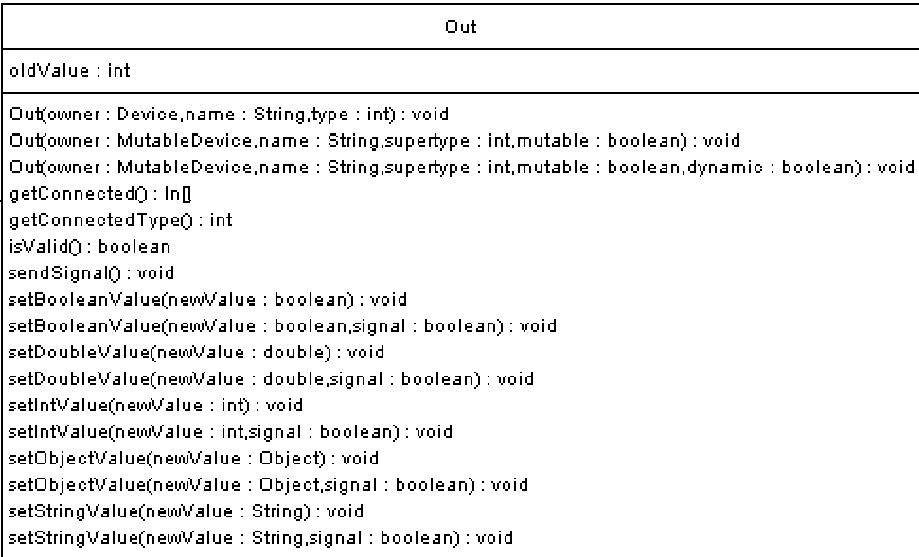

Figura E.3 - Classes Slot, In e Out 


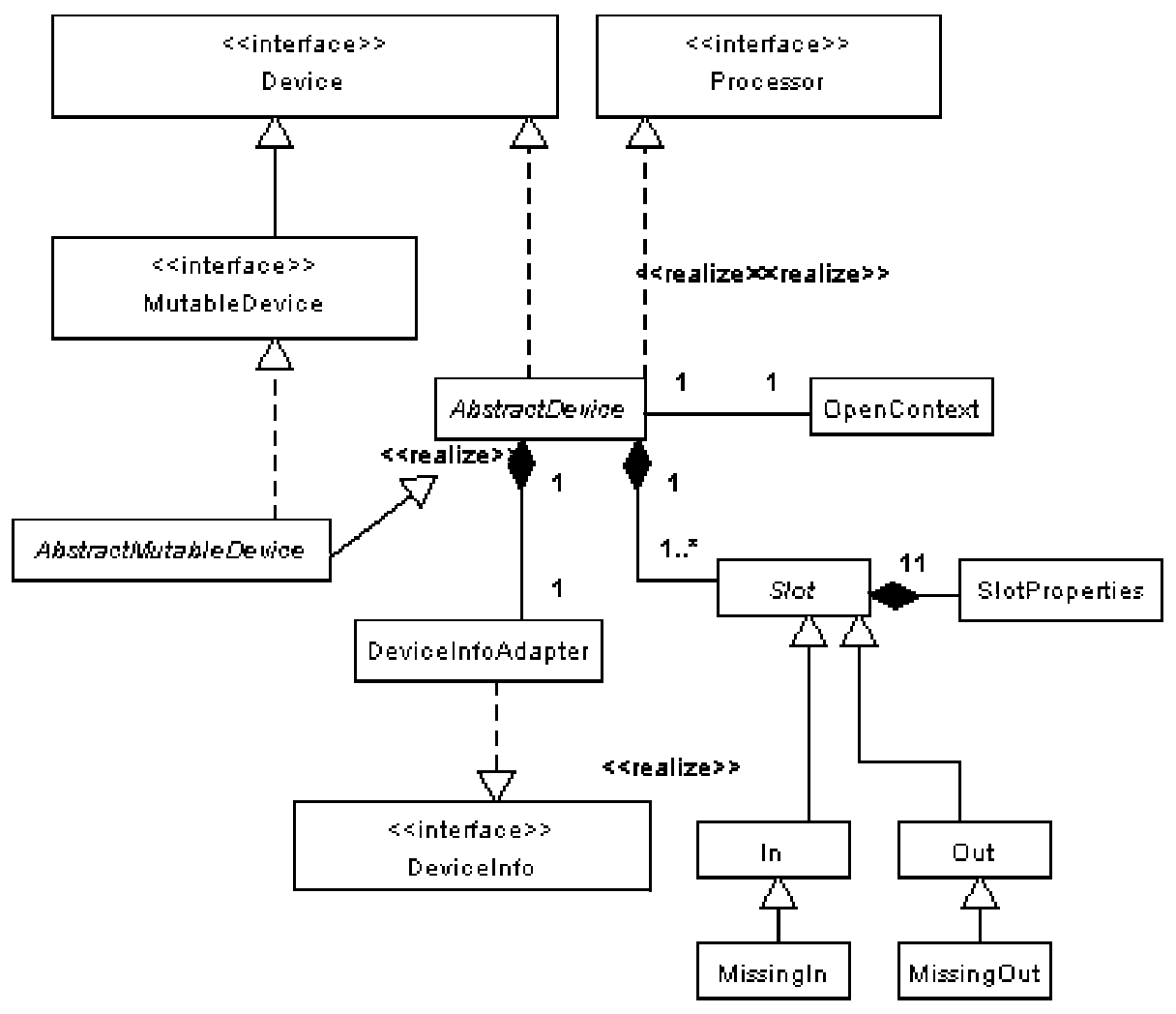

Figura E.4 - Hierarquia de Classe ICon 